UNIVERSIDADE DE SÃO PAULO

RODRIGO DIAS ARNAUT

\title{
RASTREAMENTO DE JOGADORES DE FUTEBOL EM SEQUÊNCIAS DE IMAGENS
}

São Paulo 
RODRIGO DIAS ARNAUT

\section{RASTREAMENTO DE JOGADORES DE FUTEBOL EM SEQUÊNCIAS DE IMAGENS}

Dissertação apresentada à Escola Politécnica da Universidade de São Paulo para obtenção do título de Mestre em Engenharia Elétrica

\section{São Paulo}


RODRIGO DIAS ARNAUT

\section{RASTREAMENTO DE JOGADORES DE FUTEBOL EM SEQUÊNCIAS DE IMAGENS}

Dissertação apresentada à Escola Politécnica da Universidade de São Paulo para obtenção do título de Mestre em Engenharia Elétrica

Área de Concentração:

Sistemas Digitais

Orientadora: Profa. Livre-Docente

Anna Helena Reali Costa

\section{São Paulo}


Este exemplar foi revisado e alterado em relação à versão original, sob responsabilidade única do autor e com a anuência de seu orientador.

São Paulo, 21 de dezembro de 2009.

Assinatura do autor

Assinatura da orientadora

FICHA CATALOGRÁFICA

Arnaut, Rodrigo Dias

Rastreamento de jogadores de futebol em sequências de imagens / R.D. Arnaut. -- São Paulo, 2009.

$100 \mathrm{p}$.

Dissertação (Mestrado) - Escola Politécnica da Universidade de São Paulo. Departamento de Engenharia de Computação e Sistemas Digitais.

1. Visão computacional 2. Processamento digital de imagens 3. Filtros de Kalman 4. Futebol I. Universidade de São Paulo. Escola Politécnica. Departamento de Engenharia de Computação e Sistemas Digitais II. t. 


\section{DEDICATÓRIA}

À minha esposa, Luciana, que me deu forças e compreensão durante toda esta jornada.

Aos meus pais, Armindo e Cleide, testemunhas de todo o meu esforço.

Aos meus avós, Antonio, Maria Emilia, João e Josepha, grandes criadores e observadores que deixam saudades inesgotáveis em minha vida. 


\section{AGRADECIMENTOS}

À Deus, pela existência de nossas vidas, permitindo que neste momento eu esteja registrando este reconhecimento nesta obra. Este é o resultado de minha vida acadêmica, apresentando uma pequena e valiosa parte de um grande esforço realizado ao longo de pelo menos três anos.

À minha orientadora, professora Livre-Docente Anna Helena Reali Costa, que me instruiu em todos os momentos e apoiou no desenvolvimento deste trabalho, diante das dificuldades e desafios que passamos juntos.

Aos meus familiares, que me incentivaram nesta jornada, com destaque ao meu querido irmão André Dias Arnaut, à minha querida irmã Juliana Arnaut Fontes e à minha estimada prima, cunhada e companheira Adriana dos Santos Arnaut.

Aos meus amigos, em especial Fernando Antônio Alonso Lopez e André Camilo Falcao da Silva, por me apoiarem neste período, aos meus colegas de trabalho, destacando-se Cleveland Oliveira Albuquerque, e a todos os colaboradores que de forma direta ou indireta me ajudaram neste estudo.

Um especial agradecimento ao Mestre Rodrigo Andrade de Bem e ao Doutor Antonio Henrique Pinto Selvatici pelo apoio com o fornecimento de informações relevantes à execução desta obra. 
Descoberta consiste em ver o que todo mundo já viu e pensar o que ninguém havia pensado. (Albert von Szent-Györgyi Nagyrapolt) 


\section{RESUMO}

Rastreamento visual em sequências de imagens tem sido muito estudado nos últimos 30 anos devido às inúmeras aplicações que possui em sistemas de visão computacional em tempo real; entretanto, poucos são os algoritmos disponíveis para que tal tarefa seja realizada com sucesso. Esta dissertação apresenta um método e uma arquitetura eficazes e eficientes para rastrear jogadores em jogos de futebol. A entrada do sistema consiste de vídeos capturados por câmeras estáticas instaladas em estádios de futebol. A saída é a trajetória descrita pelo jogador durante uma partida de futebol, dada no plano de imagem. O sistema possui dois estágios de processamento: inicialização e rastreamento. A inicialização do sistema é crítica no desempenho do rastreador e seu objetivo consiste em produzir uma estimativa aproximada da configuração e características de cada alvo, a qual é usada como uma estimativa inicial do estado pelo rastreador. O sistema de rastreamento utiliza Filtros de Kalman para modelar o contorno, posição e velocidade dos jogadores. Resultados são apresentados usando dados reais. Avaliações quantitativas são fornecidas e o sistema proposto é comparado com outro sistema correlato. Os experimentos mostram que o sistema proposto apresenta resultados bastante promissores.

Palavras-chave: Rastreamento Visual. Filtro de Kalman. Jogadores de Futebol. Visão Computacional. 


\begin{abstract}
Visual tracking in image sequences has been extensively studied in the last 30 years because of the many applications it has in real-time computer vision systems; however, there are few algorithms available for this task so that it is performed successfully. This work presents an effective and efficient system architecture and method to track players in soccer games. The system input consists of videos captured by static cameras installed in soccer stadiums. The output is the trajectory described by the player during a soccer match, given in the image plane. The system comprises two processing stages: initialization and tracking. The system startup is critical in the tracking performance and its goal is to produce a rough estimate of the configuration and characteristics of each target, which is used as an initial estimate of the state by the visual tracker. The tracking system uses Kalman filters to model the shape, position and speed of the players. Results are presented using real data. Quantitative assessments are provided and the proposed system is compared with related systems. The experiments show that our system can achieve very promising results.
\end{abstract}

Keywords: Visual Tracking. Kalman Filter. Soccer Players. Computer Vision. 


\section{LISTA DE ILUSTRAÇÕES}

Figura 2.1 - Ciclo recursivo do Filtro Discreto de Kalman ...................................23

Figura 2.2 - Imagem completa da operação do Filtro de Kalman ........................24

Figura 2.3 - Diagrama de blocos de um sistema com a representação do Filtro Discreto de Kalman .................................................................25

Figura 3.1 - Arquitetura de Software para o sistema ASPOGAMO......................29

Figura 3.2 - Inicialização do Rastreamento por De Bem (2007) ...........................31

Figura 3.3 - Função B-Spline cúbica (linha tracejada), definida por seus pontos de controle (asteriscos), aproximando o polígono convexo (linha contínua)

Figura 3.4 - Etapa de rastreamento e as interações com os blocos das equações do Filtro de Kalman: estimação e correção

Figura 3.5 - (a) Intensidade dos pixels de uma linha de medida. (b) Aplicação dos detectores de contorno e movimento. (c) Densidade de probabilidade Gaussiana. (d) Probabilidade de cada pixel corresponder ao contorno (mais escuro corresponde à maior probabilidade)

Figura 3.6 - Centro de área e retângulo envolvente do alvo

Figura 3.7 - Detecção e Rastreamento de Jogadores. Nos quadros centrais há oclusão, mas a estimação se mantém (linha inferior) com base no quadro anterior (coluna da esquerda)

Figura 4.1 - Blocos da proposta REALIFUT

Figura 4.2 - Exemplo de um quadro com jogador em uma sequência de imagens

Figura 4.3 - Imagens resultantes da proposta de detecção automática de alvos após (a) subtração da cena de fundo do quadro atual, (b) binarização da imagem resultante. (c) aplicação do filtro de abertura morfológica e (d) aplicação do filtro de fechamento morfológico.

Figura 4.4 - Retas de medidas (amarelas) e representação poligonal (linha cyan), pontos de controle (rosa) e contorno com o uso de BSplines (linha vermelha) de um jogador, representados no espaço de cor RGB da imagem

Figura 4.5 - Imagens resultantes do algoritmo de detecção automática de alvos, com erro de oclusão de alvos, causando a detecção de dois jogadores como um único alvo (lado direito da imagem). (a) Erro mostrado na imagem binária e (b) na imagem na banda V (HSV), circundados pelo contorno B-Spline envolvente resultante da detecção 
Figura 4.6 - Funcionamento dos dois Filtros de Kalman intercalados na proposta REALIFUT....................................................................59

Figura 5.1 - Resultados do teste da cena 1. Sequências de imagens com 100 quadros.

Figura 5.2 - Resultados do teste da cena 2. Sequências de imagens com

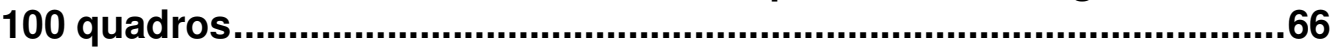

Figura 5.3 - Resultados do teste da cena 3. Sequências de imagens com 99 quadros.

Figura 5.4 - Resultados do teste da cena 1. Sequências de imagens com

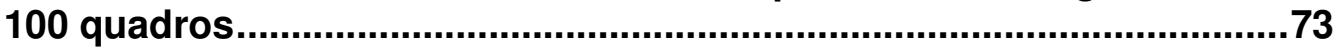

Figura 5.5 - Resultados do teste da cena 2. Sequências de imagens com

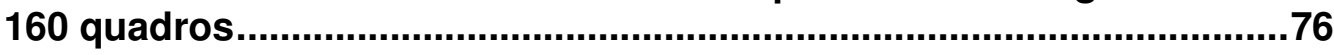

Figura 5.6 - Resultados do teste da cena 3. Sequências de imagens com 89

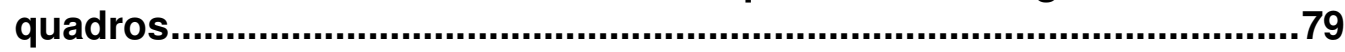




\section{LISTA DE GRÁFICOS}

Gráfico 5.1 - Resultado do teste da cena 1. Trajetória estimada do centro de área do alvo em posições com coordenadas $X$ e $Y$ determinadas em pixels

Gráfico 5.2 - Resultado do teste da cena 2. Trajetória estimada do centro de área do alvo em posições com coordenadas $X$ e $Y$ determinadas em pixels

Gráfico 5.3 - Resultado do teste da cena 3. Trajetória estimada do centro de área do alvo em posições com coordenadas $X$ e $Y$ determinadas em pixels

Gráfico 5.4 - Resultado do teste da cena 1. Trajetória estimada do centro de área do alvo em posições com coordenadas $X$ e $Y$ determinadas em pixels

Gráfico 5.5 - Resultado do teste da cena 2. Trajetória estimada do centro de área do alvo em posições com coordenadas $\mathrm{X}$ e $\mathrm{Y}$ determinadas em pixels

Gráfico 5.6 - Resultado do teste da cena 3. Trajetória estimada do centro de área do alvo em posições com coordenadas $X$ e $Y$ determinadas em pixels

Gráfico 5.7 - Gráfico comparativo em relação à eficiência na cena 1 ................84

Gráfico 5.8 - Gráfico comparativo em relação à eficácia na cena 1 ....................85

Gráfico 5.9 - Gráfico comparativo em relação à eficiência na cena 2 ..................88

Gráfico 5.10 - Gráfico comparativo em relação à eficácia na cena 2 ..................88

Gráfico 5.11 - Gráfico comparativo em relação à eficiência na cena 3..............91

Gráfico 5.12 - Gráfico comparativo em relação à eficácia na cena 3 ..................91

Gráfico 5.13 - Gráfico comparativo em relação à eficiência de todas as cenas.

Gráfico 5.14 - Gráfico comparativo em relação à eficácia (REQM) de todas as cenas.

Gráfico 5.15 - Gráfico comparativo em relação à eficácia (EPRXY) de todas as cenas.

Gráfico 5.16 - Gráfico comparativo em relação à eficácia (EPAM) de todas as cenas. 


\section{LISTA DE TABELAS}

Tabela 3.1 - Tabela comparativa com os dois trabalhos correlatos principais.

Tabela 5.1 - Parâmetros utilizados na configuração do sistema de rastreamento no teste da cena 1

Tabela 5.2 - Parâmetros utilizados na configuração do sistema de rastreamento no teste da cena 2

Tabela 5.3 - Parâmetros utilizados na configuração do sistema de rastreamento no teste da cena 3

Tabela 5.4 - Parâmetros utilizados na configuração do sistema de rastreamento no teste da cena 1

Tabela 5.5 - Parâmetros utilizados na configuração do sistema de rastreamento no teste da cena 2

Tabela 5.6 - Parâmetros utilizados na configuração do sistema de rastreamento no teste da cena 3

Tabela 5.7 - Resultados da proposta inspirada em Xu et al. (2005) no teste da cena 1

Tabela 5.8 - Resultados da proposta REALIFUT no teste da cena 1

Tabela 5.9 - Resultados da proposta inspirada em Xu et al. (2005) no teste 2

Tabela 5.10 - Resultados da proposta REALIFUT no teste da cena 2.

Tabela 5.11 - Resultados da proposta inspirada em Xu et al. (2005) no teste da cena 3

Tabela 5.12 - Resultados da proposta REALIFUT no teste da cena 3 .90

Tabela 5.13 - Tabela comparativa com os resultados e análise final. 


\section{SUMÁRIO}

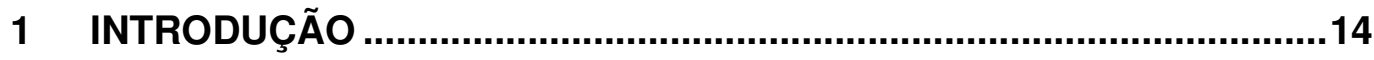

1.1 OBJETIVO

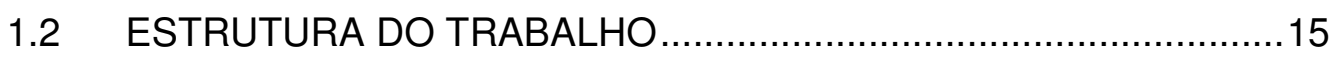

2 RASTREAMENTO COM FILTRO DE KALMAN....................................17

2.1 ESTIMAÇÃO COM FILTRO DE KALMAN....................................19

2.2 ALGORITMO DO FILTRO DE KALMAN ……...............................22

2.3 CONSIDERAÇÕES FINAIS DO CAPÍTULO …................................25

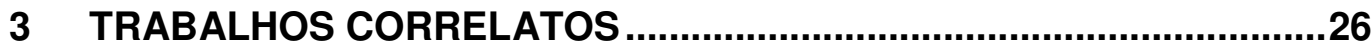

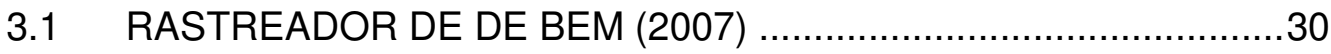

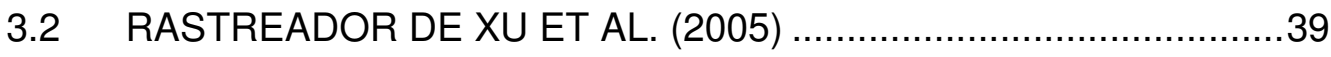

3.3 CONSIDERAÇÕES FINAIS DO CAPÍTULO ..................................4

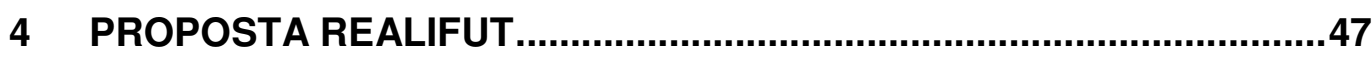

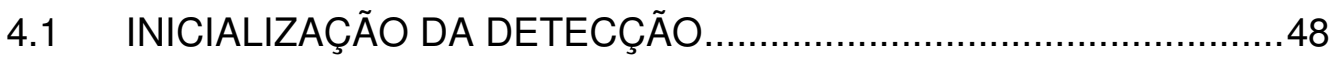

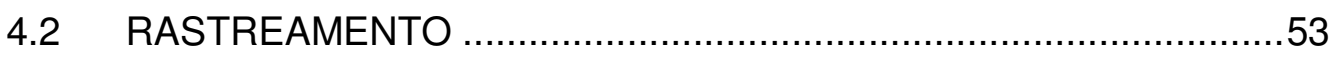

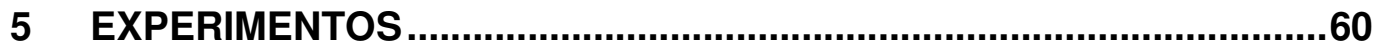

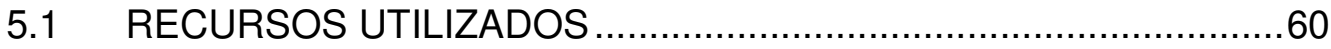

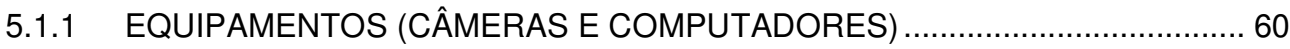

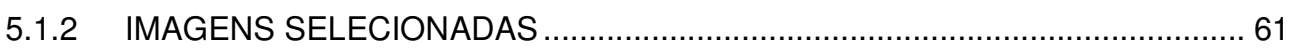

5.2 IMPLEMENTAÇÃO INSPIRADA EM XU ET AL. (2005) …...............62

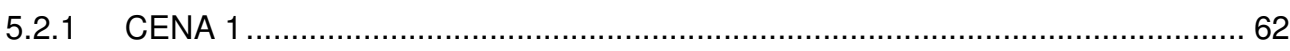

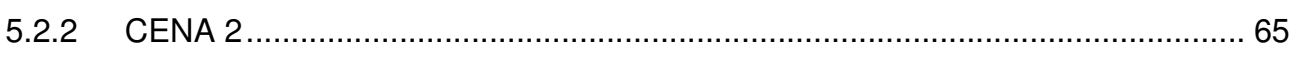

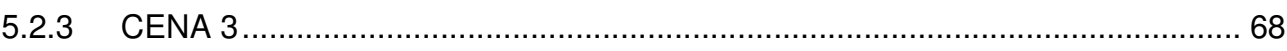

5.3 IMPLEMENTAÇÃO DA PROPOSTA ATUAL - REALIFUT ................70

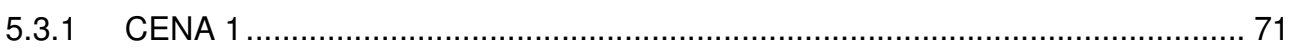

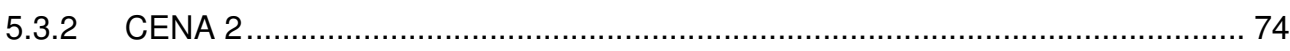

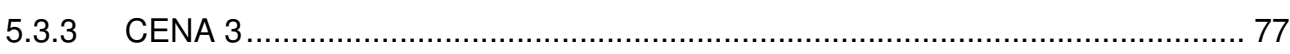

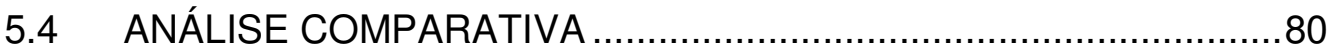

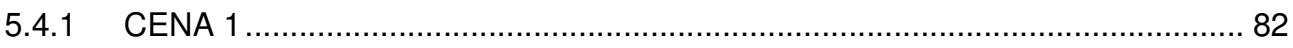

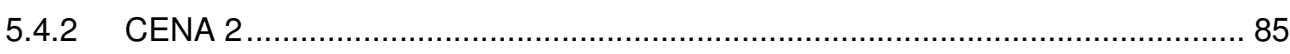

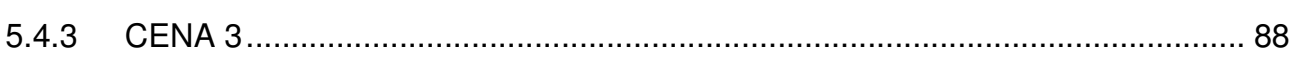

5.4.4 CONSIDERAÇÕES FINAIS DO CAPÍTULO ……………………………….... 91

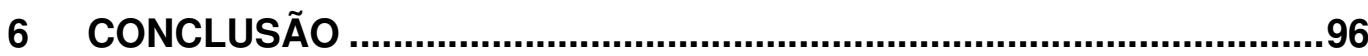

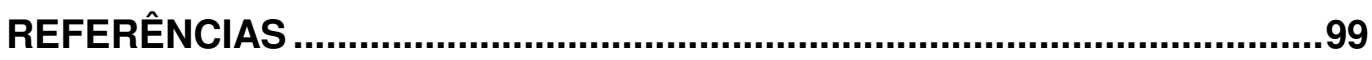




\section{INTRODUÇÃO}

O rastreamento de jogadores em uma partida de futebol é uma complexa tarefa devido a alguns aspectos particulares: os jogadores possuem fisionomias ou formas com características heterogêneas, suas velocidades de deslocamento variam de acordo com o tempo, o tamanho dos jogadores na imagem sofre alterações de escala, ocorrem mudanças bruscas na trajetória de movimentação, mais de um jogador pode ser detectado na imagem, pode ocorrer oclusão entre jogadores, entre outros. A maioria dos estádios de futebol não possui cobertura superior, ficando sujeito a variações de intensidade de iluminação natural, causadas pelos efeitos das condições climáticas, tais como sol, chuva, céu nublado e entardecer, por exemplo. Ainda, existem casos onde é utiliza uma iluminação artificial em jogos noturnos, acarretando dificuldades no rastreamento.

No entanto, os resultados de um bom rastreamento, neste cenário, possibilitam diversas aplicações, dentre as quais algumas têm 0 foco em informações estatísticas, permitindo avaliar aspectos como, por exemplo, a velocidade média e a distância percorrida por cada jogador durante uma partida. Estas informações são relevantes ferramentas para emissoras de televisão, clubes e técnicos de futebol (BORG, 2007), ou até mesmo para o apoio oficial no auxílio de arbitragem em uma partida real, como, por exemplo, o rastreamento automático da bola, indicando sua posição dentro do campo de futebol em situações de dúvida visual. Esta ferramenta já é adotada em jogos oficiais, desde 2003, para partidas de tênis, em importantes competições como as de Wimbledon (OWENS; HARRIS; STENNETT, 2003).

Entretanto, há uma grande carência na resolução dos problemas de rastreamento de alvos em sequências de imagens, visto que muitos trabalhos pesquisados na literatura não possuem uma boa eficácia nos resultados apresentados o que motiva o presente estudo, cujas principais contribuições consistem na avaliação de algumas técnicas propostas em trabalhos correlatos e na implementação de uma nova proposta, permitindo que esta seja utilizada com melhor eficácia, melhorando alguns aspectos como, por exemplo, a qualidade no 
processo de tratamento dos contornos dos jogadores e o tratamento da variação de movimento e velocidade dos alvos.

\section{$1.1 \quad$ OBJETIVO}

Realizar o rastreamento automático dos jogadores de futebol em sequências de imagens, sem a necessidade de interações humanas durante o processo, utilizando técnicas de alto desempenho, com o emprego de dois Filtros de Kalman intercalados permitindo o desacoplamento de sistemas não lineares, garantindo uma boa eficiência e máxima eficácia na qualidade do rastreamento, principalmente em relação à forma dos alvos. Motivado por este contexto, este estudo possui em seu escopo a descrição das principais técnicas e métodos encontrados na literatura sobre rastreamento visual de alvos móveis. Com base no estudo das técnicas e algoritmos mais promissores, objetiva-se selecionar a proposta mais eficaz e adequá-la para a aplicação no rastreamento de jogadores de futebol em sequências de imagens capturadas por câmeras fixas em partidas de futebol reais. Especificamente duas abordagens da literatura foram selecionadas, implementadas e analisadas, servindo como base para o desenvolvendo de modificações e inovações na abordagem que apresentou a melhor solução, sugerindo uma nova proposta, que será denominada REALIFUT (Rastreamento Eficaz Automático Livre de Intervenções para FUTebol). Experimentos e análises comparativas são conduzidos nas duas propostas, para mostrar o funcionamento de ambos os algoritmos, nas mesmas cenas e situações.

\subsection{ESTRUTURA DO TRABALHO}

A fim de alcançar os objetivos propostos, esta pesquisa está estruturada da seguinte forma:

O presente capítulo aborda a motivação e objetivo deste estudo. 
No capítulo 2 é exposta uma breve descrição do principal problema discutido neste trabalho - o rastreamento visual de alvos utilizando o Filtro de Kalman detalhando os estudos que envolvem esta importante técnica. Alguns trabalhos selecionados, englobando o rastreamento de jogadores e pessoas, são apresentados no capítulo 3 e constituem a base da proposta oferecida pelo presente trabalho. O capítulo 4 descreve a proposta deste trabalho. Os experimentos e análises comparativas são apresentados no capítulo 5, e, por fim, as considerações finais no Capítulo 6. 


\section{RASTREAMENTO COM FILTRO DE KALMAN}

O rastreamento em sequências de imagens, ou rastreamento visual, é a tarefa que consiste em seguir a posição de um alvo de interesse, determinando sua trajetória bidimensional, no plano de imagem, utilizando informações advindas de sensores óticos, geralmente câmeras, além de informações sobre os ruídos e de todo o conhecimento a priori disponível sobre a dinâmica dos alvos desejados (SÄRKKÄ, 2004).

A atual literatura aborda diferentes técnicas para resolver o problema do rastreamento de alvos, sendo eles a simples detecção visual das características nos pixels de cada quadro na sequência de imagens, técnicas pervasivas com a utilização de sensores de localização instalados nos alvos ou a abordagem probabilística baseado em conjuntos de informações analisadas em cada quadro da sequência de imagens, porém esta última é a que tem apresentado melhores resultados (RUSSELL; NORVIG, 2004), (GOLDENSTEIN, 2004).

Dentro da abordagem probabilística, o rastreamento é um problema de estimação de um sistema dinâmico, pois as informações dos alvos podem sofrer alterações, quadro a quadro, na sequência de imagens. Estas informações possuem ruídos e incertezas que devem ser consideradas e modeladas em um processo de estimação.

O processo de estimação é a tarefa de prever o estado de um sistema estocástico utilizando informações que são funções do estado e das observações (GREWAL; ANDREWS, 2008). Este processo pode ser executado por meio de três tipos de estimadores (RUSSELL; NORVIG, 2004), considerando $x_{t}$ o conjunto de variáveis de estado no tempo $t$ e $z_{t}$ o conjunto de variáveis de observação:

- Filtragem: Calcula a distribuição posterior sobre o estado atual, dada toda a observação até o momento $p\left(x_{t} \mid z_{1: t}\right)$, para $t$ iniciando em 1 ;

- Predição: Calcula a distribuição posterior sobre o estado futuro, dada toda a observação até o momento $p\left(x_{t+k} \mid z_{1: t}\right)$, para $k>0$; 
- Suavização: Calcula a distribuição posterior sobre o estado passado, dada toda a observação até o momento $p\left(x_{k} \mid z_{1: t}\right)$, para $0 \leq k<t$.

Por outro lado, um sistema de rastreamento em uma sequência de imagens é dividido em quatro componentes: a representação, que traz a descrição do alvo e a definição do vetor de estado; o modelo de observação, que identifica na imagem as características específicas do alvo de interesse; o modelo de movimento, descrevendo a dinâmica da trajetória do alvo; e o algoritmo de rastreamento, que utiliza os últimos três componentes para estimar a posição e determinar os parâmetros do alvo, em cada quadro, na sequência de imagens (DE BEM, 2007). O rastreamento é realizado como um processo de filtragem, já que a estimação de interesse consiste em determinar a posição e, às vezes, a forma do alvo de interesse no quadro atual, dada toda a sequência de imagens processada até este quadro, como apresentado anteriormente por $p\left(x_{t} \mid z_{1: t}\right)$.

Dentre os algoritmos existentes que realiza de modo eficaz a filtragem estocástica, um dos mais difundidos e que norteia o sucesso de diversas aplicações é o Filtro de Kalman (KALMAN, 1960).

O Filtro de Kalman, criado em 1960 por Rudolf E. Kalman, é um método aplicado em problemas onde há a necessidade de avaliar o estado de um sistema físico, tal como posições e velocidades, por meio de observações ruidosas em função do tempo (RUSSELL; NORVIG, 2004). Entende-se por filtro digital um algoritmo, composto por um conjunto de equações matemáticas, capaz de separar um sinal que tenha sido combinado ou restaurar um sinal que tenha se perdido em algum momento no tempo (SMITH, 1997).

O Filtro de Kalman é um estimador, representado por um algoritmo de processamento de dados recursivo ótimo (MAYBECK, 1979), e é frequentemente utilizado para realizar fusão sensorial, combinando dados obtidos de diferentes sensores em uma estimativa estatisticamente ótima, muito bem empregado em sistemas descritos através de um modelo linear, e as incertezas dos sensores e do sistema podem ser modeladas como ruídos gaussianos brancos (ou normais). Ruídos gaussianos brancos são sinais aleatórios estacionários com média nula.

Para sistemas que consideram dados não-lineares ao longo do tempo como aqueles onde, por exemplo, existe uma variação grande na velocidade dos alvos ou há mudanças bruscas de trajetória de cada alvo, é recomendado o uso do Filtro de 
Kalman Estendido (EKF - Extended Kalman Filter) (WELCH; BISHOP, 1995), que procura transpor a falha na hipótese de linearidade adotada pelo Filtro de Kalman por meio da realização de uma linearização em torno da estimativa do estado.

O Filtro de Kalman trata o problema de inferência em um modelo de probabilidade temporal, considerando que o modelo de movimento (sistema) descreve a física do movimento, e o modelo de observação (sensores) caracteriza o processo de observação (RUSSELL; NORVIG, 2004).

Para descrever o estado de um sistema são necessárias diversas variáveis lineares. Como exemplo pode-se citar a movimentação de um jogador de futebol em uma sequência de imagens que poderia ser especificada pela posição $(X, Y)$ e pela velocidade $(V x, V y)$ em cada instante de tempo de uma parte previamente especificada de seu corpo.

Para representar os modelos de movimento e de observação utilizam-se densidades condicionais específicas como as distribuições gaussianas. A condição do próximo estado $x_{k+1}$ deve ser uma função linear do estado atual $x_{k}$, somada a algum ruído gaussiano $w$, e assim sucessivamente (RUSSELL; NORVIG, 2004). Assim, o Filtro de Kalman torna-se um estimador linear ótimo (MAYBECK, 1979).

\section{1 $\quad$ ESTIMAÇÃO COM FILTRO DE KALMAN}

Welch e Bishop (1995) relatam que o Filtro de Kalman trata o problema geral de estimação de estados $x \in \mathfrak{R}^{n}$ para processos controlados no tempo discreto, resultando na estimação da densidade a posteriori $p\left(x_{k} \mid z_{1: k}\right)$, em que $x_{k}$ é o

estado atual no instante $k$, e $z_{1: k}$ é a observação até o instante $k$. A densidade $a$ posteriori é conduzida por uma equação diferencial estocástica linear:

$$
x_{k}=A x_{k-1}+B u_{k-1}+w_{k-1}
$$


com uma equação de observação $z \in \mathfrak{R}^{m}$, em que:

$$
z_{k}=H x_{k}+v_{k}
$$

sendo que a variável $u_{k}$ representa a entrada conhecida do processo, as variáveis aleatórias $w_{k}$ e $v_{k}$ exprimem o ruído do processo $(Q)$ e da observação $(R)$, respectivamente, e são independentes entre si, representando distribuições de probabilidades normais:

$$
\begin{aligned}
& p(w) \sim N(0, Q), \\
& p(v) \sim N(0, R) .
\end{aligned}
$$

A matriz $A(\mathrm{n} \times \mathrm{n})$ na Equação 2.1 representa o estado anterior $k-1 \mathrm{em}$ relação ao estado atual $k$, na ausência de uma função de transferência ou do ruído no processo. A matriz $B(\mathrm{n} \times \mathrm{I})$ representa a entrada do controle ótimo $u \in \mathfrak{R}^{l}$ para o estado $x$. A matriz $H(\mathrm{~m} \times \mathrm{n})$ na Equação 2.2 representa o estado da observação $z_{k}$. Na prática, as matrizes $A$ e $H$ podem sofrer variações com relação ao tempo. No entanto, neste estudo, são consideradas constantes.

Segundo Welch e Bishop (1995), define-se $\hat{x}_{k}^{-} \in \mathfrak{R}^{n}$ sendo a estimação a priori no instante $k$ baseada na observação do conhecimento do processo anterior, e $\hat{x}_{k} \in \Re^{n}$ sendo o estado estimado a posteriori no instante $k$, dada as observações $z_{k}$. Desta forma, os erros estimados a priori e a posteriori são definidos, respectivamente, como:

$$
\hat{e}_{k}^{-} \equiv x_{k}-\hat{x}_{k}^{-} \mathrm{e}
$$




$$
\hat{e}_{k} \equiv x_{k}-\hat{x}_{k}
$$

Note que o símbolo = encontra-se no sentido de "é definido como".

As covariâncias de erros estimados a priori e a posteriori são, respectivamente:

$$
\begin{gathered}
P_{k}^{-}=E\left[e_{k}^{-} e_{k}^{-T}\right] \mathrm{e} \\
P_{k}=E\left[e_{k} e_{k}^{T}\right] .
\end{gathered}
$$

Com o objetivo de encontrar a equação para o Filtro de Kalman que calcula a estimação do estado a posteriori $\hat{x}_{k}$, como uma combinação linear de um estado a priori $\hat{x}_{k}^{-}$, e a diferença de peso entre a observação atual $z_{k}$ e a observação estimada $H \hat{x}_{k}^{-}$, obtém-se:

$$
\hat{x}_{k}=\hat{x}_{k}^{-}+K\left(\mathrm{z}_{\mathrm{k}}-H \hat{x}_{k}^{-}\right) .
$$

A diferença $\left(\mathrm{z}_{\mathrm{k}}-H \hat{x}_{k}^{-}\right)$é chamada de observação de inovação ou residual. O residual reflete a discrepância entre a observação estimada $H \hat{x}_{k}^{-}$e a observação atual $z_{k}$. Um residual zero indica que as duas observações são iguais.

A matriz $K(\mathrm{n} \times \mathrm{m})$ na Equação 2.9 é o fator de ganho que minimiza a covariância de erros a posteriori definida pela Equação 2.8.

Na explicação de Welch e Bishop (1995), a justificativa para a Equação 2.9 é originada na probabilidade da estimação a priori $\hat{x}_{k}^{-}$e condicionada em todas as observações anteriores $z_{k}$. O Filtro de Kalman mantém os dois primeiros momentos da distribuição de estado:

$$
E\left[x_{k}\right]=\hat{x}_{k}
$$




$$
E\left[\left(x_{k}-\hat{x}_{k}\right)\left(x_{k}-\hat{x}_{k}\right)^{T}\right]=P_{k}
$$

A estimação do estado a posteriori da Equação 2.9 reflete a média no primeiro momento da distribuição de estado, que é distribuída somente se a condição dada na Equação 2.5 e na Equação 2.6 for igual. A covariância de erro estimada a posteriori na Equação 2.8 reflete a variância da distribuição de estado, não representando a média no segundo momento:

$$
p\left(x_{k} \mid z_{k}\right) \sim N\left(E\left[x_{k}\right], E\left[\left(x_{k}-\hat{x}_{k}\right)\left(x_{k}-\hat{x}_{k}\right)^{T}\right]=N\left(\hat{x}_{k}, P_{k}\right) .\right.
$$

\subsection{ALGORITMO DO FILTRO DE KALMAN}

A implementação do Filtro de Kalman divide-se em dois grupos: equação de atualização do instante (estimação) e equação de atualização da observação (correção).

A equação de atualização do instante, ou equação de estimação, é responsável por projetar adiante, no tempo, o estado atual e estimar a covariância do erro para obter a estimação a priori no instante seguinte.

A equação de atualização da observação, ou equação da correção, é responsável pela realimentação do sistema, incorporando uma nova observação dentro de uma estimação a priori para alcançar uma otimização da estimação a posteriori.

As equações formam um algoritmo de estimação-correção, baseado na observação, conforme ilustrado na Figura 2.1, onde a atualização do instante prevê o estado atual para o instante posterior e a atualização da observação corrige a estimativa projetada por uma observação naquele instante de tempo.

A Figura 2.2 relaciona as principais equações no algoritmo do Filtro de Kalman. O sistema está dividido em equações de atualização do instante (estimação) e de atualização da observação (correção). 
Um grande desafio do Filtro de Kalman está na determinação dos parâmetros de inicialização do sistema, tais como as covariâncias dos ruídos $R$ e $Q$, tanto para o modelo de observação quanto para a estimação do modelo do processo, respectivamente.

As covariâncias do ruído do modelo de observação $R$ precisam ser definidas antes do início da operação do filtro. Determinar o ruído de observação $R$ é geralmente uma tarefa prática, empírica e necessária, porque deve-se medir o processo quando o filtro está em operação. É necessário extrair algumas observações de amostras para determinar a variância do ruído de observação.

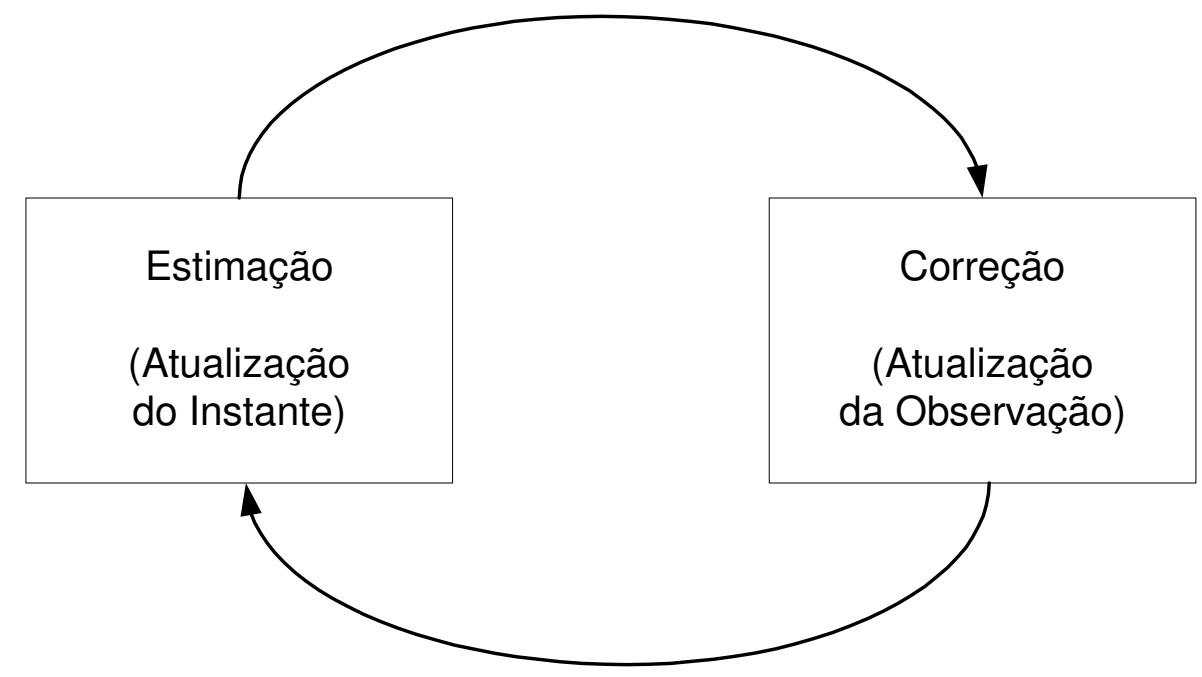

Figura 2.1 - Ciclo recursivo do Filtro Discreto de Kalman

Fonte: Adaptado de Welch e Bishop (1995).

A determinação da covariância do ruído da estimação do processo $Q$ é um pouco mais difícil de ser encontrada, pois não é possível observar o que está sendo estimado. Às vezes, a simplicidade do modelo de um processo pode produzir resultados aceitáveis quando as incertezas são bem definidas no processo por meio de $Q$. Neste caso, supõe-se que as observações do processo são confiáveis.

Por outro lado, tendo ou não uma base racional para escolher os parâmetros do filtro, estes podem ser ajustados para garantir um desempenho eficiente do modelo. $\mathrm{O}$ ajuste é executado fora da operação do filtro, com a ajuda de outro filtro distinto ou de um modelo de referência. Este processo é denominado como identificação das variáveis do sistema. 


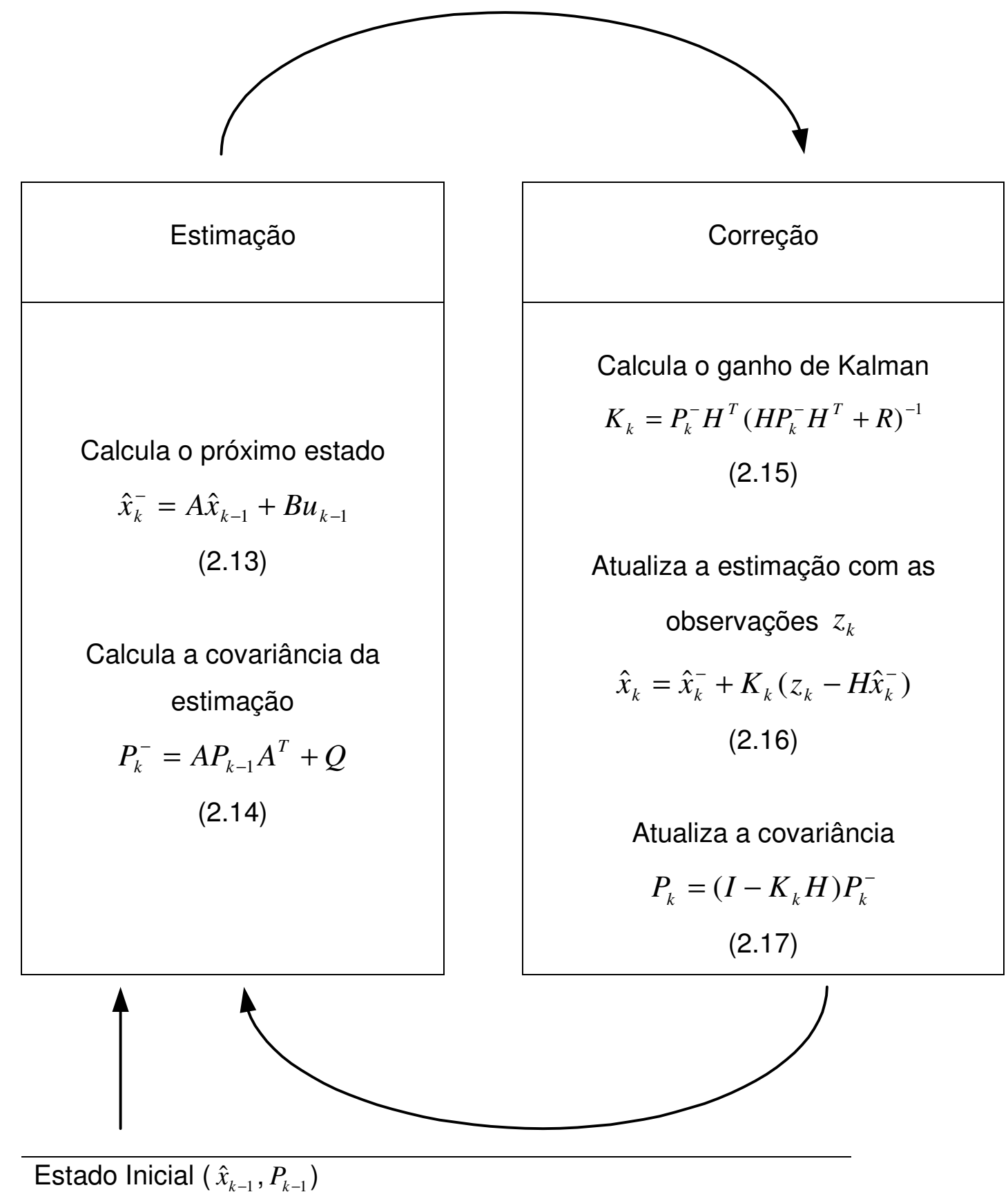

Figura 2.2 - Imagem completa da operação do Filtro de Kalman Fonte: Adaptado de Welch e Bishop (1995).

A Figura 2.3 ilustra, em diagrama de blocos, as equações mostradas na Figura 2.2. Nota-se, na Figura 2.3, que o vetor de estado atual $\hat{x}_{k}$ é incrementado a cada ciclo do Filtro de Kalman, pela soma entre o seu estado anterior $\hat{x}_{k}^{-}$e o 
produto do ganho de Kalman pela diferenca da observação $K_{k}\left(z_{k}-H \hat{x}_{k}^{-}\right)$. Então, para o próximo ciclo o vetor de estado calculado passa a ser o vetor de estado no instante anterior $\hat{x}_{k-1}$ conforme ilustrado pelo bloco "Delay".

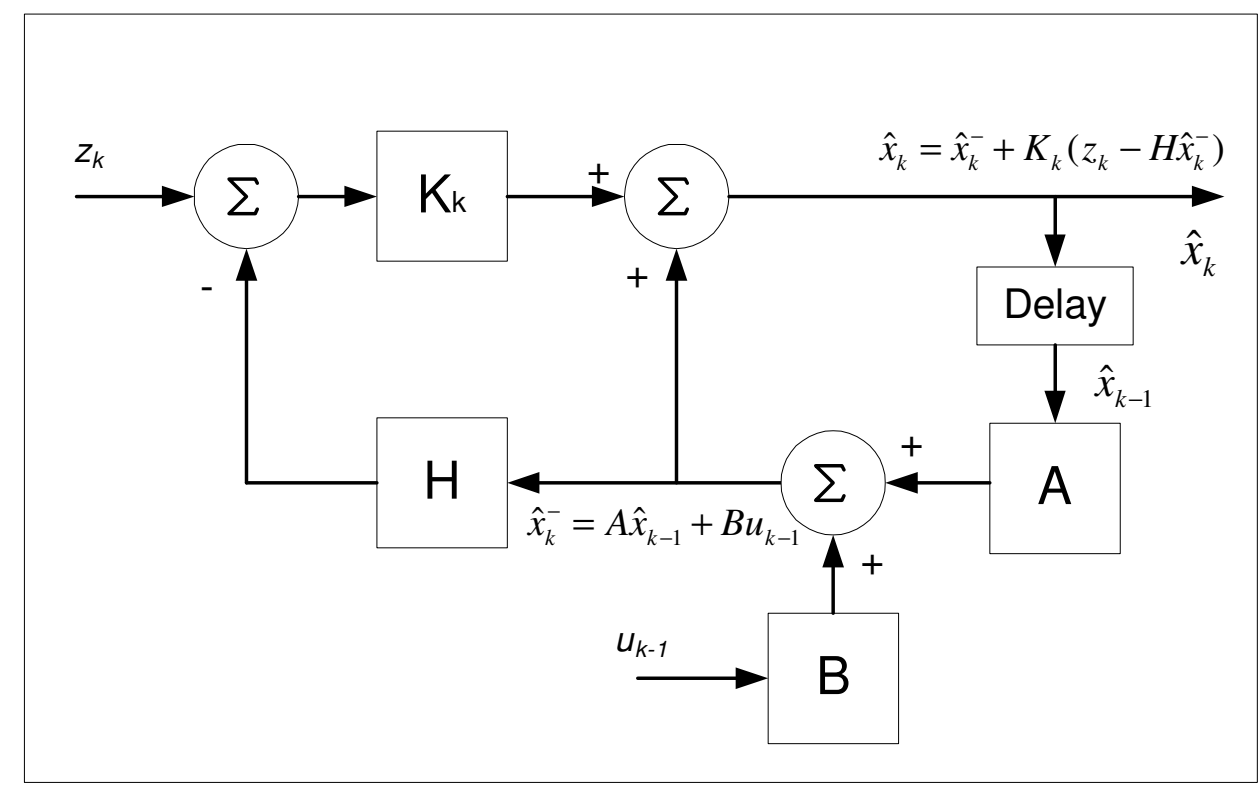

Figura 2.3 - Diagrama de blocos de um sistema com a representação do Filtro Discreto de Kalman

Fonte: Adaptada de Grewal; Andrew (2008).

\subsection{CONSIDERAÇÕES FINAIS DO CAPÍTULO}

O Filtro de Kalman é a base para muitas aplicações de sucesso em rastreamento visual de alvos e também é a ferramenta adotada no presente trabalho. A hipótese de linearidade do sistema impõe algumas restrições, limitando o uso em sistemas lineares. Contudo, por se tratar de um filtro ótimo, atua com eficiência e eficácia. As principais dificuldades deste tipo de implementação estão na modelagem dos ruídos de observação do sistema. 


\section{TRABALHOS CORRELATOS}

Este capítulo apresenta trabalhos relacionados ao rastreamento visual específicos para jogadores de futebol e também de pessoas. Dos trabalhos apresentados, dois deles (DE BEM, 2007; XU et al., 2005) foram selecionados por possuirem uma boa relação como objetivo deste estudo sendo detalhados em suas implementações, servindo de base à proposta da presente pesquisa.

Nos parágrafos seguintes serão apresentados alguns trabalhos de destaque na literatura, onde empregam diferentes soluções para tratar o problema de rastreamento visual de alvos móveis, incluindo principalmente trabalhos que consideram jogadores de futebol e pessoas como alvos.

Borg (2007) utiliza um algoritmo simples para a tarefa de rastreamentode jogadores de futebol, baseado somente em heurísticas definidas por detecções dos alvos realizados em quadros subsequentes, porém recomenda o Filtro de Kalman para uma implementação futura mais elaborada. O foco principal de seu trabalho não está no rastreamento, mas sim na calibração e configuração das câmeras do campo de futebol e na detecção dos jogadores e da bola. Borg (2007) aponta que para executar o rastreamento, as informações de posição, velocidade e aceleração dos jogadores no quadro anterior são armazenadas, e para cada novo quadro o algoritmo faz uma comparação com os novos dados. O cálculo da nova posição é realizado por um sistema de pontuação, baseado na diferença entre a posição estimada e a posição atual, e a diferença entre o vetor de velocidade antigo e o vetor de velocidade novo. O sistema de Borg (2007) foi implementado pela empresa TRACAB, na Suécia, que desenvolve produtos na área de rastreamento visual, com o objetivo de detectar e rastrear jogadores, árbitros e bola, oferecendo soluções de exibição gráfica 3D integradas com informações estatísticas. A TRACAB emprega uma técnica de visão estérea com utilização de 8 pares de câmeras para capturar as imagens de todo o campo de futebol, sendo este dividido em 8 quadrantes. Os resultados divulgados pela empresa apresentam bons indicadores de robustez dos seus produtos, pois até a presente data suas soluções de rastreamento de jogadores de futebol foram utilizadas em mais de 1000 partidas de futebol (TRACAB, 2009). 
Siebel (2003) apresentou um sistema denominado Reading People Tracker, que executa o rastreamento de pessoas baseado em um modelo de características de aparência de pessoas. Siebel utiliza um Filtro de Kalman, como um modelo de movimento de segunda ordem para modelar a velocidade e aceleração dos alvos e estimar a posição das pessoas nos quadros da sequência de imagens. Este projeto foi aplicado em sistemas de vigilância visual na área de segurança, conhecido também como circuito fechado de TV (CFTV). O trabalho de Siebel consistiu na melhoria do subsistema de rastreamento inicialmente proposto por Baumberg (1995) durante a construção do sistema ADVISOR, projeto europeu envolvendo três instituições acadêmicas e três parceiros da indústria. $O$ trabalho apresentado por Siebel (2003) possui características específicas para o rastreamento de pessoas, baseado em modelos 2D, do corpo humano, dificultando seu emprego em jogadores de futebol devido a mudanças bruscas dos membros e postura do corpo na imagem.

Outra técnica utilizada em sistemas de rastreamento de alvos, incluindo alvos de pessoas é o Condensation (Conditional Density Propagation), denominado por Isard e Blake (1998), conhecido também como Filtro de Partículas. O Condensation consegue lidar com problemas onde o modelo de movimento e o modelo de observação são não-lineares, inclusive quando as variáveis aleatórias não são gaussianas (ou não são processos normais), o que não ocorre com o Filtro de Kalman. Neste processo é empregado um conjunto de amostras do estado denominadas partículas. Quanto maior for a dimensão do vetor de estado, maiores deverão ser as amostras necessárias para que se obtenha uma boa representação da densidade de probabilidade. Por outro lado, isto causa um alto consumo computacional do sistema, o que não ocorre com o Filtro de Kalman (DE BEM, 2007).

Segundo Isard e Blake (1998) e Koller-Meier e Ade (2001), além de ser um pouco mais custoso computacionalmente, também pode resultar em muitos erros, sendo necessário realizar interferências manuais no rastreamento, principalmente em casos de mudança na direção da trajetória e perda do alvo por problemas no algoritmo com as oclusões.

Outro sistema baseado no Filtro de Partículas para jogadores é o Video2Cartton, de Liang et al. (2007). Este sistema realiza uma modelagem em 3D dos alvos rastreados para um campo de futebol, permitindo uma visualização da cena em três dimensões. $\mathrm{O}$ algoritmo de rastreamento utiliza um Filtro de Partículas 
aprimorado e baseado nas características de cores dos jogadores. Além do rastreamento dos jogadores, Liang et al. (2007) também desenvolveu o rastreamento da bola. No entanto, o sistema proposto por Liang et al. (2007) não trata problemas de oclusões de forma completa e ainda não está totalmente automatizado, sendo necessário realizar interferências manuais, tanto para determinar a posição da bola quanto para relacionar o rastreamento dos jogadores na imagem com a projeção no campo 3D. Sistemas que necessitem de muitas interações humanas no processo não possuem um bom compromisso com os objetivos e resultados do rastreamento automático de alvos.

ASPOGAMO (Automated SPOrt Game Analysis MOdel) é um projeto da Universidade de Munique, Alemanha, com o objetivo de rastrear visualmente jogadores de futebol em uma partida, utilizando imagens das câmeras de emissoras de TV disponíveis no evento, determinando a trajetória e as coordenadas da posição de cada jogador dentro de determinadas cenas (BEETZ et al., 2007). As trajetórias são determinadas no plano 3D do campo de futebol representando as posições em cada instante de tempo de cada jogador, em coordenadas do mundo real. Três problemas foram abordados neste projeto: a estimação da direção da câmera e do fator de zoom, já que neste caso não se tratava de câmeras fixas; a detecção e o rastreamento dos jogadores; e a identificação dos jogadores rastreados. O sistema foi testado com sucesso na Copa do Mundo de 2006, na Alemanha. Segundo Beetz et al. (2007), estão sendo realizadas algumas melhorias para concluir o projeto e obter um produto pronto. Uma grande diferença do projeto ASPOGAMO, para a proposta deste trabalho, está na utilização das imagens fornecidas pelas próprias câmeras das emissoras de TV para fazer o rastreamento, não sendo necessárias instalações de câmeras fixas exclusivas ao rastreamento.

A Figura 3.1 apresenta a arquitetura completa do sistema, dividido em 3 grupos de blocos. O primeiro grupo representa a localização do jogador, com os sub-blocos de busca por características correspondentes e a detecção do jogador. $O$ segundo grupo de blocos representa a estimação de estado, tendo como sub-blocos a estimação dos parâmetros de câmera, da posição do jogador e as hipóteses do rastreamento de cada alvo. O terceiro e último grupo de blocos representa os rastros percorridos pelos jogadores, com dois sub-blocos: um que permite editar manualmente os rastros e o outro que gera o modelo de movimento que cada jogador poderia realizar. 


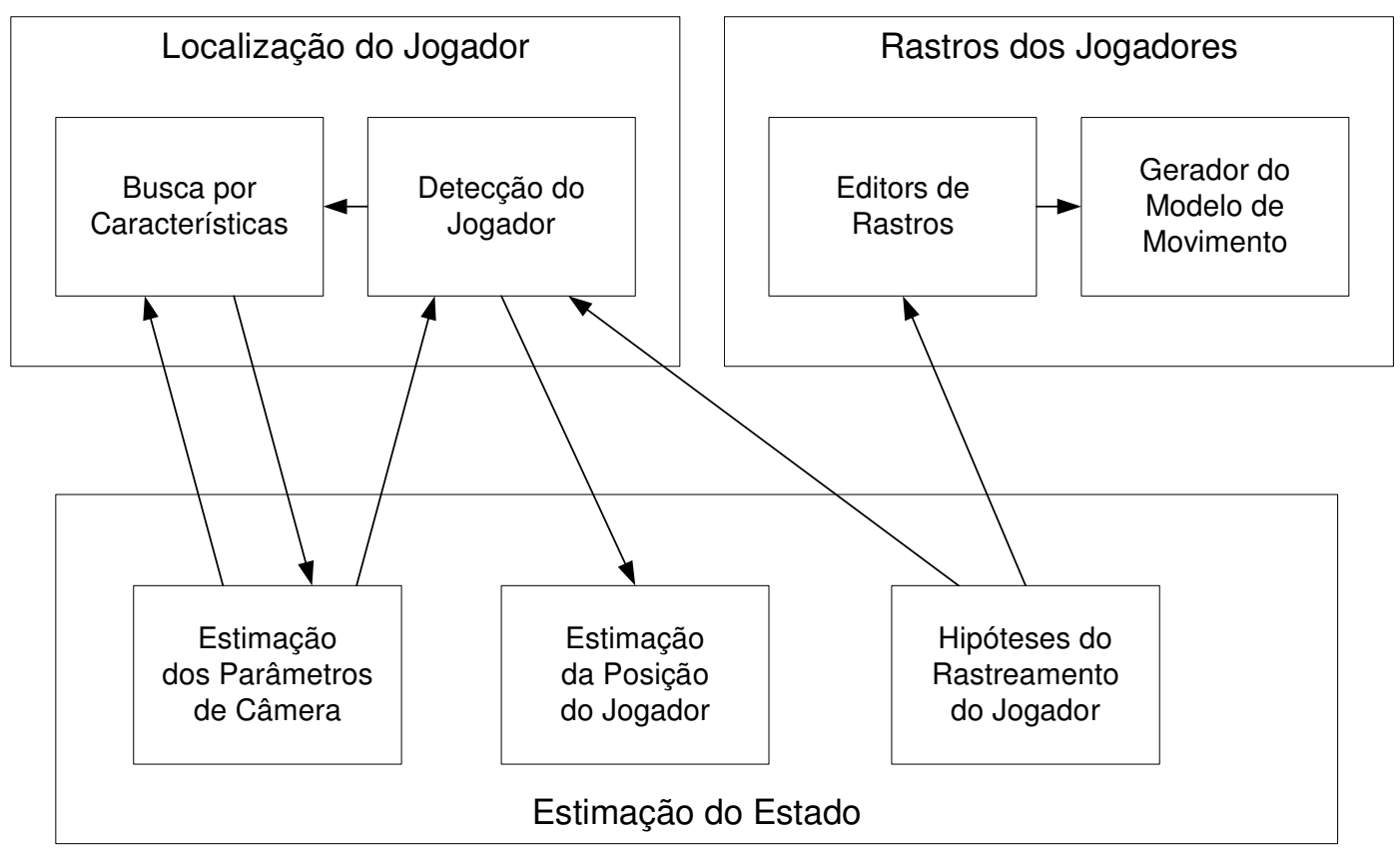

Figura 3.1 - Arquitetura de Software para o sistema ASPOGAMO

Fonte: Adaptada de Beetz et al. (2007).

O interesse maior no projeto ASPOGAMO está na etapa de detecção e rastreamento dos jogadores, e por este motivo este estudo somente abordará esta etapa. Para a detecção de jogadores é empregado o método de segmentação de bordas externas, baseado no modelo de tamanho dos alvos e no modelo de cores dos uniformes da equipe.

Os jogadores são localizados utilizando a estimação pelo canto superior esquerdo de seu retângulo envolvente. Para a etapa de rastreamento foi utilizado o MHT (Multiple Hypothesis Tracker), proposto por Reid (1979), melhorando a eficiência do rastreamento de alvos, decorrentes dos erros de observação, tais como: a indicação incorreta da categoria do jogador - definida pela cor do uniforme, trilhas falso positivas podem ter sido observadas pelo rastreamento, bem como jogadores não detectados. Todas estas condições interferem no processo de rastreamento (BEETZ et al., 2007). As variáveis de entrada para o MHT são as posições dos jogadores e as matrizes de covariâncias de observações. Para cada alvo a ser rastreado pelo MHT, múltiplos rastros no alvo são supostos, mas apenas a hipótese que possuir a maior nota ou peso no algoritmo será selecionada. $A$ implementação utilizada por Beetz et al. (2007) pode ser pesquisada com maior 
profundidade em Cox, Hingorani (1996). Para cada hipótese do rastreamento dos alvos é utilizado um Filtro de Kalman.

A principal desvantagem na implementação do MHT está na complexidade computacional da técnica, pois utiliza múltiplas hipóteses para o resultado do rastreamento para cada alvo, em cada quadro de imagem analisada (COX; HINGORANI, 1996).

Como o interesse deste trabalho consiste em obter um bom compromisso entre eficiência e eficácia para o sucesso do rastreamento visual de jogadores de futebol, os trabalhos de rastreamento de pessoas ou rastreamento de jogadores que utilizam o Filtro de Kalman, foram tomados como base.

Dois destes trabalhos foram selecionados: o sistema de rastreamento proposto por De Bem (2007) e o apresentado por Xu et al. (2005). Estes trabalhos foram selecionados por terem boa eficácia e bom desempenho computacional no rastreamento. O trabalho de Xu et al. (2005) possui uma modelagem simples do alvo e de seu movimento, além de utilizar o Filtro de Kalman para o rastreamento de jogadores, reportando resultados muito bons. Por outro lado, o trabalho de De Bem (2007) não foi aplicado especificamente no rastreamento de jogadores de futebol, mas explora uma modelagem mais fidedigna da forma humana, tendo sido empregado para o rastreamento de pessoas, conseguindo modelar a solução com sistemas lineares de modo a poder fazer o rastreamento com a aplicação de Filtros de Kalman, desacoplando o sistema através de dois filtros intercomunicantes, em uma interessante, eficaz e eficiente proposta. Estes trabalhos são detalhados a seguir.

\subsection{RASTREADOR DE DE BEM (2007)}

O sistema proposto por De Bem (2007) de rastreamento de alvos em sequências de imagens utiliza o Filtro de Kalman para alvos com formas heterogêneas, livres de modelo. A implementação divide-se em duas etapas: inicialização e rastreamento. 
$\mathrm{Na}$ inicialização é executado, em cada quadro, o processo de detecção dos alvos de interesse para o rastreamento, utilizando técnicas de processamento de imagens (GONZALEZ; WOODS, 1993), e também são definidas as estimativas dos estados iniciais de cada alvo, com relação a sua forma e movimento, conforme exposto na Figura 3.2.

O algoritmo proposto na inicialização possui dois tipos de detecção de alvo: uma detecção manual, onde cada alvo a ser rastreado é indicado pelo usuário; e uma detecção automática, baseada em morfologia matemática e utilizando técnicas de subtração de fundo de cena e extração de componentes conexos (GONZALEZ; WOODS, 1993). O fundo de cena é composto por todos os elementos que não são definidos como alvos de interesse, considerando que tudo o que não é alvo, é fundo de cena. Após a detecção, são inicializadas as variáveis de estado dos alvos que serão utilizadas pelo Filtro de Kalman durante o rastreamento. A estimativa do estado de cada alvo é definida por sua forma e movimento no plano de imagem.

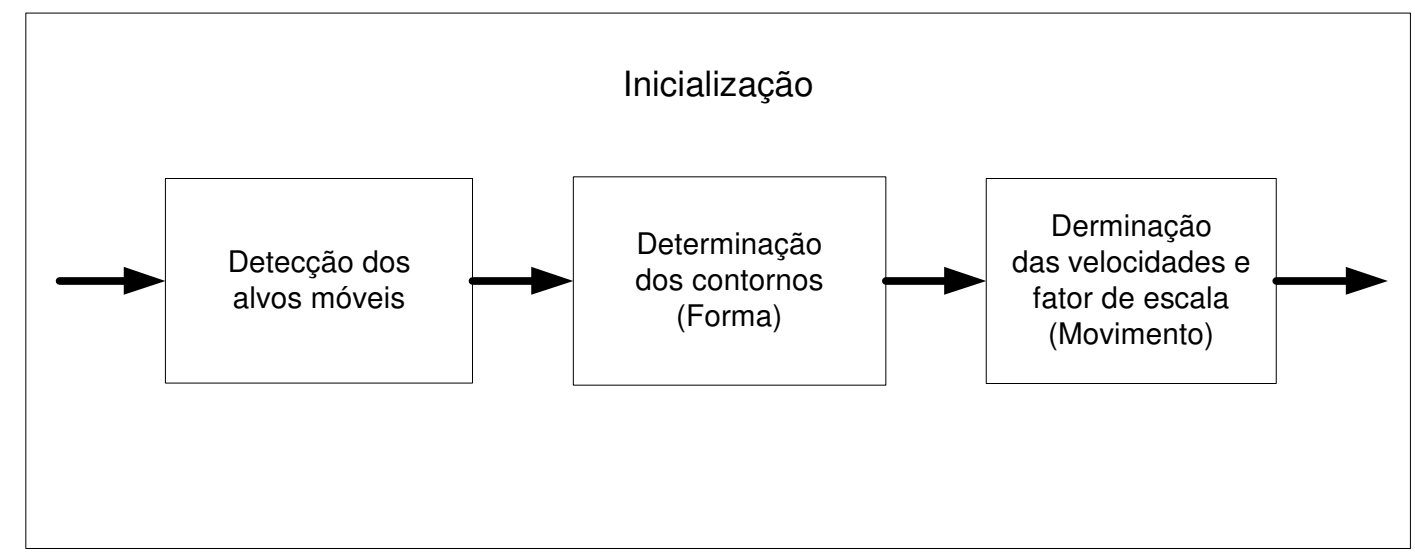

Figura 3.2 - Inicialização do Rastreamento por De Bem (2007)

Fonte: Adaptada de De Bem (2007).

A forma é representada por pontos de controle de uma B-Spline fechada, uma técnica bastante conhecida para a construção de curvas (DE BEM, 2007), que aproxima sua forma a um contorno de um polígono convexo, que é então aproximado por curvas diversas, conforme ilustrado na Figura 3.3. O movimento é dado pelos parâmetros de translação, do centro de área do contorno e mudança de escala, definidos no modelo de movimento da cinemática do alvo. Devido à variação de velocidade dos alvos de um quadro para o quadro subsequente ser pequena, as variáveis de velocidades são modeladas como ruídos gaussianos. 
O vetor que descreve a forma do alvo e que contém as posições de todos os $n C$ pontos de controle da B-Spline que descreve o alvo é dado por:

$$
\vec{X}_{k=0}=\left(\chi_{0, k}, \ldots, \chi_{i, k}, \ldots, \chi_{n C-1, k}\right)^{T},
$$

e cada ponto de controle, possui as coordenadas $\mathrm{X}$ e $\mathrm{Y}$, definidas como:

$$
\chi_{i, k}=\left(x_{i, k}, y_{i, k}\right)^{T}
$$

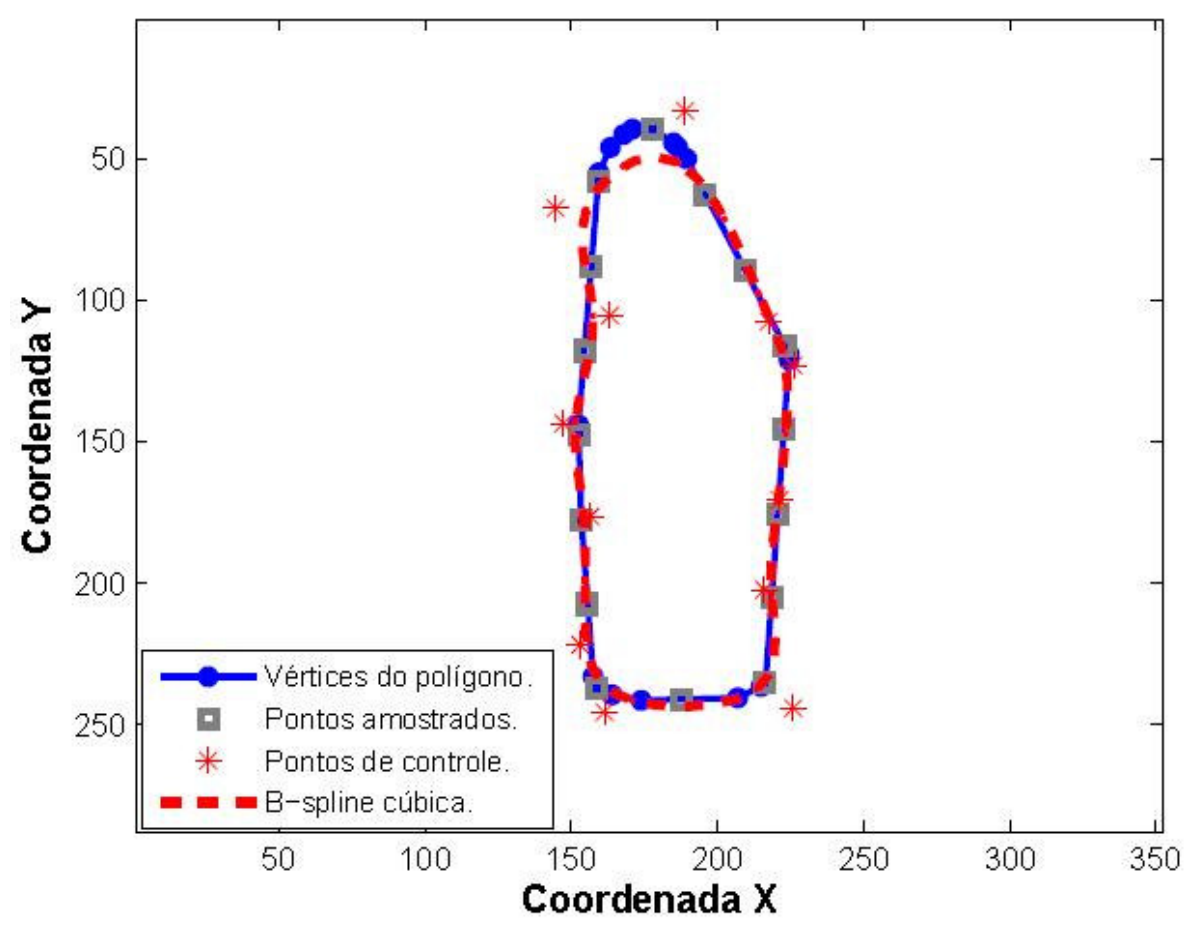

Figura 3.3 - Função B-Spline cúbica (linha tracejada), definida por seus pontos de controle (asteriscos), aproximando o polígono convexo (linha contínua)

Fonte: Extraída de De Bem (2007).

O vetor que descreve o movimento do alvo contém a velocidade e escala de cada alvo e é dado por:

$$
\vec{M}_{k=0}=\left(\mathbf{v}_{k}, s_{k}\right)=\left(v_{x, k}, v_{y, k}, s_{k}\right)^{T}
$$


Neste caso, $v_{x, k}$ e $v_{y, k}$ referem-se aos parâmetros de translação horizontal e vertical do centróide de cada ponto do contorno, respectivamente, e $s_{k}$ é a variável que define o fator de escala, sendo $s_{k}=0$ quando não há variação na escala, $s_{k}<0$ quando o tamanho do alvo na imagem diminui e $s_{k}>0$ quando o tamanho do alvo aumenta dentro da imagem em relação ao quadro anterior.

$\mathrm{Na}$ etapa de rastreamento concentra-se a parte principal do trabalho de De Bem (2007), pois é onde foi empregado o Filtro de Kalman. Na Figura 3.4, dadas as estimativas dos estados iniciais dos alvos, as quais foram definidas de acordo com seus vetores de forma e movimento na etapa de inicialização, o rastreamento inicia a execução recursiva das etapas de estimação e correção, baseada nos modelos de movimento e de observação com o propósito de estimar a trajetória de cada alvo. Sendo que o modelo de movimento é aquele que considera as observações das posições e velocidades dos alvos, e o modelo de observação o que utiliza as linhas de medidas dos contornos das formas de cada alvo para realizar o rastreamento.

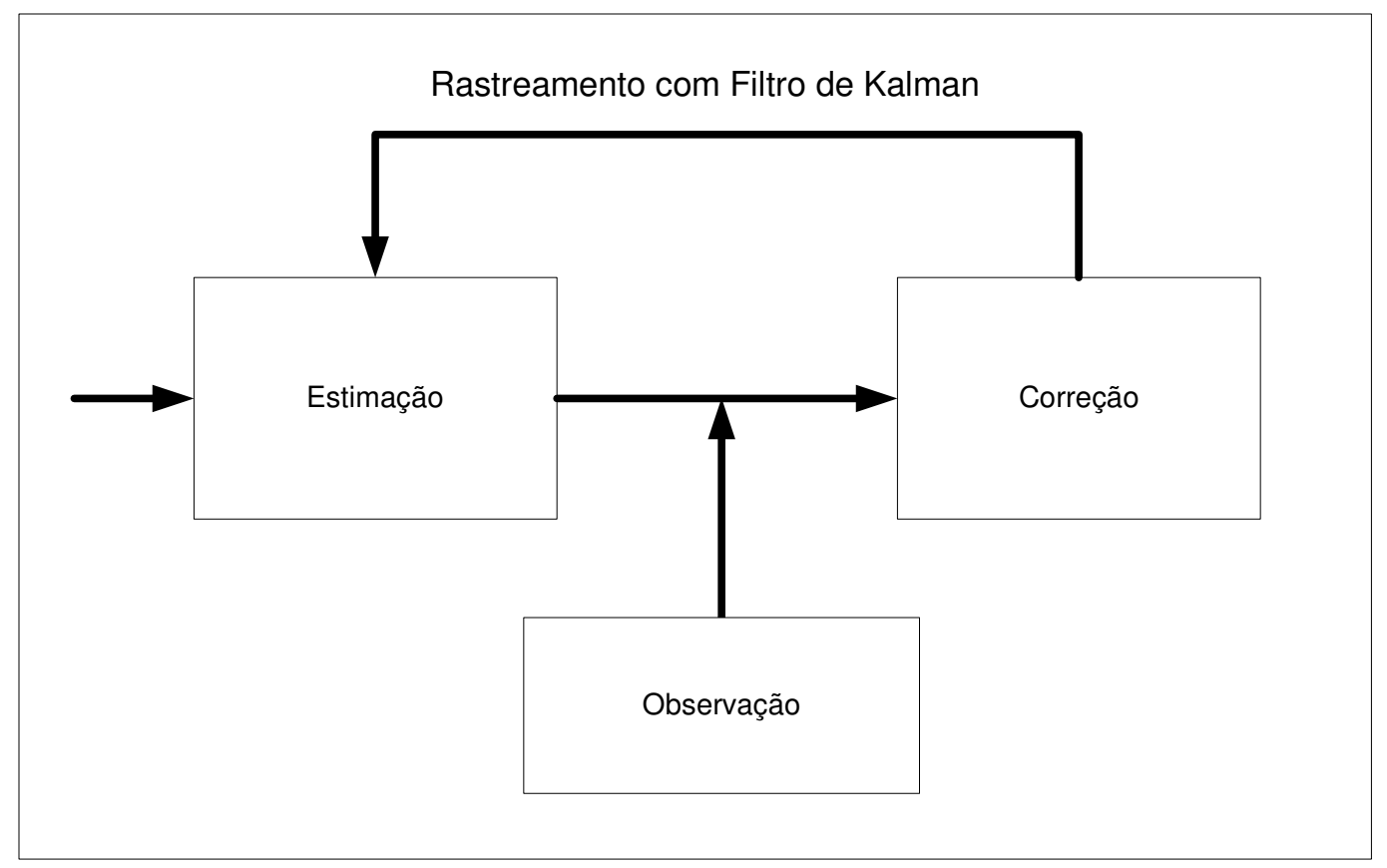

Figura 3.4 - Etapa de rastreamento e as interações com os blocos das equações do Filtro de Kalman: estimação e correção

Fonte: Adaptada de De Bem (2007). 
As linhas de medidas representam pontos em torno da envoltória do alvo. Elas são construídas de forma normal aos contornos do jogador, distribuídas uniformemente e fixas no seu ponto central ao longo do contorno gerado por uma função B-Spline (DE BEM, 2007). Busca-se, na linha de medida, um ponto que melhor defina o limiar de transição do contorno do alvo para o fundo de cena da imagem, conforme ilustrado na Figura 3.5d. Uma linha de medida exemplo é representada na Figura 3.5a. Na Figura 3.5b é exposto o resultado da detecção do contorno e do movimento, após análise da melhor probabilidade de localização do novo ponto que representa o contorno, conforme ilustrado na Figura 3.5c.

(a)

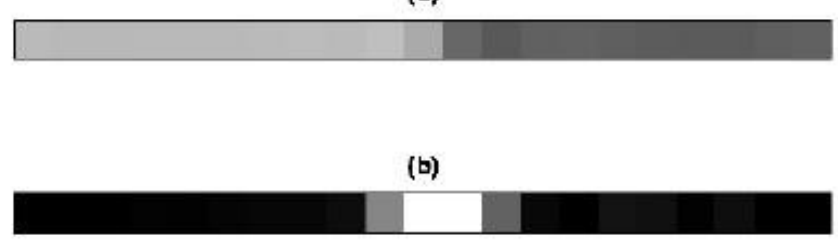

(c)

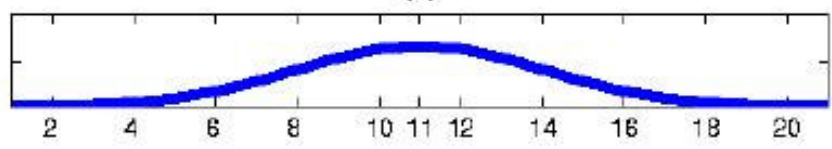

(d)

Figura 3.5 - (a) Intensidade dos pixels de uma linha de medida. (b) Aplicação dos detectores de contorno e movimento. (c) Densidade de probabilidade Gaussiana. (d) Probabilidade de cada pixel corresponder ao contorno (mais escuro corresponde à maior probabilidade)

Fonte: Extraída de De Bem (2007).

Estes pontos definem os pontos do contorno observado de cada alvo e são incluídos no vetor de observação para atualizar a estimativa do estado do Filtro de Kalman dentro do algoritmo de rastreamento. Devido aos erros de observação causados por ruídos e imperfeições no processo, é necessário considerar um desvio padrão para as linhas de medidas, que representa a incerteza quanto à posição do contorno do alvo.

Assim, o vetor de estado de cada alvo é dado por:

$$
\left(\begin{array}{l}
\vec{X}_{k} \\
\vec{M}_{k}
\end{array}\right)=\left(\chi_{0, k}, \ldots, \chi_{i, k}, \ldots, \chi_{n C-1, k}, v_{x, k}, v_{y, k}, s_{k}\right)^{T}
$$


A equação da cinemática do modelo de movimento dos alvos, envolvendo a posição, velocidade e fator de escala, para cada ponto do contorno descrito no vetor da forma $\vec{X}_{k}$, é dada por:

$$
\left(\begin{array}{l}
x_{i, k} \\
y_{i, k}
\end{array}\right)=\left(\begin{array}{l}
x_{i, k-1}+v_{x, k-1}+s_{k-1}\left(x_{i, k-1}-c_{k-1}^{x}\right) \\
y_{i, k-1}+v_{y, k-1}+s_{k-1}\left(y_{i, k-1}-c_{k-1}^{y}\right)
\end{array}\right),
$$

Sendo $\left(c_{k-1}^{x}, c_{k-1}^{y}\right)$ o centróide do alvo, representado pelo centro de área definido pelo contorno envolvente.

Considerando que as variações das velocidades e dos fatores de escala são constantes em relação ao quadro anterior, devido ao comportamento e movimentos dos alvos serem suaves entre os quadros na sequência de imagens, obtém-se:

$$
\left(\begin{array}{c}
v_{x, k} \\
v_{y, k} \\
s_{k}
\end{array}\right)=\left(\begin{array}{c}
v_{x, k-1} \\
v_{y, k-1} \\
s_{k-1}
\end{array}\right)
$$

Observando as Equações 3.5 e 3.6, a matriz de estado completa pode ser representada pela multiplicação da matriz de transição, $A_{k-1}$, pela matriz de estado anterior (já que neste caso, não há uma entrada $u_{k-1}$ do processo, como apresentado na Equação 2.13 do capítulo anterior), conforme apresentado na Equação 3.7.

Nota-se que o sistema dinâmico modelado é um sistema não-linear. Portanto, para fazer o desacoplamento do sistema, e torná-lo um sistema linear, é necessário realizar uma manipulação algébrica da matriz de transição na Equação 3.8 (DE BEM, 2007).

$$
\left(\begin{array}{l}
\vec{X}_{k} \\
\vec{M}_{k}
\end{array}\right)=A_{k-1} \cdot\left(\begin{array}{l}
\bar{X}_{k-1} \\
\bar{M}_{k-1}
\end{array}\right)
$$




$$
\left(\begin{array}{c}
x_{i, k} \\
y_{i, k} \\
v_{x, k} \\
v_{y, k} \\
s_{k}
\end{array}\right)=\left(\begin{array}{ccccc}
1 & 0 & 1 & 0 & x_{i, k-1}-c_{k-1}^{x} \\
0 & 1 & 0 & 1 & y_{i, k-1}-c_{k-1}^{y} \\
0 & 0 & 1 & 0 & 0 \\
0 & 0 & 0 & 1 & 0 \\
0 & 0 & 0 & 0 & 1
\end{array}\right) \cdot\left(\begin{array}{c}
x_{i, k-1} \\
y_{i, k-1} \\
v_{x, k-1} \\
v_{y, k-1} \\
s_{k-1}
\end{array}\right)
$$

Para demonstrar este desacoplamento segue um exemplo supondo o contorno de um alvo representado por dois pontos, $\left(x_{i, k}, y_{i, k}\right)$ e $\left(x_{j, k}, y_{j, k}\right)$. Sendo assim, a equação $A_{k-1}$ é reescrita como $A^{\prime}{ }_{k-1}$ :

$$
\begin{aligned}
& A_{k-1}=
\end{aligned}
$$

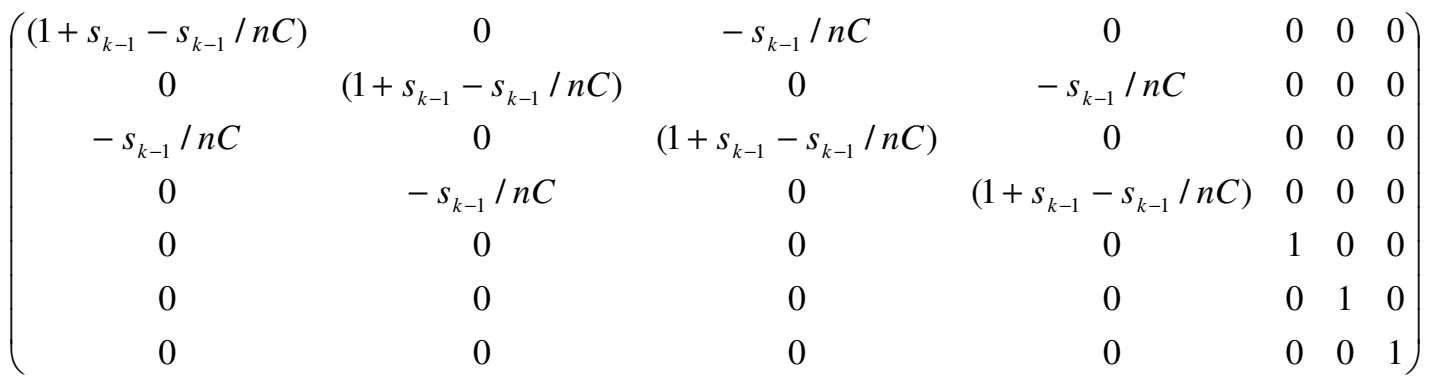

$$
\begin{aligned}
& \left(\begin{array}{c}
x_{i, k} \\
y_{i, k} \\
x_{j, k} \\
y_{j, k} \\
v_{x, k} \\
v_{y, k} \\
s_{k}
\end{array}\right)=A_{k-1}^{\prime} \cdot\left(\begin{array}{c}
x_{i, k-1} \\
y_{i, k-1} \\
x_{j, k-1} \\
y_{j, k-1} \\
v_{x, k-1} \\
v_{y, k-1} \\
s_{k-1}
\end{array}\right)+\left(\begin{array}{c}
v_{x, k-1} \\
v_{y, k-1} \\
v_{x, k-1} \\
v_{y, k-1} \\
0 \\
0 \\
0
\end{array}\right),
\end{aligned}
$$

com $n C$ sendo a dimensão do vetor $\vec{X}_{k}$ e o número de pontos de controle.

Assim como na Equação 3.9, a matriz de transição é uma matriz diagonal em blocos, permitindo o desacoplamento do sistema e tornando-o, assim, um sistema linear (BAR-SHALOM; LI; KIRUBARAJAN, 2001), conforme as Equações 3.10 e 3.11. 


$$
\begin{aligned}
& \left(\begin{array}{c}
v_{x, k} \\
v_{y, k} \\
s_{k}
\end{array}\right)=\left(\begin{array}{ccc}
1 & 0 & 0 \\
0 & 1 & 0 \\
0 & 0 & 1
\end{array}\right) \cdot\left(\begin{array}{c}
v_{x, k-1} \\
v_{y, k-1} \\
s_{k-1}
\end{array}\right), \\
& A_{k-1}^{\prime \prime}= \\
& \left(\begin{array}{cccc}
\left(1+s_{k-1}-s_{k-1} / n C\right) & 0 & -s_{k-1} / n C & 0 \\
0 & \left(1+s_{k-1}-s_{k-1} / n C\right) & 0 & -s_{k-1} / n C \\
-s_{k-1} / n C & 0 & \left(1+s_{k-1}-s_{k-1} / n C\right) & 0 \\
0 & -s_{k-1} / n C & 0 & \left(1+s_{k-1}-s_{k-1} / n C\right),
\end{array}\right. \\
& \left(\begin{array}{l}
x_{i, k} \\
y_{i, k} \\
x_{j, k} \\
y_{j, k}
\end{array}\right)=A_{k-1}^{\prime \prime} \cdot\left(\begin{array}{c}
x_{i, k-1} \\
y_{i, k-1} \\
x_{j, k-1} \\
y_{j, k-1}
\end{array}\right)+\left(\begin{array}{c}
v_{x i, k-1} \\
v_{y i, k-1} \\
v_{x j, k-1} \\
v_{y j, k-1}
\end{array}\right),
\end{aligned}
$$

Observando a Equação 3.12, nota-se que os parâmetros de velocidade não pertencem a parte do vetor de estado, contendo os pontos de controle, e estes também não pertencem a parte do vetor de estado que representa a velocidade (DE BEM, 2007), sendo assim, as matrizes de transição de ambos os sistemas lineares.

Desta forma o sistema torna-se também um sistema linear, pois as matrizes de transição são separadas em duas, sendo uma para os parâmetros de estimação do movimento do alvo e outra para os parâmetros de estimação da forma do contorno do alvo. Com isso é possível o emprego de dois Filtros de Kalman para a estimação de cada um destes dois vetores de estado.

O pseudo algoritmo de De Bem (2007) é dividido em 5 etapas, sendo a primeira a entrada de todos os parâmetros utilizados pelo algoritmo, tais como:

- Tipo de segmentação: manual ou automática;

- Nome do arquivo de vídeo a ser analisado;

- Resolução dos quadros da sequência de imagem;

- Número de pontos de controle da B-Spline $(n C)$;

- Número de pontos amostrados no polígono envolvente $(n A)$;

- Comprimento das linhas de medida $(c L)$;

- Desvio padrão sobre a linha de medida $(\sigma)$; 
- Covariância inicial do movimento $(\vec{P})$;

- Covariância inicial da forma $\left(P x_{0}\right)$;

- Covariância da estimação do movimento $(\vec{Q})$;

- Covariância da estimação da forma $\left(Q_{X}\right)$;

- Covariância da observação do movimento $\left(R_{M}\right)$;

- Covariância da observação do forma $\left(R_{X}\right)$.

$\mathrm{Na}$ segunda etapa é realizada a segmentação da imagem de fundo de cena, subtraindo o fundo pela intensidade de cor e extraindo todos os alvos de interesse por meio de processos, tais como:

- "Binarização" da imagem, aplicando uma limiarização automática pela intensidade de cor;

- Execução de uma abertura morfológica na imagem, eliminando pequenas partes (conjunto de pixels vizinhos) que não são alvos;

- Cálculo do número total de alvos detectados, baseado nos componentes conexos resultantes.

$\mathrm{Na}$ terceira etapa são inicializados os parâmetros e os estados dos Filtros de Kalman para cada alvo (forma e movimento) e também é construída a representação das linhas de medidas para cada um. Após a criação das linhas de medidas, é criada uma estrutura de dados que contém todas as informações dos alvos (componentes conexos), associando e calculando o centróide, determinando o polígono envolvente de cada alvo e aproximando cada polígono envolvente por uma B-Spline de grau três, definindo $n C$ pontos de controle.

$\mathrm{Na}$ etapa quatro é executado o algoritmo de rastreamento baseado em dois Filtros de Kalman, considerando inicialmente os centróides de cada alvo no primeiro quadro. Para cada alvo a ser rastreado inicia-se um ciclo do segundo ao último quadro da sequência de imagens, salvando todas as informações de cada um (centróide, pontos de controle, matriz de estimação e observação do movimento e da forma, entre outros). A parte principal desta etapa está no processamento dos filtros, onde primeiramente é executado o Filtro de Kalman para o movimento dos alvos e em seguida é empregado o Filtro de Kalman para a forma dos alvos. Após a execução do rastreamento são armazenadas, na quinta etapa, além das 
informações relativas ao centróide estimado do alvo, as informações resultantes do rastreamento em uma estrutura de imagem, para posterior visualização do vídeo com o alvo sendo rastreado.

\subsection{RASTREADOR DE XU ET AL. (2005)}

O sistema de Xu et al. (2005) aplica o Filtro de Kalman para o rastreamento de jogadores com câmeras fixas. A proposta faz parte do projeto INMOVE, formado por um consórcio europeu integrando instituições da área de pesquisa e desenvolvimento, telefonia e tecnologia, envolvendo cinco países: Finlândia, Holanda, Itália, Dinamarca e Inglaterra. O objetivo é desenvolver projetos na área de visão computacional, com foco em mobilidade (ANDERSIN et al., 2005). O projeto INMOVE incorporou o desenvolvimento do sistema de rastreamento de jogadores de futebol como uma importante ferramenta para os usuários de dispositivos móveis e fãs de futebol.

O sistema de rastreamento está dividido em duas etapas principais. $\mathrm{Na}$ primeira é realizada a detecção dos alvos nas imagens utilizando técnicas de subtração de fundo, atualização dinâmica do modelo de fundo e fechamento morfológico do resultado da subtração. Estas técnicas podem ser vistas detalhadamente em Gonzalez e Woods (1993). Como resultados, são gerados, além do número total de alvos detectados, o centro de área e o retângulo envolvente de cada alvo. Na segunda etapa é executado o rastreamento dos alvos com um Filtro de Kalman, utilizando uma representação baseada na região do retângulo envolvente do alvo e seu centro de área como variável de estado $x$ e de observação $z$ :

$$
\begin{gathered}
x=\left[\begin{array}{llllllll}
r_{c} & c_{c} & \dot{r}_{c} & \dot{c}_{c} & \Delta r_{1} & \Delta c_{1} & \Delta r_{2} & \Delta c_{2}
\end{array}\right]^{T} \mathrm{e} \\
z=\left[\begin{array}{llllllll}
r_{c} & c_{c} & r_{1} & c_{1} & r_{2} & c_{2}
\end{array}\right]^{T},
\end{gathered}
$$


sendo $r_{c}$ e $c_{c}$ as coordenadas do centro de área de cada jogador; $\dot{r}_{c}$ e $\dot{c}_{c}$ a velocidade do jogador; $r_{1}, c_{1}$, e $r_{2}, c_{2}$ representam os dois pontos do retângulo envolvente, respectivamente o ponto superior esquerdo e o ponto inferior direito, considerando que $\left(r_{1}<r_{2}, c_{1}<c_{2}\right),\left(\Delta r_{1}, \Delta c_{1}\right)$ e $\left(\Delta r_{2}, \Delta c_{2}\right)$ representam as posições relativas dos pontos $r_{1}, c_{1}, r_{2}$ e $c_{2}$ do retângulo envolvente até o centro de área, conforme ilustrado na Figura 3.6.

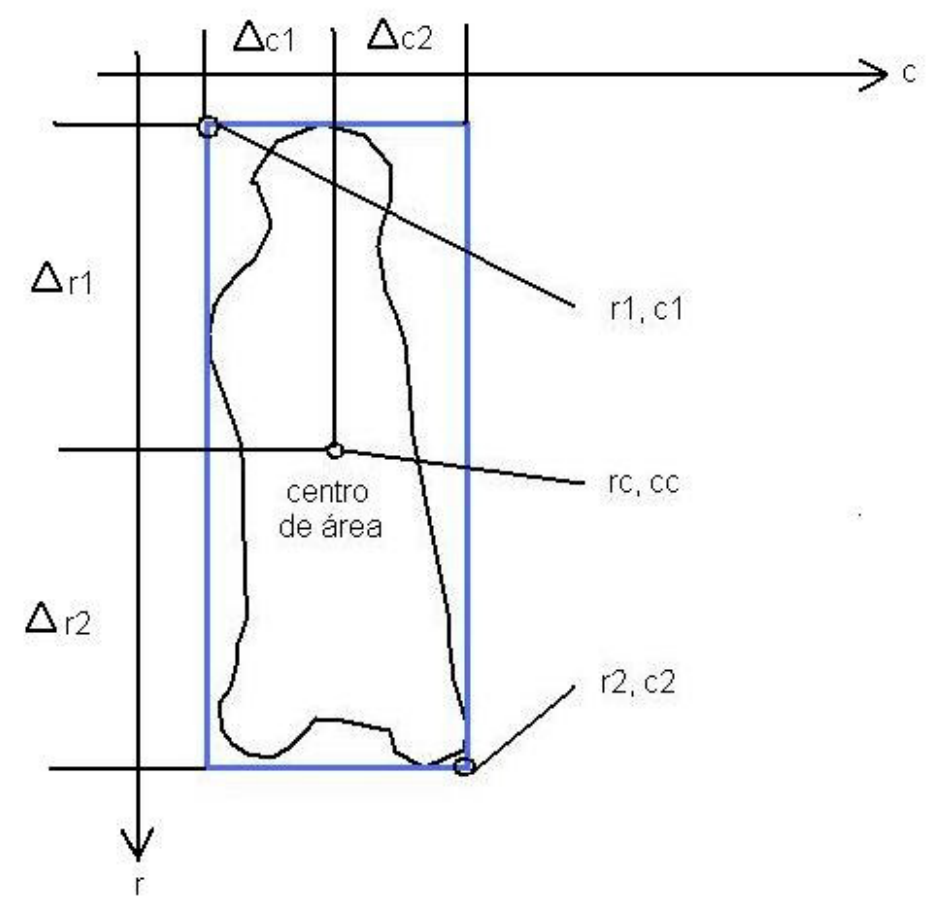

Figura 3.6 - Centro de área e retângulo envolvente do alvo

As equações de estado e de observação são, respectivamente:

$$
\begin{gathered}
x_{k+1}=A x_{k}+w_{k} \mathrm{e} \\
z_{k}=H x_{k}+v_{k},
\end{gathered}
$$

em que, $w_{k}$ é o ruído do processo e $v_{k}$ é o ruído da observação. As matrizes de transição de estado e de observações são: 


$$
\begin{gathered}
A_{I}=\left[\begin{array}{cccc}
I_{2} & \mathrm{TO}_{2} & O_{2} & O_{2} \\
O_{2} & I_{2} & O_{2} & O_{2} \\
O_{2} & O_{2} & I_{2} & O_{2} \\
O_{2} & O_{2} & O_{2} & I_{2}
\end{array}\right] \mathrm{e} \\
H_{I}=\left[\begin{array}{llll}
I_{2} & O_{2} & O_{2} & O_{2} \\
I_{2} & O_{2} & I_{2} & O_{2} \\
I_{2} & O_{2} & O_{2} & I_{2}
\end{array}\right],
\end{gathered}
$$

em que, $I_{2}$ e $\mathrm{O}_{2}$ são a matriz identidade $2 \times 2$ e a matriz zero, respectivamente. $T$ representa o intervalo de tempo entre o quadro anterior e o atual, para o cálculo das velocidades $\dot{r}_{c}$ e $\dot{c}_{c}$. A estimação a priori, $\hat{x}_{k}^{-}$, e a estimação a posteriori, $\hat{x}_{k}$ são dados por:

$$
\begin{gathered}
\hat{x}_{k}^{-}=A \hat{x}_{k-1} \mathrm{e} \\
\hat{x}_{k}=\hat{x}_{k}^{-}+K_{k}\left(z_{k}-H \hat{x}_{k}^{-}\right),
\end{gathered}
$$

em que $K_{k}$ é a matriz do ganho de Kalman que minimiza a covariância a posteriori (XU; ELLIS, 2002).

Assumindo que há pouca variação dos valores de altura e largura do retângulo envolvente do alvo (entre o quadro anterior e o atual, em uma sequência de imagens) e que a área do retângulo é observável em todos os quadros, quando ocorre uma variação grande no valor da largura e/ou altura do retângulo, por exemplo no caso de uma oclusão parcial, a estimação da área do retângulo envolvente atual pode ocorrer por aproximação da largura e da altura em relação ao quadro anterior, como mostra a Figura 3.7.

Observa-se que na célula superior do meio, onde é exposta a oclusão parcial, o algoritmo de rastreamento definiu o retângulo envolvente, na cor verde, considerando os dois jogadores em oclusão. Já na célula inferior do meio, nota-se que o algoritmo levou em consideração a altura e largura dos dois jogadores, 
definidas pelos retângulos envolventes na cor vermelha, e já na célula inferior direita são indicados os dois jogadores com a oclusão parcial sendo desfeita. Esta atualização da estimação baseada em aproximação, utilizando as observações parciais disponíveis, possui uma maior precisão no tratamento de oclusão do que somente a utilização dos valores de altura e largura da área do retângulo envolvente de cada alvo (XU; ORWELL; JONES, 2004).

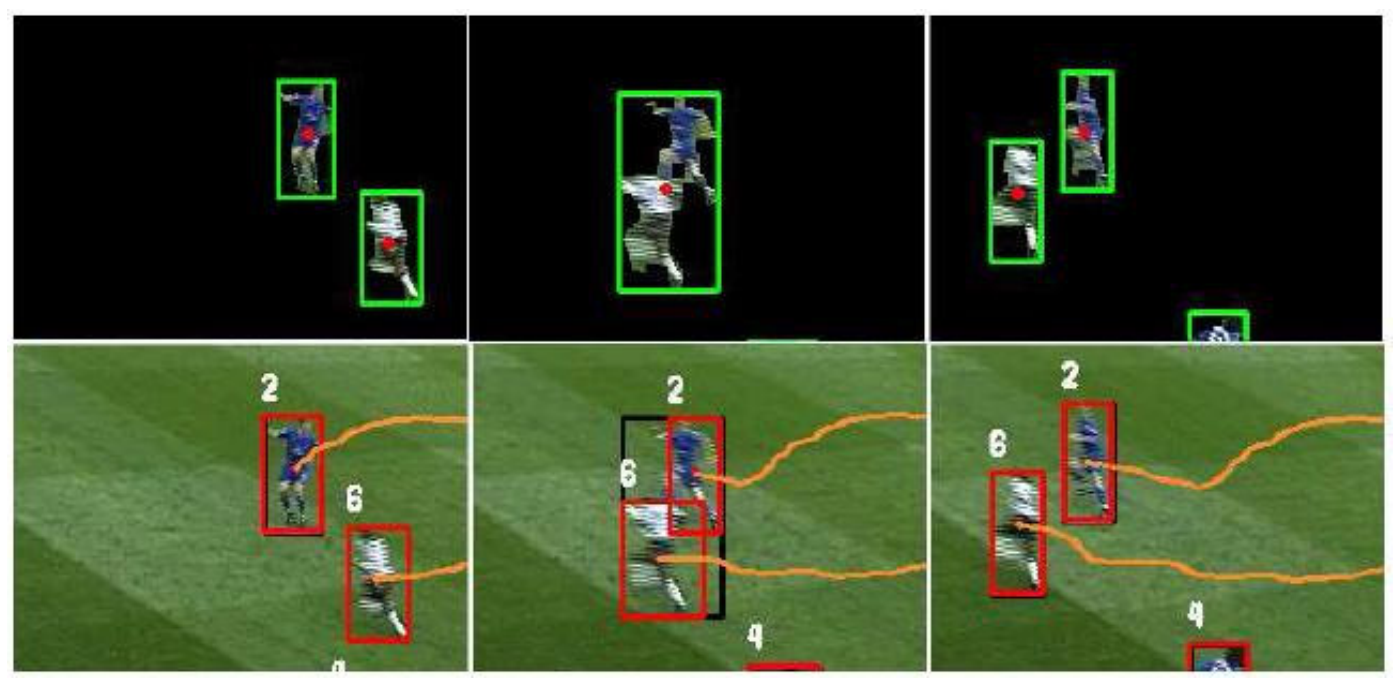

Figura 3.7 - Detecção e Rastreamento de Jogadores. Nos quadros centrais há oclusão, mas a estimação se mantém (linha inferior) com base no quadro anterior (coluna da esquerda)

Fonte: Extraído de Xu, Orwell e Jones (2004).

O rastreamento de cada jogador é realizado considerando seu retângulo envolvente, que é o próprio alvo, e fazendo uma correlação com o histograma de cor entre o próximo quadro e o quadro anterior, tanto do retângulo envolvente do alvo como do retângulo envolvente que define a cor do jogador. Assim sendo, o Filtro de Kalman é aplicado para a estimação da posição do próximo retângulo envolvente, corrigindo a posição também do retângulo envolvente do alvo. O pseudo algoritmo inspirado na proposta de Xu et al. (2005), considerando informação de cor do alvo e da cena de fundo, é descrito em quatro etapas.

$\mathrm{Na}$ primeira etapa, considerando que a sequência de imagens está na memória do computador, define-se manualmente os retângulos envolventes do alvo, sendo eles:

- Alvo de interesse. Vetor indicando as coordenadas do retângulo envolvente do jogador no primeiro quadro da sequência; 
- Cor do fundo de cena. Seleciona na imagem uma área retangular com a cor predominante do fundo de cena.

$\mathrm{Na}$ segunda etapa, após determinar os retângulos envolventes, definem-se os parâmetros do rastreamento, tamanho das janelas de buscas, cor média da cena de fundo, calculam-se as posições relativas do retângulo envolvente do uniforme dentro do retângulo envolvente do alvo, e define-se a cor do uniforme.

Os parâmetros para o Filtro de Kalman são definidos na terceira etapa, sendo eles:

- Matriz de transição de estados $(A)$;

- Matriz de observação de posição X e Y $(H)$;

- Covariância inicial da estimação $\left(P_{0}\right)$;

- Covariância da estimação do movimento $(Q)$;

- Covariância da observação da estimação $(R)$.

O processo de rastreamento é a quarta etapa e a mais importante do algoritmo, e é realizada através de um ciclo do primeiro ao último quadro: lê o quadro a ser processado, procura dentro do retângulo envolvente do alvo onde está a localização do retângulo envolvente, calculando a nova posição do alvo, e por fim aplica o Filtro de Kalman, considerando pouca variação de velocidade e um sistema linear. Dentro do algoritmo do Filtro de Kalman são consideradas as informações sobre o ruído de observação, a covariância de estimação, a estimação do estado atual, calcula-se o ganho de Kalman e o vetor de estimação atualizando a estimação do estado e a posição do retângulo envolvente estimado. Após o cálculo da nova posição estimada, calcula-se a covariância do erro estimado e salvam-se os parâmetros do algoritmo para o próximo ciclo e para os gráficos que serão gerados com os resultados.

A abordagem do trabalho de Xu et al. (2005) trata a oclusão de uma forma simples. A proposta aqui apresentada não considera a oclusão de alvos. 


\subsection{CONSIDERAÇÕES FINAIS DO CAPÍTULO}

A forma de um jogador de futebol sofre mais deformações do que a forma de pessoas comuns, caminhando pela rua, por exemplo. Devido às grandes variações de movimento ocorridas durante a prática de esportes, quando um jogador de futebol realiza suas ações dentro do campo, sua forma sofre deformações que dificultam a representação baseada em modelos simples, seja pela região retangular da imagem que envolve o alvo, seja por somente suas características visuais, tais como cores e texturas do corpo ou uniforme.

Contudo, para obter uma boa aproximação do contorno do alvo em relação à sua forma, é necessário o emprego de técnicas livres de modelos e que se adaptem às dinâmicas destas deformações durante o rastreamento. $O$ emprego destas técnicas garante uma boa precisão na representação da forma do alvo, permitindo extrair algumas informações relevantes como, por exemplo, a altura do jogador, a posição do pé naquele quadro, indicação nos casos de oclusões parciais, e até mesmo uma possível identificação do evento no qual o jogador está participando daquela cena.

Outro frequente problema que ocorre na sequência de imagens em uma partida de futebol, e que a maioria dos trabalhos correlatos não resolve totalmente, é a oclusão entre os alvos. Resolver o problema de oclusão significa controlar exatamente o rastreamento da forma dos alvos mantendo o alvo rastreado, mesmo depois de passar por oclusões parciais, onde o alvo desaparece parcialmente e reaparece em cena alguns quadros seguintes. $O$ presente trabalho não pretende resolver o problema de oclusão entre alvos, mas garantir o desenvolvimento do rastreamento de jogadores de futebol que possua uma base de informações suficientes e que permita a exploração do problema de oclusão em futuros trabalhos, como continuidade do corrente.

Para comparar os dois trabalhos correlatos principais aqui detalhados, segundo algumas dimensões de interesse, visando principalmente à eficiência computacional, à eficácia dos resultados de rastreamento e à simplicidade no rastreamento, é apresentada a Tabela 3.1. 
Tabela 3.1 - Tabela comparativa com os dois trabalhos correlatos principais

\begin{tabular}{|l||c||l|l|l|}
\hline $\begin{array}{l}\text { Trabalho } \\
\text { Correlato }\end{array}$ & Técnica & $\begin{array}{l}\text { Câm. } \\
\text { Fixa }\end{array}$ & Vantagem & Desvantagem \\
\hline $\begin{array}{l}\text { De Bem } \\
\text { (2007) }\end{array}$ & $\begin{array}{c}\text { Livre de } \\
\text { Fodelos. 2 } \\
\text { Filtros de } \\
\text { Kalman por } \\
\text { alvo }\end{array}$ & Sim & $\begin{array}{l}\text { Bom desempenho e } \\
\text { excelente eficácia, sendo } \\
\text { livre de modelos em } \\
\text { relação ao tamanho e } \\
\text { forma do contorno dos } \\
\text { alvos. Foco somente nos } \\
\text { alvos. }\end{array}$ & $\begin{array}{l}\text { Difícil modificação da } \\
\text { variável de estado } \\
\text { devido ao } \\
\text { desacoplamento do } \\
\text { sistema. Não considera } \\
\text { informação de cor para o } \\
\text { rastreamento. }\end{array}$ \\
\hline $\begin{array}{l}\text { Xu et al. } \\
(2005)\end{array}$ & $\begin{array}{l}\text { Baseado em } \\
\text { Regiões. 1 } \\
\text { Filtro de } \\
\text { Kalman por } \\
\text { alvo }\end{array}$ & Sim & $\begin{array}{l}\text { Excelente desempenho, } \\
\text { razoável eficácia, fácil } \\
\text { detecção do retângulo } \\
\text { envolvente dos alvos. } \\
\text { Considera características } \\
\text { como a informação de } \\
\text { cor do fundo de cena. }\end{array}$ & $\begin{array}{l}\text { Limitada restrição na } \\
\text { definição do contorno } \\
\text { dos alvos e na variação } \\
\text { do tamanho do alvo. } \\
\text { Representação muito } \\
\text { simples do alvo. }\end{array}$ \\
\hline
\end{tabular}

A proposta de De Bem (2007) garante um bom desempenho e eficácia devido ao desacoplamento do sistema utilizando dois Filtros de Kalman, e é livre de modelos em relação às características do alvo e ao contorno de sua forma. Por outro lado, é uma proposta que possui como principais desvantagens uma complexidade maior na definição das variáveis de estado, devido ao desacoplamento do sistema utilizando dois Filtros de Kalman, por não considerar informação de cor no algoritmo de rastreamento e por não ter sido aplicado na tarefa de interesse.

A proposta de Xu et al. (2005) é baseada em regiões, considerando que os alvos são detectados conforme suas características visuais e são rastreados pelas informações de região do retângulo envolvente. Possui excelente desempenho por utilizar um retângulo envolvente e considerar a informação de cor para detectar o alvo rastreado. A principal desvantagem está na limitação da representação muito simples do contorno do alvo, por um retângulo envolvente, não garantindo precisão de algumas informações do alvo, como a largura e a altura, por exemplo. O sistema é eficiente, porém não tão eficaz.

Os estudos com os trabalhos correlatos mostraram que para uma boa eficiência computacional e uma melhor eficácia nos resultados seria necessário rastrear os alvos de modo que seu contorno ficasse o mais próximo possível de sua forma real. Deste modo, escolheu-se seguir a linha da proposta de De Bem (2007), por possuir uma notável eficiência e uma eficácia comprovada em rastreamento de pessoas e objetos móveis, conforme apresentado nos resultados do trabalho de De 
Bem (2007). No rastreamento, o principal motivo da escolha está no excelente resultado alcançado pelo desacoplamento do sistema empregando dois Filtros de Kalman e também por considerar a informação de contorno do alvo. Todavia, considera-se necessário implementar uma nova proposta para o rastreamento de jogadores de futebol, que considere a informação de contorno do alvo e também inclua novos parâmetros e informações sobre outras características como, por exemplo, a cor do alvo ou da cena de fundo, visando eficácia computacional para aplicações de rastreamento de jogadores de futebol. 


\section{PROPOSTA REALIFUT}

Os estudos dos trabalhos correlatos de rastreamento de alvos, descritos no capítulo 3, apontaram duas interessantes abordagens. A contribuição e o objetivo desta pesquisa é melhorar estas técnicas, apresentando uma nova proposta para que seja utilizada no rastreamento de jogadores de futebol com mais eficácia. $O$ modelo utilizado na proposta de De Bem (2007) executa a detecção de alvos baseada em linhas de medidas, representadas por um vetor unidimensional. A utilização de variáveis mais simples como entrada para o Filtro de Kalman garante uma implementação eficaz, com bons resultados na representação da forma dos alvos, e eficiente computacionalmente, melhorando o desempenho do algoritmo. Por outro lado, a proposta de Xu et al. (2005) considera a cor de fundo da cena no algoritmo de rastreamento simplificando o processo e resultando em um excelente desempenho, mas não se preocupa muito com a forma dos alvos, aproximando-os a retângulos. A ideia da presente proposta é utilizar a base do algoritmo de De Bem (2007), que transformou um sistema não linear, desacoplando-o em dois sistemas lineares, possibilitando o emprego de dois Filtros de Kalman (um para o tratamento do movimento e o outro para a forma dos alvos) de modo eficiente e eficaz, e incluir uma contribuição no algoritmo com o objetivo de aplicar a solução no processo de rastreamento automático de jogadores de futebol com sucesso, livre de intervenções humanas, considerando algumas modificações e inovações principalmente na técnica de análise das observações dos alvos, que utiliza linhas de medidas perpendiculares a curva B-Spline para detecção do contorno de cada jogador, e também a inclusão de novas informações no processo, tais como as cores da cena de fundo, inspirada no trabalho de Xu et al. (2005).

Assim, a nova proposta será denominada REALIFUT (Rastreamento Eficaz Automático Livre de Intervenções para FUTebol) e consiste nos blocos exibidos na Figura 4.1. 


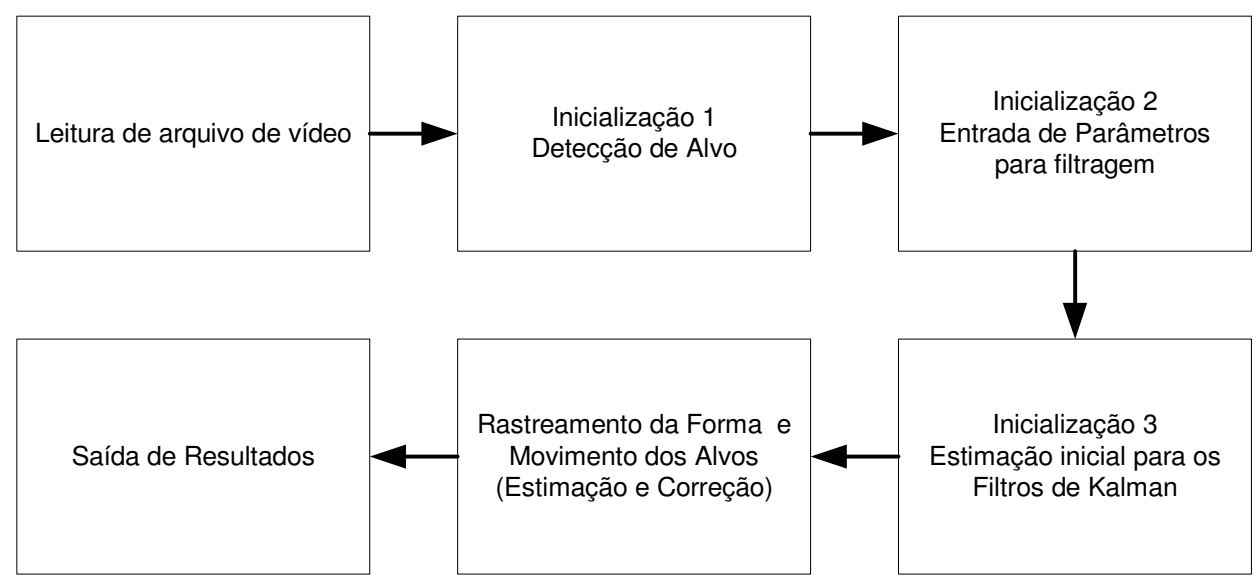

Figura 4.1 - Blocos da proposta REALIFUT

Os módulos da proposta atual da proposta REALIFUT são: leitura de arquivos de vídeo dado pelo bloco um, inicialização da detecção, dado pelo bloco dois, inicialização do rastreamento, dado pelos blocos três e quatro, rastreamento de alvos, dado no bloco cinco e resultados, dado pelo bloco seis.

\subsection{INICIALIZAÇÃO DA DETECÇÃO}

Inicialmente, no primeiro bloco, é lido o arquivo de vídeo e feita a conversão para sequência de imagens que serão analisadas e então, no segundo bloco, é executada a segmentação da imagem, que consiste na detecção dos alvos de interesse (jogadores). A Figura 4.2 ilustra um exemplo de um quadro.

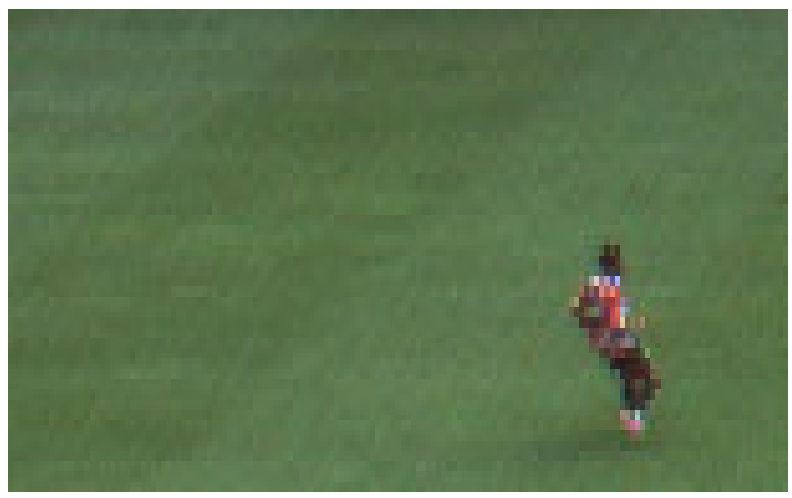

Figura 4.2 - Exemplo de um quadro com jogador em uma sequência de imagens 
Para a detecção dos jogadores, a primeira tarefa consiste em converter a imagem colorida para monocromática (banda $\mathrm{V}$ da representação da imagem no espaço HSV), visando agilizar o processamento; logo após é executada a subtração da cena de fundo, através de uma imagem de cena vazia com o campo na cor predominante "verde", sem nenhum alvo de interesse, construída manualmente antes da etapa de detecção, a partir do primeiro quadro da sequência a ser analisada. A subtração de fundo é, então, realizada subtraindo-se pixel a pixel do quadro da cena vazia dos pixels do primeiro quadro da sequência de imagens, e seu resultado é ilustrado na Figura 4.3a. Com isto, os elementos restantes são identificados como possíveis jogadores e, a seguir, um método de binarização de imagens é aplicado, utilizando um filtro linear de limiarização, resultando em uma imagem como a apresentada na Figura 4.3b.

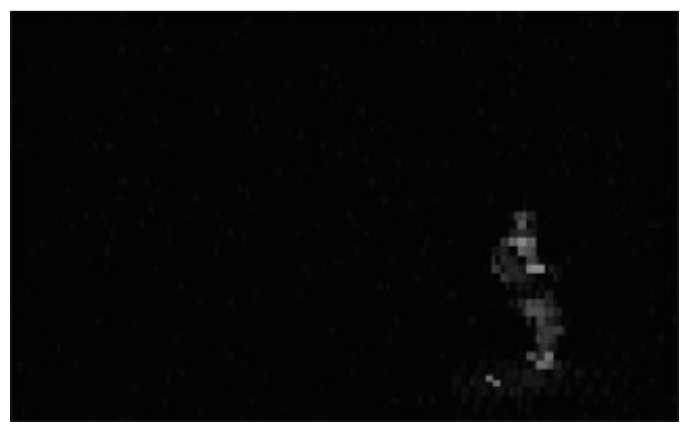

(a)

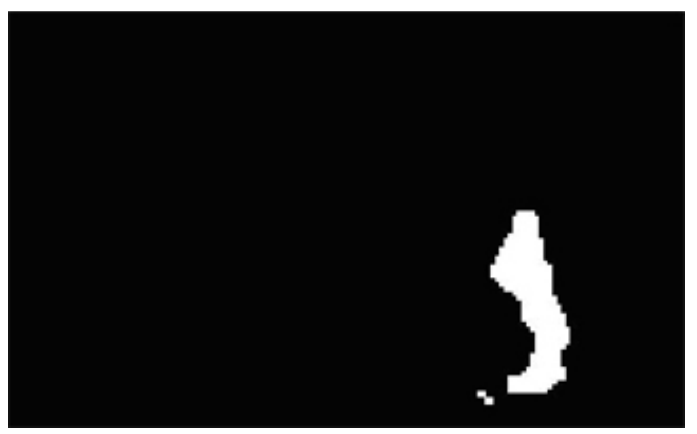

(c)

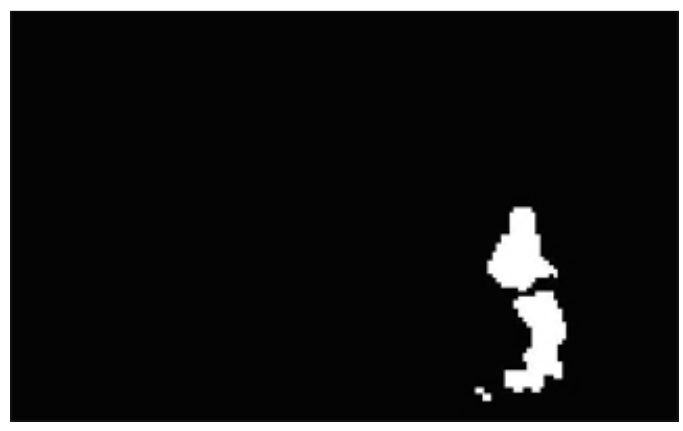

(b)

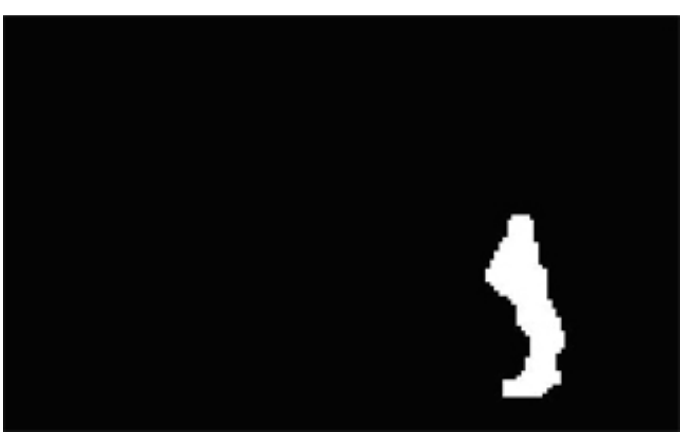

(d)

Figura 4.3 - Imagens resultantes da proposta de detecção automática de alvos após (a) subtração da cena de fundo do quadro atual, (b) binarização da imagem resultante. (c) aplicação do filtro de abertura morfológica e (d) aplicação do filtro de fechamento morfológico

Também foi introduzida a implementação de um filtro de abertura morfológica, que agrupa os componentes conexos maiores do que 20 pixels, conforme ilustrado na Figura 4.3c, seguido da aplicação de um filtro de fechamento morfológico para 
eliminar pequenas partes, como mostrado na Figura 4.3d, resultando cada alvo em um componente conexo.

Considerando a hipótese de que cada componente conexo corresponde a um alvo de interesse (jogador), é então criado um polígono convexo envolvente a este alvo com $n A$ vértices, o qual é aproximado por uma curva B-Spline fechada de grau 3 e $n C$ pontos de controle, suavizando melhor a representação do contorno de cada alvo. Sobre este contorno de B-Spline são distribuídas, uniformemente, segmentos de retas de medidas normais ao contorno, com comprimento de $c L$ pixels. $O$ resultado deste processo é superposto no quadro de imagem colorida original e ilustrado na Figura 4.4, após ter sido definido no seu correspondente quadro binário.

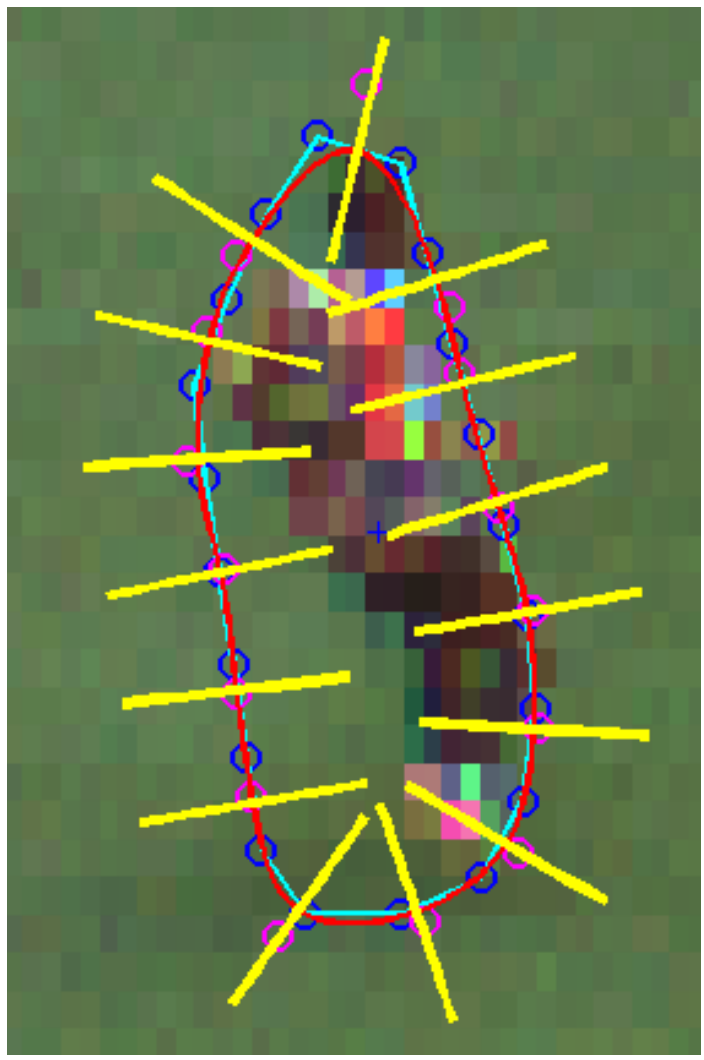

Figura 4.4 - Retas de medidas (amarelas) e representação poligonal (linha cyan), pontos de controle (rosa) e contorno com o uso de B-Splines (linha vermelha) de um jogador, representados no espaço de cor RGB da imagem

Os círculos na cor azul representam os pontos dos vértices do polígono convexo (linha na cor ciano) que aproxima o contorno do jogador detectado. Os pontos de controle da B-Spline estão na cor magenta e foram utilizados para a construção do contorno em linha na cor vermelho, representando a forma do 
jogador. As retas em amarelo são as linhas de medidas, normais ao contorno e uniformemente distribuídas pela B-Spline.

Resumo dos parâmetros utilizados para esta etapa:

- Número de pontos de controle $(n C)$ : usado na construção da B-Spline fechada envolvendo cada jogador, e na construção das linhas de medidas. No caso desta implementação, o número de linhas de medidas é igual ao número de pontos de controle;

- Número de pontos amostrados no polígono $(n A)$ : para cada jogador detectado, um polígono convexo envolvente é construído, constituído por $n A$ vértices;

- Comprimento das linhas de medida $(c L)$ : o comprimento das linhas de medidas é definido em pixels. Quanto maior o número de pixels da linha de medida, mais tempo de processamento será necessário para o rastreamento dos jogadores;

- Cor de Fundo de Cena mínima (bgmin): valor mínimo de intensidade da cor de fundo predominante na cena (gramado), na banda $V$ do espaço de representação de cores HSV;

- Cor de Fundo de Cena máxima (bgmax): valor máximo de intensidade da cor de fundo predominante na cena (gramado), na banda $V$ do espaço de representação de cores HSV;

A implementação de De Bem (2007) utiliza linhas de medidas para observar e representar a forma do contorno de alvos, no espaço monocromático de representação das imagens, e os contornos são detectados durante o processo de filtragem pela busca por pontos de variação brusca da intensidade da imagem. No caso deste trabalho, também foi adotado o uso das retas de medidas para observar o contorno dos jogadores de futebol para garantir uma maior precisão na representação da forma do alvo e no rastreamento. Contudo, na proposta REALIFUT, passou-se a utilizar a informação da intensidade de cor da cena de fundo, representada pela banda $V$ do espaço de cor HSV, mas optou-se pela 
aplicação de um filtro que avalia o que é fundo de cena e o que é jogador ao longo das linhas de medidas, procurando na linha de medida o ponto que melhor define a transição entre o jogador e o fundo de cena.

A busca pela borda da transição do jogador com a cena de fundo, nas retas de medida, se dá percorrendo cada reta de modo radial (partindo do centro de área do contorno), comparando cada ponto com a faixa de valor estipulada para o fundo, e marcando cada ponto como pertencente ao jogador ou ao fundo. Se todos os pontos da reta de medida forem considerados como jogador, marca-se como borda o ponto mais distante do centro do contorno fechado. Por outro lado, marca-se o ponto mais próximo do centro de área do contorno do jogador como borda no caso de somente encontrar informação de fundo de cena ao longo da linha de medida.

Entretanto, este processo pode cometer equívoco quando há proximidade de alvos na imagem. As Figuras 4.5a e 4.5b mostram um erro causado pela detecção de dois jogadores como um único alvo. Este é um típico problema de oclusão de alvos, que poderia ser resolvido aplicando-se técnicas de estereoscopia, como apresentando no trabalho desenvolvido por Borg (2007), mas que foge ao escopo do presente trabalho.

Ao término da execução deste segundo bloco, tem-se a detecção de cada alvo no quadro atual, juntamente com seu correspondente contorno B-Spline e suas retas de medida distribuídas sobre ele.

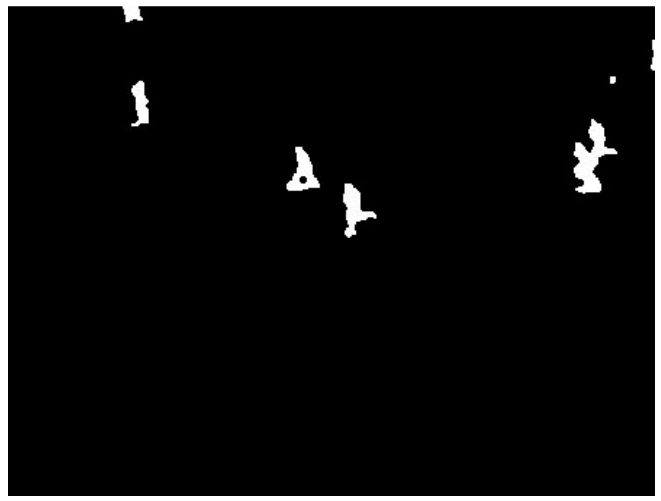

(a)

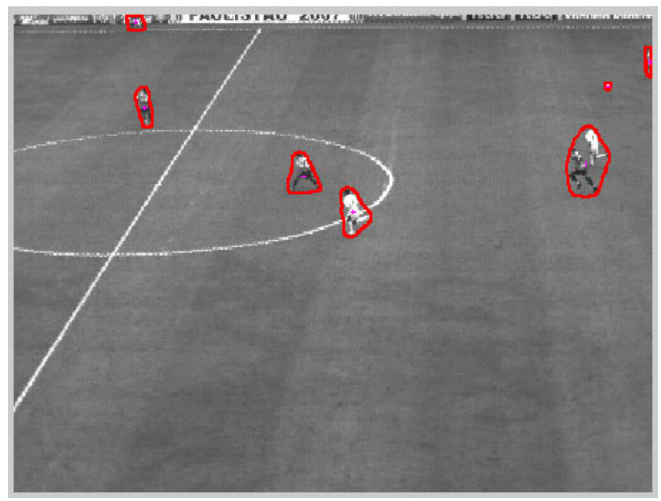

(b)

Figura 4.5 - Imagens resultantes do algoritmo de detecção automática de alvos, com erro de oclusão de alvos, causando a detecção de dois jogadores como um único alvo (lado direito da imagem). (a) Erro mostrado na imagem binária e (b) na imagem na banda V (HSV), circundados pelo contorno B-Spline envolvente resultante da detecção 


\subsection{RASTREAMENTO}

No terceiro bloco são inicializados, por um operador humano, os parâmetros utilizados pelo algoritmo de filtragem, tais como:

- Desvio padrão sobre a linha de medida $(\sigma)$ : indica a incerteza que cada ponto de controle da B-Spline (contorno do jogador) possui em relação a sua posição na imagem;

- Covariância inicial da forma $\left(P x_{0}\right)$ : representa a estimação inicial identificada para o modelo de forma, guiado pelo o conhecimento da crença que se tem em relação à variação do contorno do jogador quadro a quadro;

- Covariância da estimação da forma $\left(Q_{X}\right)$ : de acordo com a equação 4.5, este parâmetro representa o conhecimento que se tem em relação aos contornos do jogador, resultando no peso ou no grau de crença que se tem sobre estas informações. Por exemplo, se o contorno do jogador não sofre muitas alterações de um quadro para o outro, então os valores de covariância de estimação da forma devem ser mais baixos do que os valores de covariância da observação da forma;

- Covariância da observação da forma $\left(R_{X}\right)$ : de acordo com a equação 4.9, este parâmetro representa o ruído do modelo da forma, que é o conhecimento que se tem em relação ao ruído no processo de observação dos contornos dos jogadores;

- Covariância inicial do movimento $\left(P v x_{0}, P v y_{0}, P s_{0}\right)$ : representam a crença a respeito da estimação inicial do modelo de movimento, resultando no conhecimento que se tem em relação à movimentação do jogador no campo de futebol;

- Covariância da estimação do movimento, $\vec{Q}=\left(Q_{v x} Q_{v y} Q_{s}\right)^{T}$ : de acordo com a Equação 4.5, representam o conhecimento que se tem em relação à crença da 
movimentação do jogador no campo de futebol, definido com seu peso ou seu grau de crença que se tem sobre estas informações. Por exemplo, se as velocidades e fatores de escalas são quase constantes de um quadro para o outro, então podem adotar-se valores de covariâncias pequenos;

- Covariância da observação do movimento $\left(R_{m}\right)$ : de acordo com a Equação 4.6, representa o ruído identificado para o modelo do movimento, que é o conhecimento que se tem em relação ao ruído na dinâmica do processo em relação às velocidades do centróide e da mudança do fator de escala do contorno dos jogadores.

Com os parâmetros dos Filtros de Kalman inicializados (terceiro bloco da Figura 4.1) e com os contornos dos jogadores e suas respectivas linhas de medidas, definem-se os estados dos filtros para estimação de cada jogador.

O vetor de estado completo da proposta REALIFUT, assim como na proposta de De Bem (2007), é descrito pelos parâmetros que descrevem a forma do contorno e seu movimento na sequência de imagens:

$$
\left(\begin{array}{c}
\vec{X}_{k} \\
\vec{M}_{k}
\end{array}\right)=\left(\chi_{0, k}, \ldots, \chi_{i, k}, \ldots, \chi_{n C-1, k}, v_{x, k}, v_{y, k}, s_{k}\right)^{T}
$$

em que $\vec{X}_{k}$ representa todos os $n C$ pontos de controle da B-Spline do contorno envolvendo o jogador, dado por:

$$
\vec{X}_{k=0}=\left(\chi_{0, k}, \ldots, \chi_{i, k}, \ldots, \chi_{n C-1, k}\right)^{T}
$$

em que cada ponto de controle $\chi_{i, k}$ é dado por suas coordenadas x e y,

$$
\chi_{i, k}=\left(x_{i, k}, y_{i, k}\right)^{T}
$$


e $\vec{M}_{k}$ define os parâmetros que descrevem o movimento do alvo, dado pela velocidade de translação do centróide do contorno do jogador, na horizontal, $\mathrm{v}_{\mathrm{x}, \mathrm{k}}, \mathrm{e}$ na vertical, $v_{y, k}$, e o fator de escala, $s_{k}$ :

$$
\vec{M}_{k}=\left(\mathbf{v}_{k}, s_{k}\right)=\left(v_{x, k}, v_{y, k}, s_{k}\right)^{T}
$$

Ainda, no quarto bloco da Figura 4.1, é criada uma estrutura de dados identificando o jogador, contendo as seguintes informações: centróide do contorno feito pela B-Spline, pontos de controle da B-Spline, todos os parâmetros relacionados aos Filtros de Kalman descritos acima, como covariâncias e vetores de estado.

No quinto bloco é executado o algoritmo de rastreamento baseado em dois Filtros de Kalman, um para a estimação da forma e outro para a estimação do movimento, considerando também a informação de intensidade de cor da cena de fundo nos modelos de observação de cada filtro. Nesta etapa também é calculado o centróide de cada jogador em cada novo quadro da sequência de imagens, salvando todas as informações em um vetor principal (centróides e pontos de controle). O uso de dois Filtros de Kalman é feito do mesmo modo proposto por De Bem (2007), com o desacoplamento do filtro de estimação da forma e do filtro de estimação do movimento do contorno, quadro a quadro.

Para a estimação do movimento, as equações do Filtro de Kalman que representam o sistema dinâmico linear do movimento de cada jogador são descritas por:

$$
\begin{gathered}
\vec{M}_{k}=\vec{M}_{k-1}+\vec{Q} \text { e } \\
\vec{Z}_{k}=H_{k} \vec{M}_{k}+R m,
\end{gathered}
$$

em que, $\vec{M}_{k}$ é o vetor de estado do movimento e é calculado por meio do próprio vetor de estado anterior acrescido do ruído no processo, desconsiderando uma nova entrada de controle no sistema e $\vec{Z}_{k}$ é calculado com a multiplicação da matriz de 
observação $H_{k}$ pelo vetor de estado de movimento, acrescido do ruído de observação $R m$, representando a predição da observação.

A matriz de observação $H_{k}$ é descrita por:

$$
H_{k}=\left(\begin{array}{cc}
I_{2} & \left(\chi_{1, k-1}-c_{k-1}\right) \\
\vdots & \vdots \\
I_{2} & \left(\chi_{i, k-1}-c_{k-1}\right) \\
\vdots & \vdots \\
I_{2} & \left(\chi_{n C, k-1}-c_{k-1}\right)
\end{array}\right)
$$

e representa o deslocamento observado do alvo, com o valor da diferença entre os pontos de controle e o centro de área do jogador no quadro anterior.

Para a estimação da forma, as equações do Filtro de Kalman que representam o sistema dinâmico linear da forma de cada jogador são:

$$
\begin{gathered}
\vec{X}_{k}=A_{k-1} \vec{X}_{k-1}+B_{k-1} \vec{u}_{k-1}+\vec{Q} x, \\
\vec{Z} x_{k}=\vec{X}_{k}+R x,
\end{gathered}
$$

em que, $\vec{X}_{k}$ é o vetor de estado da forma e é calculado pela soma do próprio vetor de estado anterior multiplicado pela matriz de transição $A_{k-1}$, com a multiplicação da matriz de projeção $B_{k-1}$ pelo vetor de entrada $\vec{u}_{k-1}$ e com o ruído no processo $\vec{Q} x$.

O cálculo do vetor de observação $\vec{Z} x_{k}$ é feito pela soma do vetor de estado com os contornos do alvo e o ruído de observação $R x$ e representa a predição da observação da posição dos pontos do contorno.

A matriz de transição de estado $A_{k-1}$, a matriz de projeção $B_{k-1}$ e o vetor de entrada $\vec{u}_{k-1}$ são dados por:

$$
A_{k-1}=\left(\begin{array}{ccc}
\left(1+s_{k-1}-s_{k-1} / n C\right) & 0 & 0 \\
0 & \ddots & 0 \\
0 & 0 & \left(1+s_{k-1}-s_{k-1} / n C\right)
\end{array}\right),
$$




$$
\begin{gathered}
B_{k-1}=\left(\begin{array}{c}
I_{2} \\
\vdots \\
I_{2}
\end{array}\right) \mathrm{e} \\
\vec{u}_{k-1}=\left(\begin{array}{c}
v_{x, k-1} \\
v_{y, k-1}
\end{array}\right)
\end{gathered}
$$

O Algoritmo 4.1 representa os passos de rastreamento para um sistema desacoplado (movimento e forma) com o uso de dois Filtros de Kalman, um responsável pela estimação do movimento e outro pela estimação da forma de cada jogador.

Algoritmo 4.1 - Processamento com os Filtros de Kalman

Entradas: Nquadros, $P_{0}, \vec{Q}, A, \vec{M}_{0}, H_{1}, R m, B_{0}, \vec{Q} x, R x, H x_{1}, P x_{1}$

Saídas: OUTimgs , $X_{k}$ e $C_{k}$

Inicializa OUTimgs

Para $\mathrm{k}=1$ até Nquadros, fazer: // Nquadros = quantidade de imagens

(Nota: Filtro de Kalman para a estimação do movimento de 1 a 6 )

1: $P_{k}=\left(A P_{k-1} A^{T}\right)+\vec{Q}$ //calcula a covariância da estimação;

2: $\vec{M}_{k}=\vec{M}_{k-1}+\vec{Q}$ //calcula o próximo estado do movimento (Equação 4.5);

3: $K_{k}=P_{k} H_{k}{ }^{T}\left(\left(H_{k} P_{k} H_{k}{ }^{T}\right)+R_{m}\right)^{-1 / / c a l c u l a ~ o ~ g a n h o ~ d e ~ K a l m a n ; ~}$

4: Efetua observação $\vec{Z}_{k}$ //calcula a observação do movimento (novas velocidades e escala), de acordo com os valores observados dos novos pontos de controles na imagem atual;

5: $\vec{M}_{k}=\vec{M}_{k}+K_{k}\left(\vec{Z}_{k}-\left(H_{k} \vec{M}_{k}\right)\right) \quad$ //atualiza a estimação com as observações;

6: $P_{k}=\left(I-\left(K_{k} H_{k}\right)\right) P_{k} \quad$ //atualiza a covariância;

(Nota: Filtro de Kalman para a estimação da Forma de 7 a 16)

7: $P x_{k}=\left(A P x_{k-1} A^{T}\right)+Q x$ //calcula a covariância da estimação; 
8: $\vec{u}_{k-1}=\left(\begin{array}{ll}\vec{M}(1)_{k-1} & \vec{M}(2)_{k-1}\end{array}\right) / /$ valores de velocidades de $\vec{M}_{k-1}=\left(\begin{array}{l}v_{x, k-1} \\ v_{y, k-1} \\ s_{k}\end{array}\right)$;

9: $A x_{k-1}=\vec{M}(3)_{k-1} / /$ valor da escada de $\vec{M}_{k-1}=\left(\begin{array}{l}v_{x, k-1} \\ v_{y, k-1} \\ s_{k}\end{array}\right)$;

10: $\vec{X}_{k}=A x_{k-1} \vec{X}_{k-1}+B_{k-1} \vec{u}_{k-1}+\vec{Q} x$ //calcula o próximo estado;

11: $K x_{k}=P x_{k} H x_{k}^{T}\left(\left(H x_{k} P x_{k} H x_{k}{ }^{T}\right)+R x\right)^{-1 / / c a l c u l a ~ o ~ g a n h o ~ d e ~ K a l m a n ; ~}$

12: Efetua observação $\vec{Z} x_{k}$ //calcula a observação de forma (pontos de borda dos jogadores), de acordo com os pontos de controle e análise das linhas de medida, na imagem atual (mesma imagem usada no passo 4);

13: $X_{k}=X_{k}+K_{k}\left(\vec{Z} x_{k}-\left(H x_{k} X_{k}\right)\right)$ //atualiza a estimação da forma com as observações;

14: $P x_{k}=\left(I x-\left(K x_{k} H x_{k}\right)\right) P x_{k}$ //atualiza a covariância;

15: $C_{k}=\left(X(1)_{k} / n C \quad X(2)_{k} / n C\right)^{\prime}$ //salva os resultados dos centróides;

16: Atualiza OUTimgs //marca os resultados de $X_{k}$ e $C_{k}$ nas imagens de saída.

O sexto e último bloco da Figura 4.1 representa a parte final do algoritmo que armazena os resultados para análises e para posterior visualização de toda a cena com o alvo sendo rastreado.

A Figura 4.6 mostra o funcionamento dos dois Filtros de Kalman operando de forma intercalada no sistema desacoplado apresentado pela proposta REALIFUT. Os blocos e linhas verdes representam o Filtro de Kalman que estima o movimento (velocidades em $\mathrm{X}$ e $\mathrm{Y}$ e fator de escala), com base no movimento anterior, realizando as observações pela forma atual (seta na cor ciano). Após a estimação do movimento inicia-se a estimação da forma (pontos de controle da B-Spline), representados pelos blocos e linhas amarelas, baseado na forma anterior, realizando observações pela forma atual (seta na cor ciano), e assim recursivamente. 


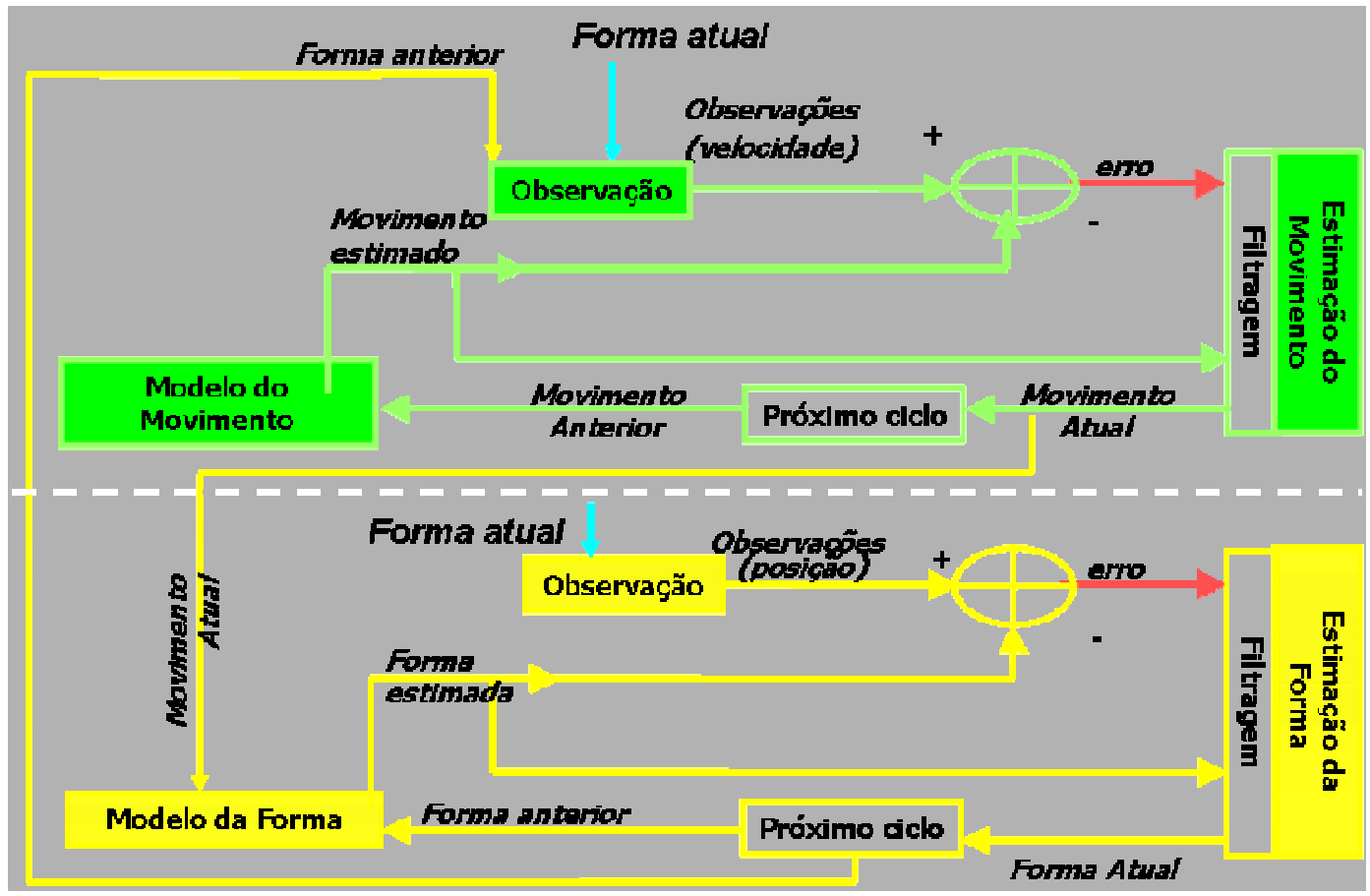

Figura 4.6 - Funcionamento dos dois Filtros de Kalman intercalados na proposta REALIFUT 


\section{EXPERIMENTOS}

Foram executados testes de rastreamento de jogadores de futebol, aplicados a sequências de imagens de partidas, capturadas em jogos reais. Para efeito de análise e comparação, tanto a proposta inspirada em Xu et al. (2005) quanto a nova proposta baseada em De Bem (2007), denominada REALIFUT, foram implementadas e submetidas aos mesmos testes com as imagens selecionadas.

\subsection{RECURSOS UTILIZADOS}

Para a realização destes testes utilizou-se equipamentos de gravação de imagens com câmeras e lentes especiais, amplamente utilizadas em sistemas de visão. Além destes, também foram necessários computadores e softwares para realizar o processamento dos algoritmos.

\subsubsection{EQUIPAMENTOS (CÂMERAS E COMPUTADORES)}

Cada estádio de futebol possui uma característica física particular, devido à sua construção, tanto do campo quanto da infra-estrutura nas arquibancadas. Dependendo da distância do local onde as câmeras serão instaladas, há a necessidade de utilizar tipos de câmeras e lentes específicas para garantir um bom enquadramento da imagem. Foram utilizados modelos de câmeras para a captura de imagens deste trabalho com resolução de 640×480 pixels e taxa de amostragem entre 30 e 210 quadros por segundo.

Devido à particularidade de construção de cada estádio, sugere-se a utilização de lentes varifocal, permitindo realizar ajustes manuais da variação focal 
da lente, garantindo um melhor enquadramento da área de visão da câmera. Este recurso é necessário para garantir uma boa qualidade e resolução da imagem, principalmente em sistemas que utilizam uma divisão do campo em regiões ou quadrantes. Tal fato influencia diretamente o tipo de lente que deve ser utilizada. Nas imagens capturadas para este trabalho, foram utilizadas lentes com especificações de $8 \mathrm{~mm}, 12.5 \mathrm{~mm}, 16 \mathrm{~mm}$ e $25 \mathrm{~mm}$, conseguindo garantir um bom enquadramento dos jogadores, resultando em dimensões que, no pior dos casos, representam 800 pixels de imagem para cada jogador, e na maioria ficam entre 3300 pixels e 4550 pixels aproximadamente; ou com uma altura e largura no pior dos casos de 20 x 40 pixels, e em grande parte os jogadores rastreados possuem uma dimensão aproximada entre $30 \times 110$ pixels e $35 \times 130$ pixels.

Para o processamento das imagens e execução dos testes foram utilizados computadores com as seguintes especificações:

- CPU1: Pentium Core 2 Duo, 1.73 GHz (T5300), 2Gbytes de memória RAM e sistema operacional Windows Vista com Service Pack 2;

- CPU2: Pentium Dual Core, 2.0 GHz, 2Gbytes de memória RAM e sistema operacional Windows XP com Service Pack 3;

- CPU3: Pentium Xeon Dual, 1.5 GHz, 3Gbytes de memória RAM e sistema operacional Windows 2003 Server com Service Pack 1.

A implementação dos algoritmos foi feita utilizando o programa Matlab, versão 7.1. Foram empregadas ferramentas de processamento de imagens, conhecidas como Toolbox, do Matlab. Dentre estas ferramentas a principal foi o Image Processing Toolbox.

\subsubsection{IMAGENS SELECIONADAS}

Analisando as imagens gravadas nas partidas reais de futebol, selecionaramse três cenas específicas e foram aplicadas nos testes dos algoritmos descritos e nos da proposta deste estudo. 
A primeira cena escolhida objetiva avaliar o rastreamento com um único alvo e um deslocamento na horizontal, quase que verticalmente linear, permitindo uma boa interpretação visual do resultado, em uma cena simples. Já a segunda cena permite avaliar o processo de rastreamento em um deslocamento tanto horizontal quanto vertical. E na terceira cena, avaliaram-se alguns problemas quando ocorre a oclusão entre os alvos - fato comum em partidas de futebol.

\subsection{IMPLEMENTAÇÃO INSPIRADA EM XU ET AL. (2005)}

A proposta de Xu et al. (2005) também está dividida em duas etapas principais. Na primeira etapa é realizada a detecção dos alvos nas imagens, resultando no número total de alvos detectados e no retângulo envolvente do alvo.

$\mathrm{Na}$ segunda etapa é executado o rastreamento dos alvos com um Filtro de Kalman, utilizando uma representação baseada na região do retângulo envolvente do alvo como variável de estado e de observação.

A seguir serão apresentados os experimentos relacionados ao rastreamento de jogadores em uma implementação inspirada no trabalho de Xu et al. (2005). Na elaboração dos testes de rastreamento foi possível avaliar o desempenho do algoritmo inspirado na proposta de Xu et al. (2005), nas 3 cenas selecionadas.

Os resultados foram eficientes computacionalmente, porém não muito eficazes. Como a proposta de Xu et al. (2005) utiliza um retângulo envolvente para definir a forma do alvo, algumas informações relevantes para o rastreamento ficam prejudicadas como, por exemplo, a posição e contorno do jogador.

\subsubsection{CENA 1}

O objetivo do teste é avaliar o deslocamento de um jogador em uma trajetória horizontal, considerando pouca oscilação na vertical, na sequência de imagens. 
Na Tabela 5.1 são relacionados os parâmetros utilizados para o algoritmo de rastreamento.

Tabela 5.1 - Parâmetros utilizados na configuração do sistema de rastreamento no teste da
\begin{tabular}{lc} 
cena 1 & \multicolumn{1}{c}{ Parâmetros do Rastreamento } \\
Parâmetro & Valor \\
\hline Tamanho do retângulo do jogador & $\mathrm{w}=20, \mathrm{~h}=40$ \\
\hline Tamanho do retângulo do uniforme & $\mathrm{w}=6, \mathrm{~h}=14$ \\
\hline Limiar que separa o alvo do fundo de cena & Threshold $=40$ \\
\hline Tamanho adicional da janela de busca & 10 \\
\hline Covariância inicial da estimação & $P_{0}=2$ \\
\hline Covariância do movimento & $Q=2$ \\
\hline Covariância da observação & $R=[4,0 ; 0,4)$ \\
\hline
\end{tabular}

O resultado do teste da cena 1 é apresentado na Figura 5.1. Nota-se, nos quadros da Figura 5.1, que há uma pequena oscilação vertical na posição estimada do alvo devido ao comportamento do rastreamento baseado em retângulo envolvente não considerar todo o contorno da forma do alvo.

Como a cada nova interação do algoritmo ocorre um processo de detecção do jogador, este tipo de implementação, baseado em retângulo envolvente, apresenta uma curva não muito suave da trajetória do rastreamento e não garante boa precisão na forma do jogador. Mesmo assim o algoritmo apresenta resultados razoáveis.

Observando o Gráfico 5.1, nota-se que esta pequena oscilação ao longo da trajetória na posição vertical do alvo em relação à imagem é de aproximadamente 10 pixels.

Conclui-se que a técnica com o emprego de retângulo envolvente apresenta resultados razoáveis com relação à estimação da posição do jogador. 
(a) Quadro 1

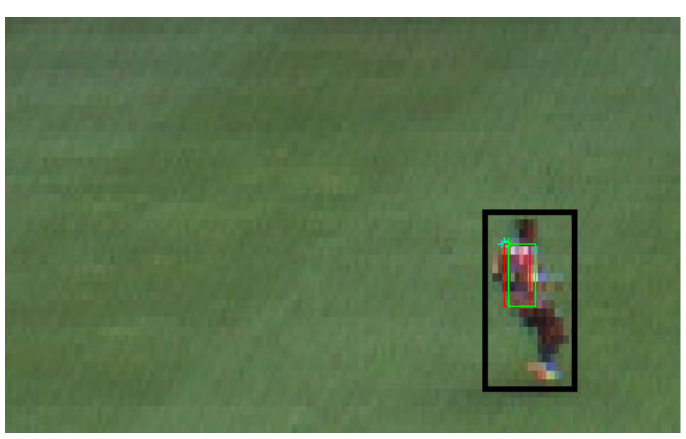

(c) Quadro 40

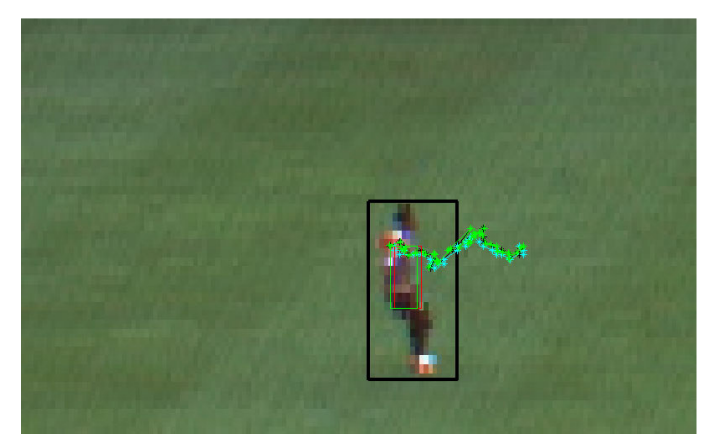

(e) Quadro 80
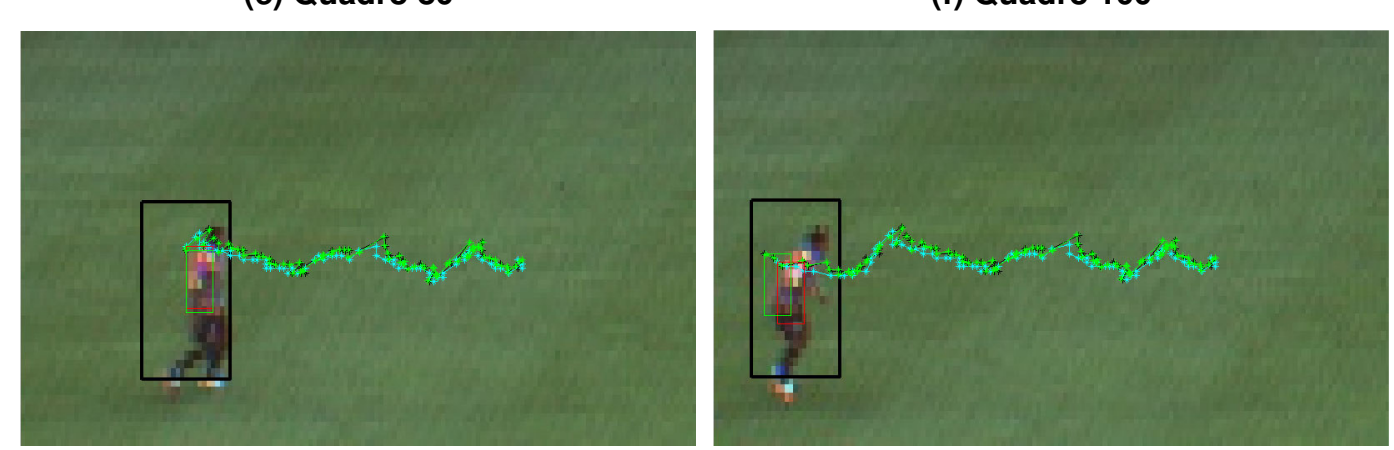

Figura 5.1 - Resultados do teste da cena 1. Sequências de imagens com 100 quadros (b) Quadro 20

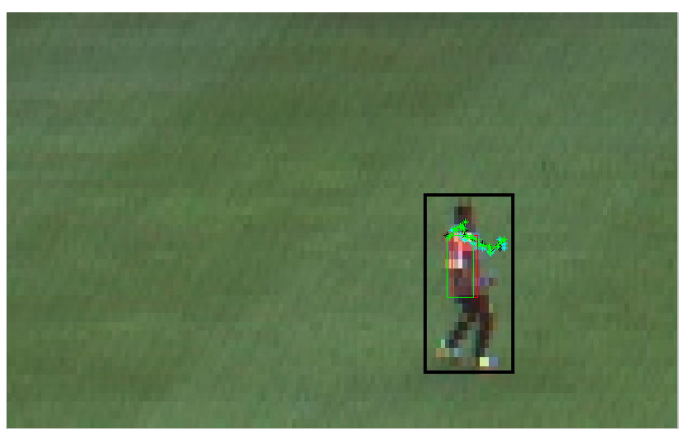

(d) Quadro 60

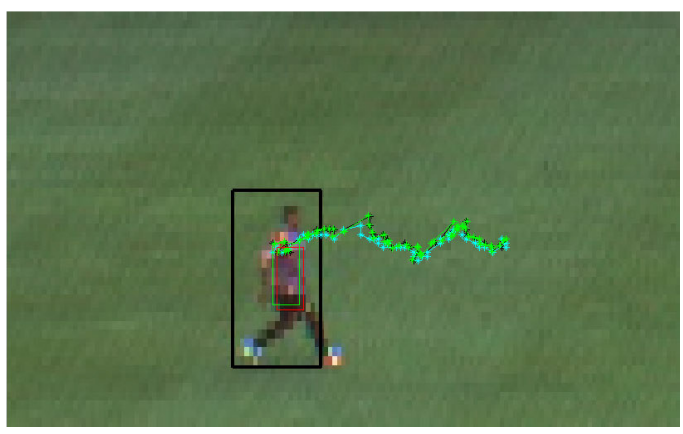

(f) Quadro 100 


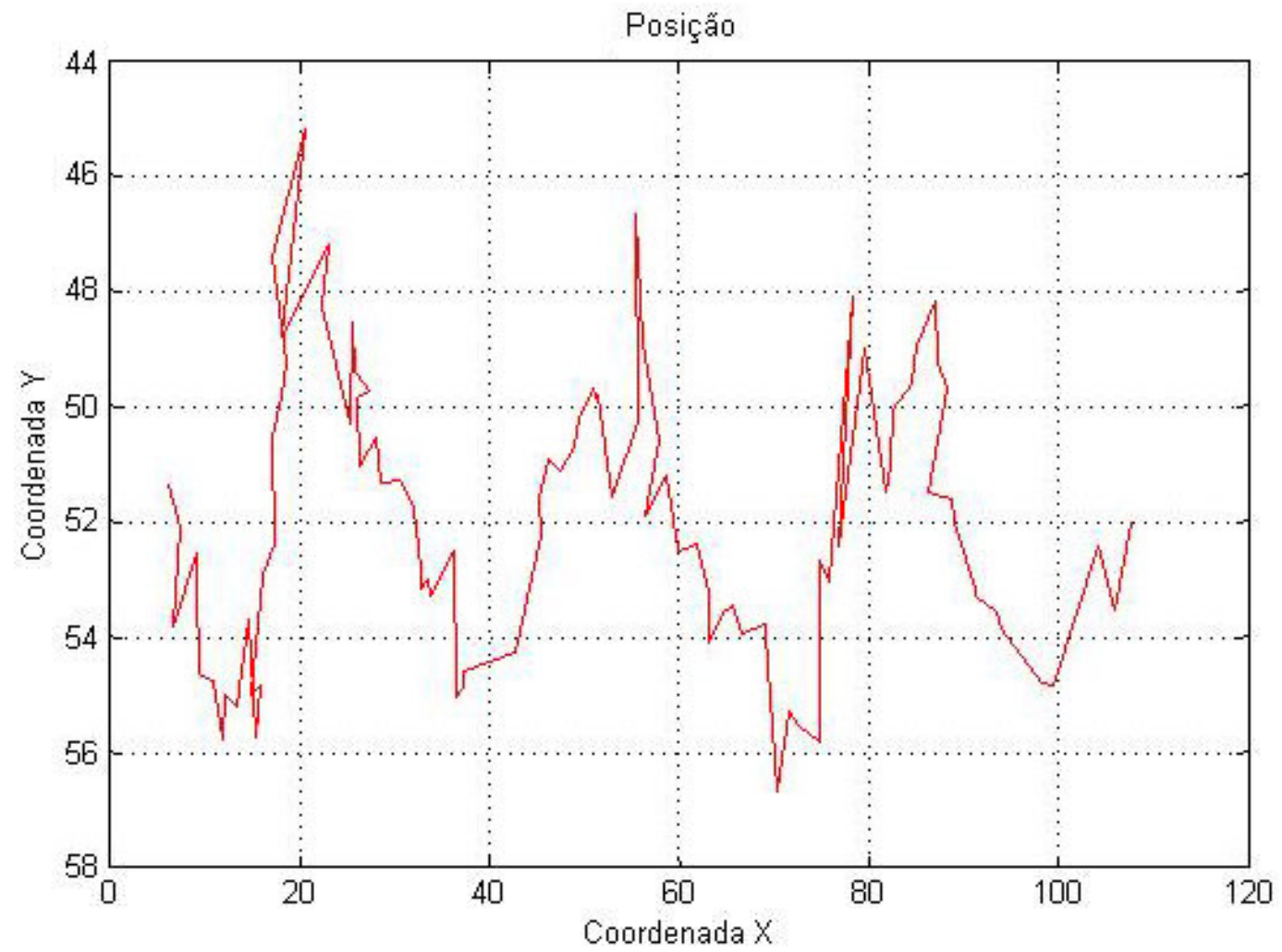

Gráfico 5.1 - Resultado do teste da cena 1. Trajetória estimada do centro de área do alvo em posições com coordenadas $\mathrm{X}$ e $\mathrm{Y}$ determinadas em pixels

\subsubsection{CENA 2}

Já no teste da cena 2, observando os resultados na Figura 5.2, obteve-se uma trajetória linear acompanhando, de fato, todo o percurso do jogador. Os parâmetros utilizados neste teste estão descritos na Tabela 5.2. 
(a) Quadro 1

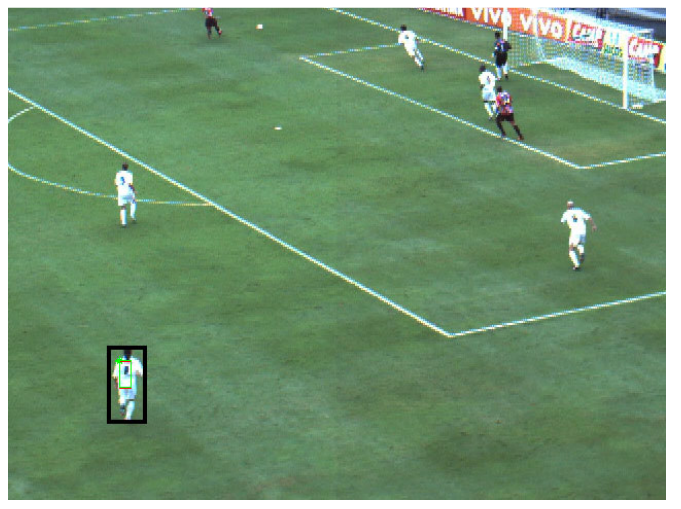

(c) Quadro 64

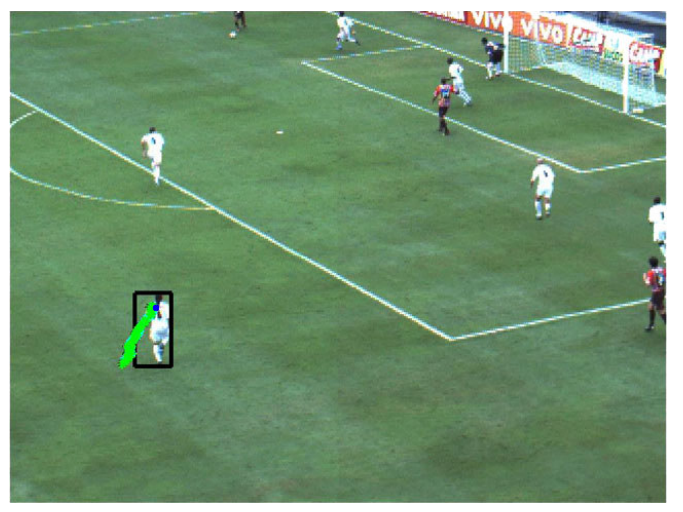

(e) Quadro 128

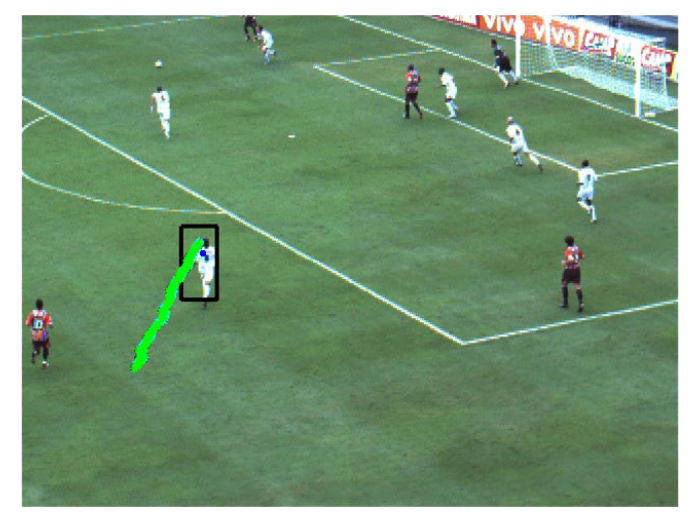

Figura 5.2 - Resultados do teste da cena 2. Sequências de imagens com 100 quadros (b) Quadro 32

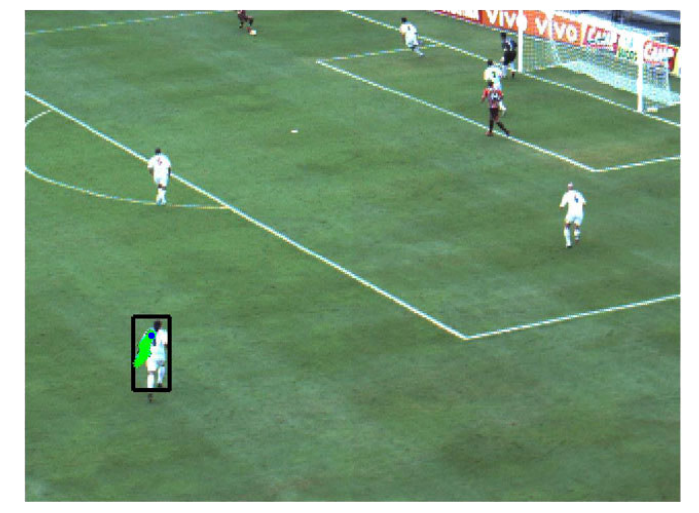

(d) Quadro 96

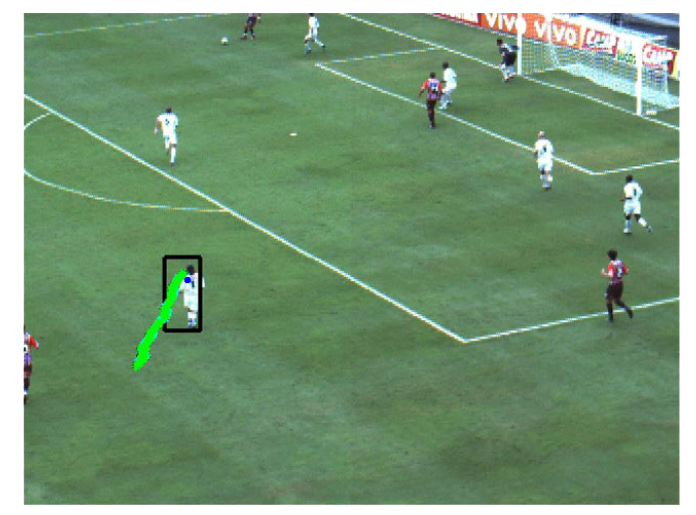

(f) Quadro 160

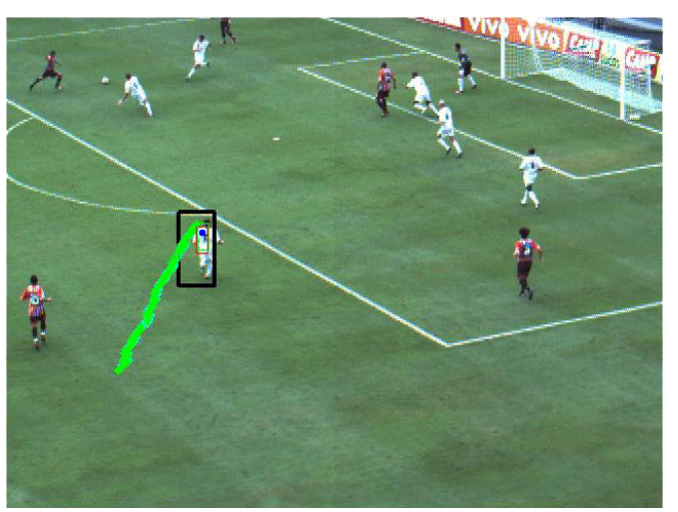


Tabela 5.2 - Parâmetros utilizados na configuração do sistema de rastreamento no teste da cena 2

\begin{tabular}{lc}
\multicolumn{1}{c}{ Parâmetros do Rastreamento } \\
\multicolumn{1}{c}{ Parâmetro } & Valor \\
\hline Tamanho do retângulo do jogador & $\mathrm{w}=35, \mathrm{~h}=72$ \\
\hline Tamanho do retângulo do uniforme & $\mathrm{w}=6, \mathrm{~h}=14$ \\
\hline Limiar que separa o alvo do fundo de cena & Threshold $=40$ \\
\hline Tamanho da janela de busca & 10 \\
\hline Covariância inicial da estimação & $P_{0}=4^{*}[\mathrm{I}]$ \\
\hline Covariância da estimação & $Q=4^{*}[\mathrm{I}]$ \\
\hline Covariância da observação & $R=[25,0 ; 0,25)$ \\
\hline
\end{tabular}

O Gráfico 5.2 mostra toda a trajetória percorrida pelo jogador, permitindo avaliar que a linha da trajetória se aproxima muito da linha de fato percorrida pelo jogador, comparando-se com a Figura 5.10.

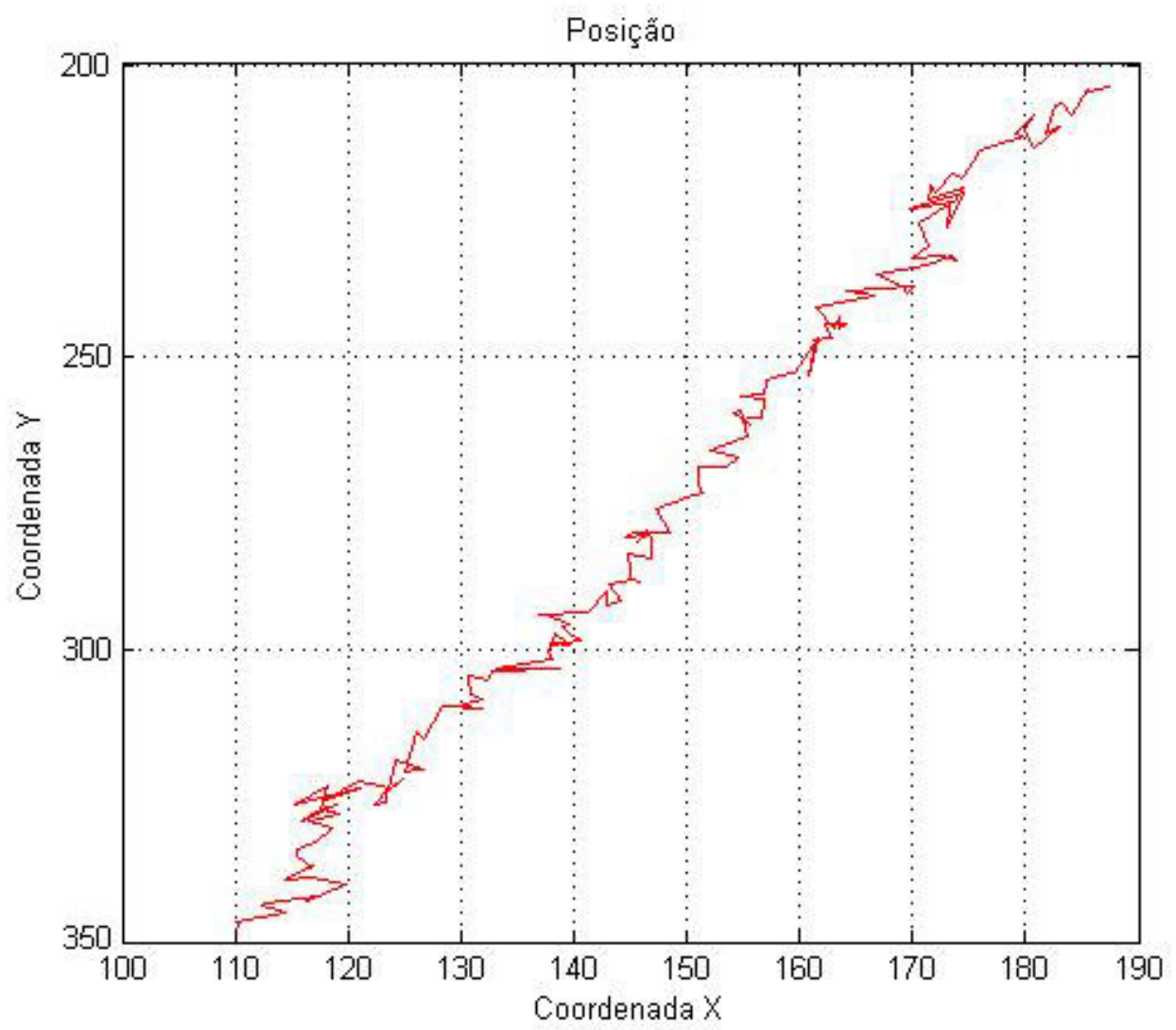

Gráfico 5.2 - Resultado do teste da cena 2. Trajetória estimada do centro de área do alvo em posições com coordenadas $\mathrm{X}$ e $\mathrm{Y}$ determinadas em pixels 
O teste mostra que o algoritmo apresenta uma razoável eficácia com relação à representação da forma do jogador durante o rastreamento pelo retângulo envolvente.

\subsubsection{CENA 3}

No teste da cena três, a implementação inspirada em Xu et al. (2005) apresentou um bom comportamento, principalmente em relação ao tratamento de oclusão parcial, pois entre o quadro 65 e quadro 80 ocorre o problema de oclusão e o jogador continua sendo rastreado pelo algoritmo. A trajetória resultante do rastreamento possui uma curva com boa aproximação da trajetória de referência visual do jogador, observados nos quadros da Figura 5.3 e o Gráfico 5.3. Os parâmetros são apresentados na Tabela 5.3.

Tabela 5.3 - Parâmetros utilizados na configuração do sistema de rastreamento no teste da cena 3

\begin{tabular}{lc}
\hline \multicolumn{1}{c}{ Parâmetros do Rastreamento } \\
\multicolumn{1}{c}{ Palto } & Valor \\
\hline Tamanho do retângulo do jogador & $\mathrm{w}=25, \mathrm{~h}=40$ \\
\hline Tamanho do retângulo do uniforme & $\mathrm{w}=11$ \\
\hline Limiar que separa o alvo do fundo de cena & Threshold $=40$ \\
\hline Tamanho adicional da janela de busca & 10 \\
\hline Covariância inicial da estimação & $P_{0}=4^{*}[\mathrm{I}]$ \\
\hline Covariância da estimação & $Q=4{ }^{*}[\mathrm{I}]$ \\
\hline Covariância da observação & $R=\left[5^{\wedge} 2,0 ; 0,5^{\wedge} 2\right)$ \\
\hline
\end{tabular}


(a) Quadro 1

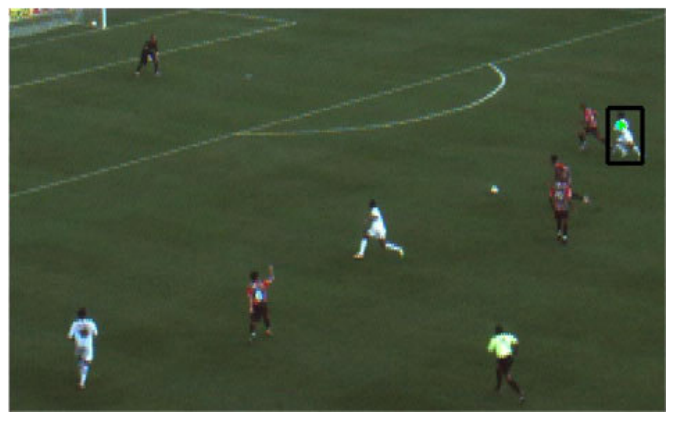

(c) Quadro 40

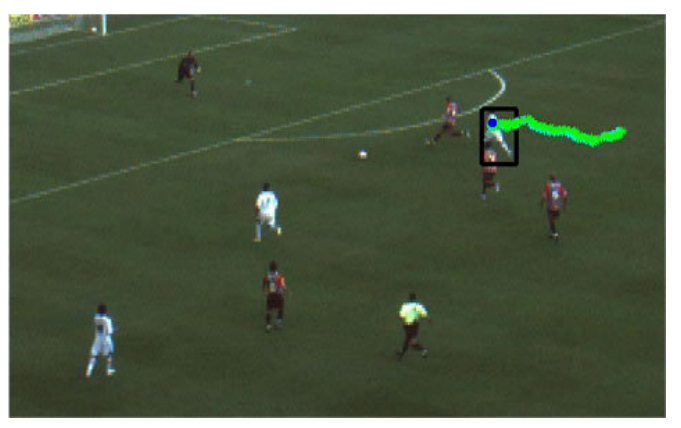

(e) Quadro 80

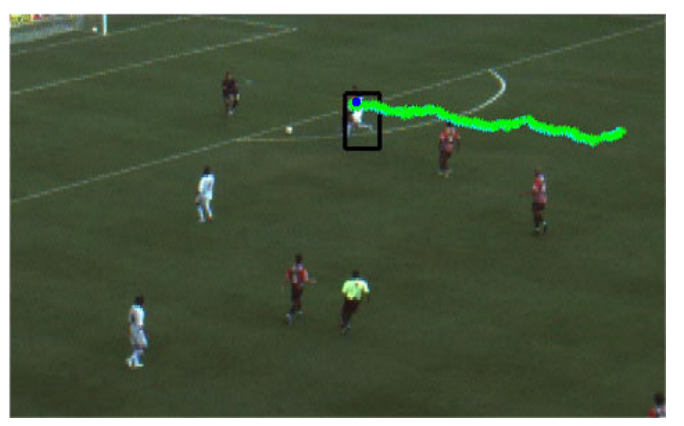

Figura 5.3 - Resultados do teste da cena 3. Sequências de imagens com 99 quadros (b) Quadro 20

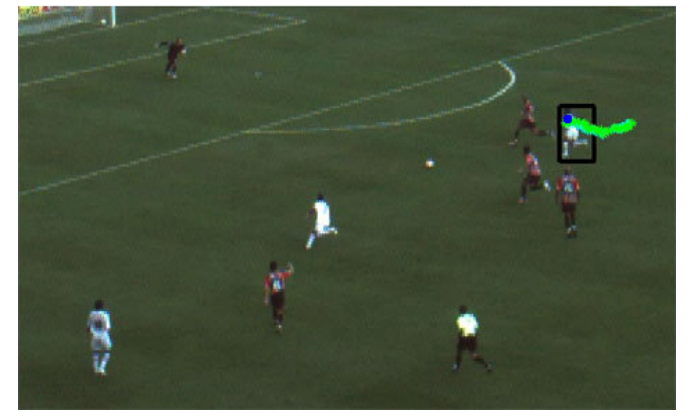

(d) Quadro 60

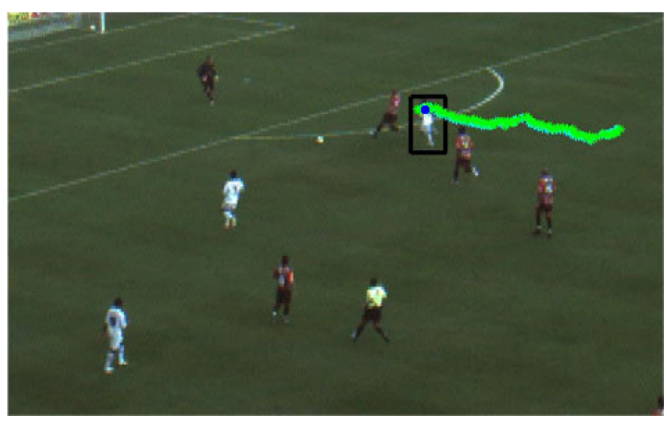

(f) Quadro 99

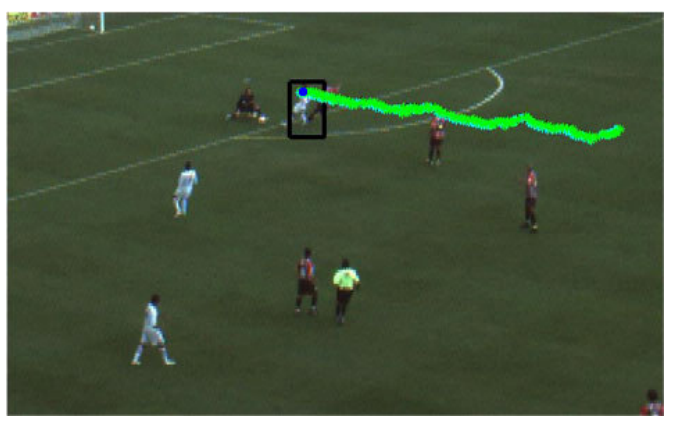

Como o contorno da forma do jogador não é bem representado pelo retângulo envolvente, para obter uma melhor precisão no rastreamento recomenda-se a implementação de algoritmos que tratam a forma do jogador de modo mais eficaz, 
ao invés de um simples retângulo envolvente, permitindo extrair informações mais precisas do rastreamento, como por exemplo a forma do contorno do alvo.

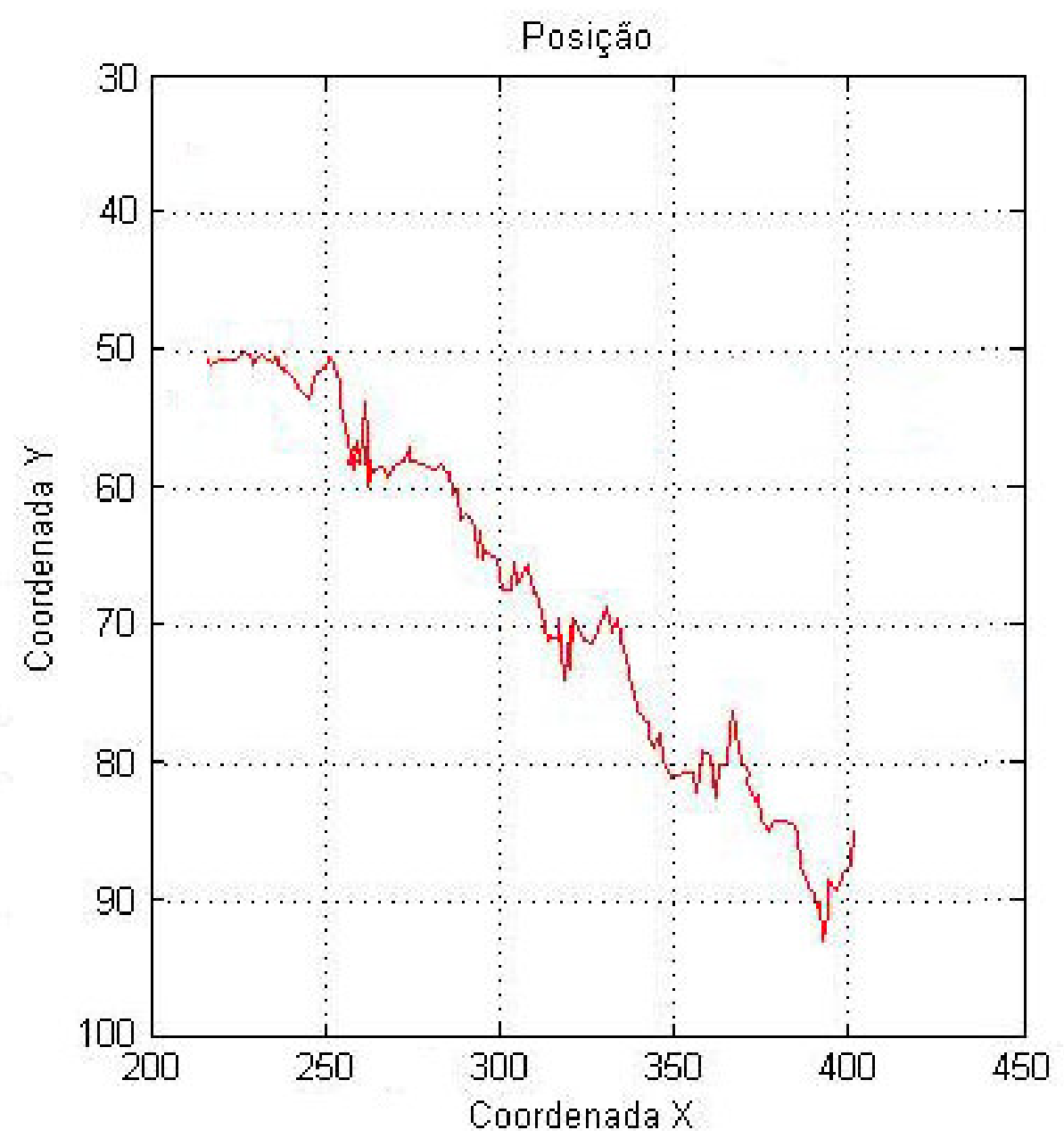

Gráfico 5.3 - Resultado do teste da cena 3. Trajetória estimada do centro de área do alvo em posições com coordenadas $\mathrm{X}$ e $\mathrm{Y}$ determinadas em pixels

\subsection{IMPLEMENTAÇÃO DA PROPOSTA ATUAL - REALIFUT}

A proposta de De Bem (2007) é dividida em duas etapas: inicialização e rastreamento. $\mathrm{Na}$ inicialização é empregado o algoritmo que realiza a estimação inicial do estado dos alvos, sendo que este é composto por variáveis de posição e velocidade. Já no algoritmo de rastreamento, duas instâncias do Filtro de Kalman 
foram empregadas para cada alvo. De Bem (2007) aplicou seu sistema de rastreamento visual em testes com imagens em ambientes internos controlados e alvos simples e planares.

No entanto, também aplicou testes em imagens reais com pessoas caminhando, porém sempre em ambientes fechados, adquirindo resultados satisfatórios. Todavia, no presente trabalho, adaptou-se o sistema para aplicá-lo em imagens reais de jogadores de futebol, em ambientes externos e abertos, que são os campos de futebol, e que dificultariam o funcionamento do algoritmo de De Bem (2007) nestas novas condições, com alvos reais, fundo de cena e iluminação sem muito controle.

A implementação do rastreador da proposta REALIFUT deste trabalho utiliza como base a proposta de De Bem (2007), porém com consideráveis modificações no algoritmo, permitindo a aplicação no rastreamento de jogadores de futebol. Dividido também em duas etapas principais, inicialização e rastreamento, o algoritmo realiza a estimação inicial do estado dos alvos, composto por variáveis para o modelo de movimento e o modelo de forma, bem como duas instâncias do Filtro de Kalman, uma para a estimação do movimento (velocidade) e outra para a estimação da forma (posição dos contornos) dos jogadores, considerando informações de intensidade de cor, inspirada na proposta de Xu et al. (2005), e realizando observações através das linhas de medidas em relação à cor do jogador em contraste com a cor de fundo de cena (intensidade na banda $V$ do espaço de cores HSV).

Os testes foram aplicados em imagens e alvos reais, jogadores de futebol, em ambientes abertos e externos, que são os campos de futebol, obtendo resultados satisfatórios.

\subsubsection{CENA 1}

$\mathrm{Na}$ elaboração dos testes de rastreamento com o algoritmo base de De Bem (2007), foi essencial adaptar os parâmetros do algoritmo do Filtro de Kalman para 
tratar problemas que dificultavam o processamento das sequências de imagens escolhidas, e encontrar a nova solução para a proposta atual, REALIFUT.

O objetivo do primeiro teste foi o de rastrear um único alvo em uma sequência de imagens para determinar os parâmetros mínimos necessários para uma tarefa mais simples, sem grandes deslocamentos do alvo e sem oclusões, porém dentro do escopo deste trabalho, com imagens reais em ambientes externos.

Desta forma foi possível avaliar o rastreamento da trajetória do jogador com uma curva bem suave na horizontal. Os parâmetros utilizados estão descritos na Tabela 5.4.

Tabela 5.4 - Parâmetros utilizados na configuração do sistema de rastreamento no teste da cena 1

\begin{tabular}{lc}
\hline \multicolumn{1}{c}{ Parâmetro } & Valor \\
\hline Número de pontos de controle & $n C=15$ \\
\hline Número de pontos amostrados no polígono & $n A=20$ \\
\hline Comprimento das linhas de medida & $c L=12$ pixels \\
\hline Desvio padrão sobre a linha de medida & $\sigma=2$ pixels \\
\hline Covariância inicial da forma & $P x_{0}=0.05$ \\
\hline Covariância da estimação da forma & $Q_{X}=0.05$ \\
\hline Covariância da observação da forma & $R_{X}=0.5$ \\
\hline Covariância inicial do movimento & $P v x_{0}=0.1, P v y_{0}=0.1 \mathrm{e}$ \\
\hline Covariância da estimação do movimento & $P s_{0}=0.001$ \\
\hline Covariância da observação do movimento & $Q v x=0.001, Q v y=0.001 \mathrm{e}$ \\
\hline Cor de fundo de cena mínima (V) & $Q s=0.000001$ \\
\hline Cor de fundo de cena máxima (V) & $R_{M}=3$ \\
\hline
\end{tabular}

A Figura 5.4 ilustra os resultados do rastreamento com as imagens submetidas no teste da cena 1. O algoritmo possui um comportamento eficaz, mantendo o contorno da forma do alvo durante todo o processamento. 
(a) Quadro1

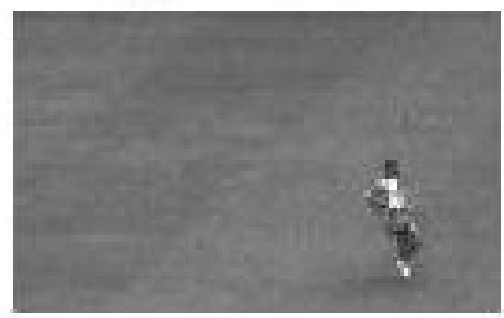

(c) Quadro40

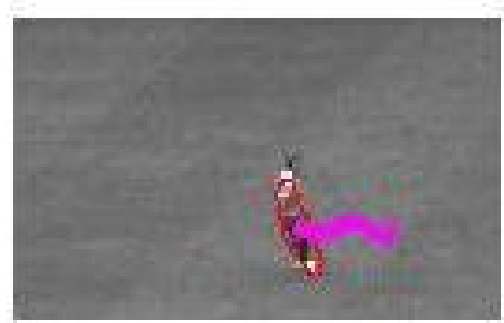

(e) Quadro80

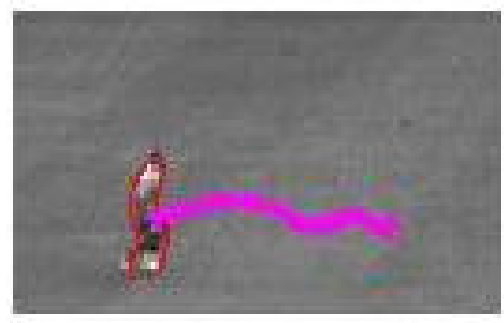

(b) Quadro20

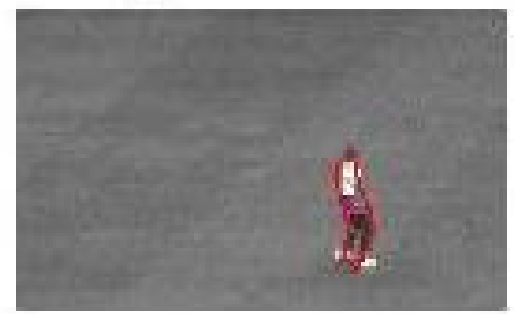

(d) Quadro60

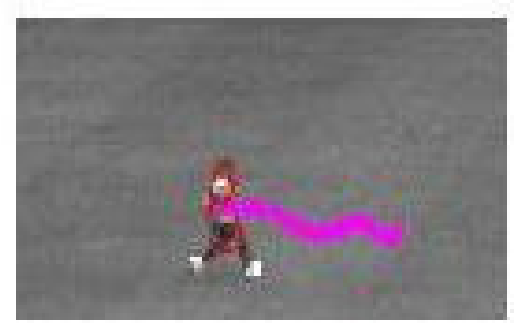

(f) Quadro100

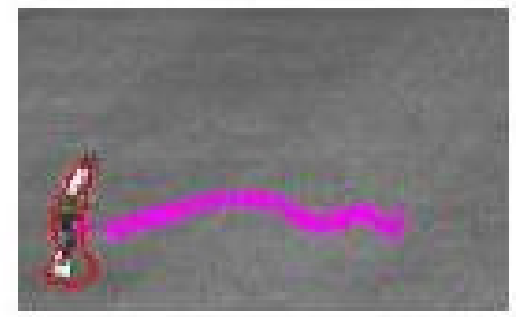

Figura 5.4 - Resultados do teste da cena 1. Sequências de imagens com 100 quadros

Observando o Gráfico 5.4, nota-se um resultado eficaz do processo de rastreamento, pois o jogador realiza uma curva suave devido à estimação de movimento apresentar bons resultados em função da análise das linhas de medidas do contorno do alvo considerar a informação de cor da cena de fundo. Esta curva suave manteve a variação natural da cena de aproximadamente 8 pixels, permitindo uma boa avaliação visual, supondo que o jogador percorreu uma trajetória suave na horizontal. 


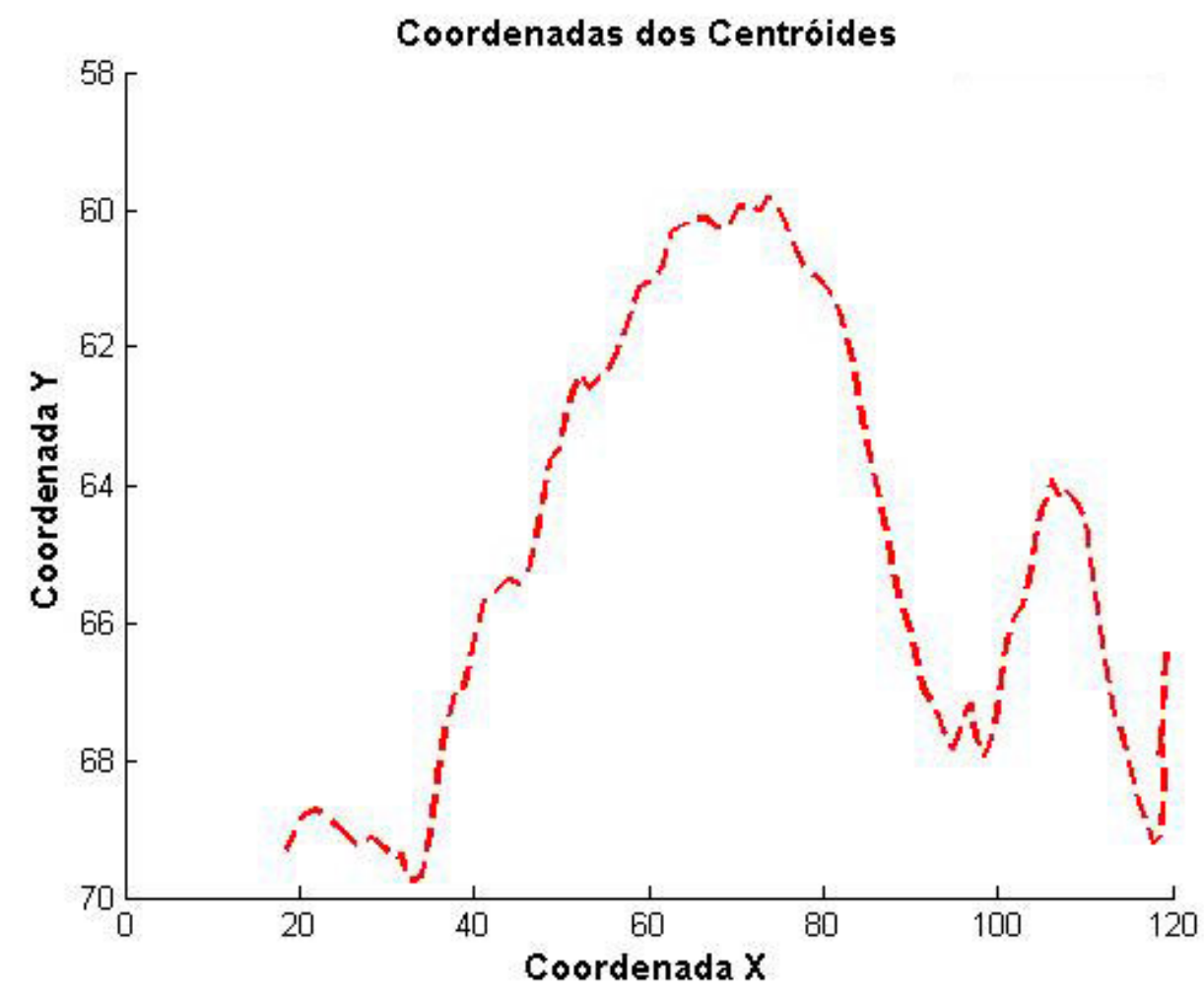

Gráfico 5.4 - Resultado do teste da cena 1. Trajetória estimada do centro de área do alvo em posições com coordenadas $\mathrm{X}$ e $\mathrm{Y}$ determinadas em pixels

\section{3 .2}

CENA 2

No teste da cena 2, é possível avaliar o deslocamento do jogador, tanto na vertical como na horizontal, mostrando que o algoritmo da proposta REALIFUT executa um rastreamento eficaz, pois mantém durante todo o percurso um contorno envolvendo toda a sua forma e uma trajetória bem suave.

Os resultados podem ser verificados na Figura 5.5, e os parâmetros na Tabela 5.5. 
Tabela 5.5 - Parâmetros utilizados na configuração do sistema de rastreamento no teste da cena 2

\begin{tabular}{lc}
\hline \multicolumn{1}{c}{ Parâmetros do Rastreamento } \\
\hline Número de pontos de controle & Valor \\
\hline Número de pontos amostrados no polígono & $n C=15$ \\
\hline Comprimento das linhas de medida & $c L=20$ pixels \\
\hline Desvio padrão sobre a linha de medida & $\sigma=1$ pixels \\
\hline Covariância inicial da forma & $Q_{X 0}=0.05$ \\
\hline Covariância da estimação da forma & $Q_{X}=0.05$ \\
\hline Covariância da observação da forma & $R_{X}=0.5$ \\
\hline Covariância inicial do movimento & $Q v x_{0}=1, Q v y_{0}=1 \mathrm{e}$ \\
\hline Covariância da estimação do movimento & $Q s_{0}=0.001$ \\
\hline Covariância da observação do movimento & $Q v x=0.001, Q v y=0.001 \mathrm{e}$ \\
\hline Cor de fundo de cena mínima (V) & $Q s=0.000001$ \\
\hline Cor de fundo de cena máxima (V) & $R_{M}=3$ \\
\hline
\end{tabular}

Observando os resultados da Figura 5.5 fica claro, visualmente, que o contorno do alvo envolve a forma do jogador de modo bem eficaz, pois a região vermelha que circunda a forma do jogador manteve o contorno em toda a sua densidade de pixels, preservando a forma do jogador. Da mesma maneira, ocorre a suavidade da linha de trajetória percorrida pelo alvo, dado pela estimativa do centro de área que visualmente possui um bom comportamento, conforme ilustrado no Gráfico 5.5 . 
(a) Quadro1

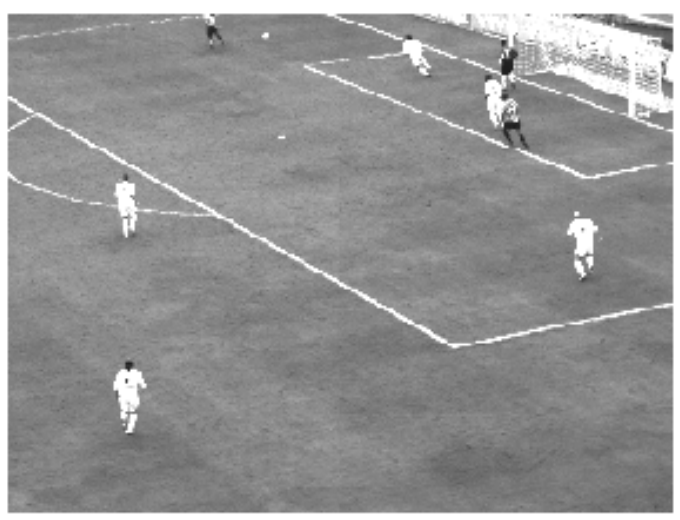

(c) Quadro64

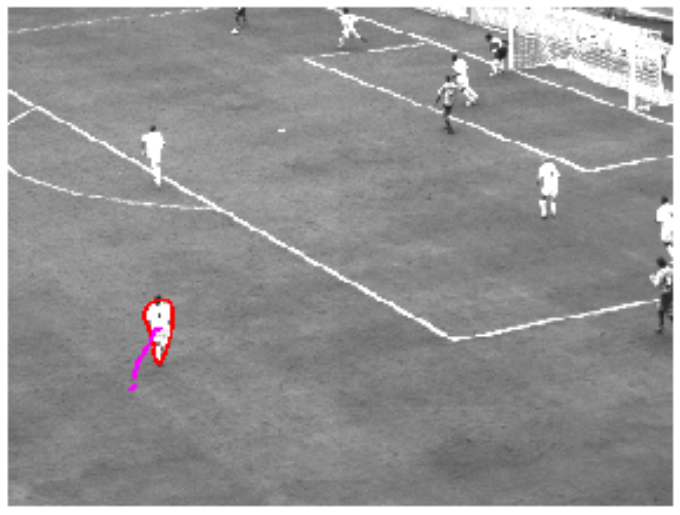

(e) Quadro128

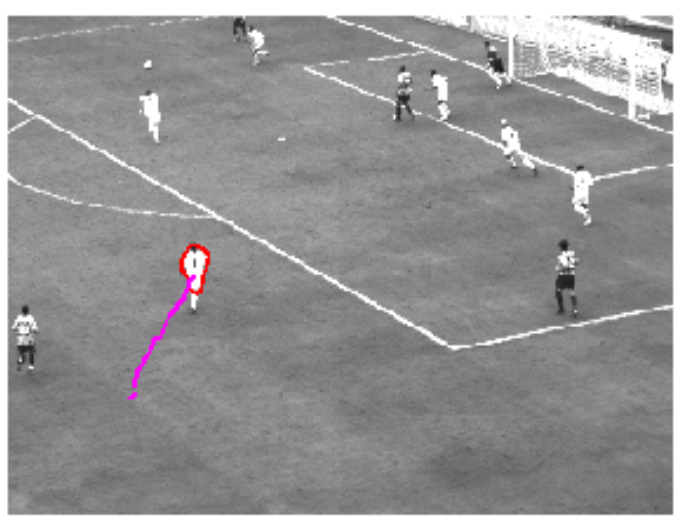

(b) Quadro32

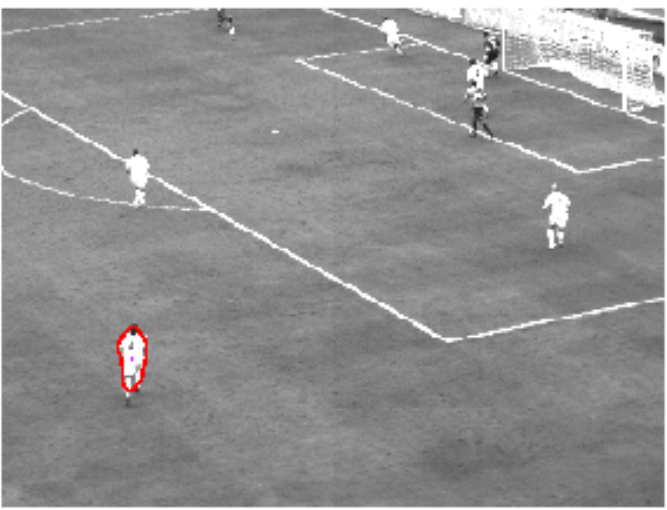

(d) Quadro96

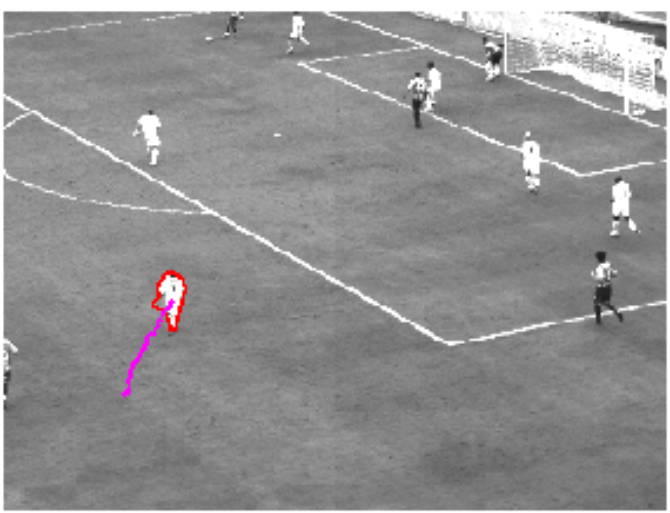

(f) Quadro160

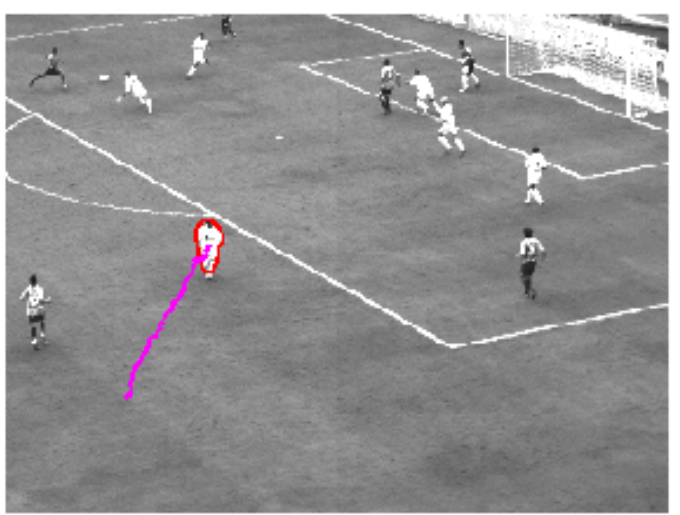

Figura 5.5 - Resultados do teste da cena 2. Sequências de imagens com 160 quadros 


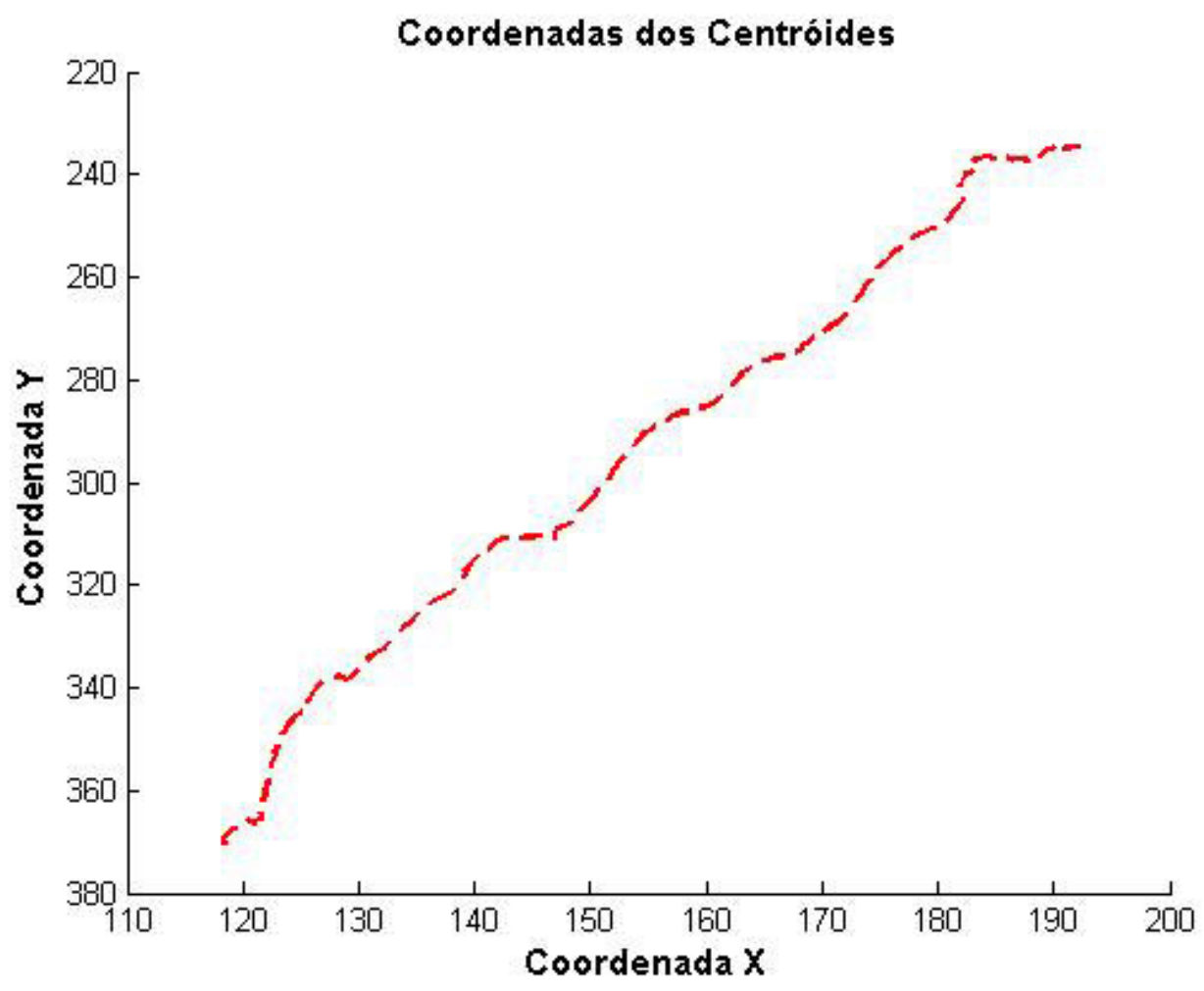

Gráfico 5.5 - Resultado do teste da cena 2. Trajetória estimada do centro de área do alvo em posições com coordenadas $\mathrm{X}$ e $\mathrm{Y}$ determinadas em pixels

\subsubsection{CENA 3}

No teste da cena 3 ocorre o problema de oclusão parcial. Desta forma conclui-se que de fato é importante considerar o tratamento de oclusão por ocorrer com frequência em partidas de futebol. Para isto, deve-se considerar que 0 alvo permaneça em oclusão por apenas alguns quadros, como na proposta de Xu et al. (2005). Em problemas de oclusão total, o rastreamento somente por abordagem probabilística torna-se muito difícil. Os resultados podem ser examinados na Figura 5.6, e os parâmetros adotados neste caso estão descritos na Tabela 5.6. 
Tabela 5.6 - Parâmetros utilizados na configuração do sistema de rastreamento no teste da cena 3

\begin{tabular}{lc}
\hline \multicolumn{1}{c}{ Parâmetro } & Valor \\
\hline Número de pontos de controle & $n C=10$ \\
\hline Número de pontos amostrados no polígono & $n A=15$ \\
\hline Comprimento das linhas de medida & $c L=13$ pixels \\
\hline Desvio padrão sobre a linha de medida & $\sigma=2$ pixels \\
\hline Covariância inicial da forma & $Q_{X 0}=4$ \\
\hline Covariância da estimação da forma & $Q_{X}=0.1$ \\
\hline Covariância da observação da forma & $R_{X}=5$ \\
\hline Covariância inicial do movimento & $Q v x_{0}=0.5, Q v y_{0}=0.3 \mathrm{e}$ \\
\hline Covariância da estimação do movimento & $Q s_{0}=0.3$ \\
\hline Covariância da observação do movimento & $Q v x=0.03, Q v y=0.01 \mathrm{e}$ \\
\hline Cor de fundo de cena mínima (V) & $Q s=0.01$ \\
\hline Cor de fundo de cena máxima (V) & $R_{M}=3$ \\
\hline
\end{tabular}

O algoritmo executa o acompanhamento da trajetória do jogador com suavidade, sem grandes oscilações na posição do centro do contorno envolvente de sua forma. Este bom resultado ocorre devido ao fato do rastreador da proposta REALIFUT realizar observações baseado nas linhas de medidas, levando em considerações informações de intensidade de cor na busca pela borda do contorno do jogador, utilizadas pelos dois Filtros de Kalman intercalados. 
(a) Quadro1

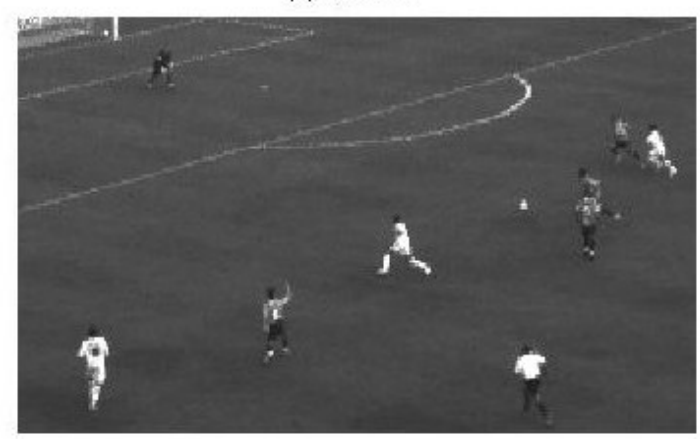

(c) Quadro40

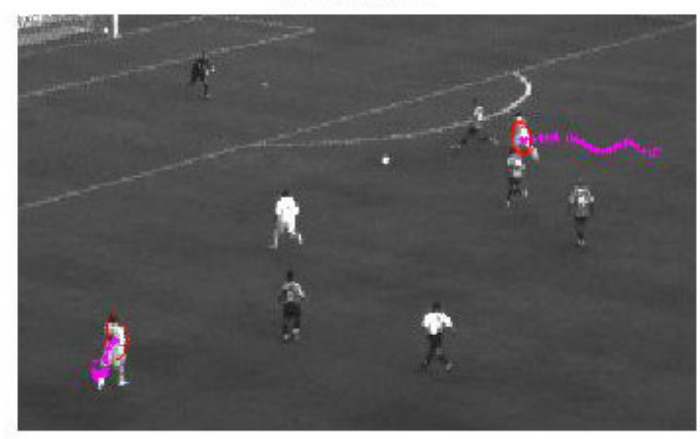

(e) Quadro80

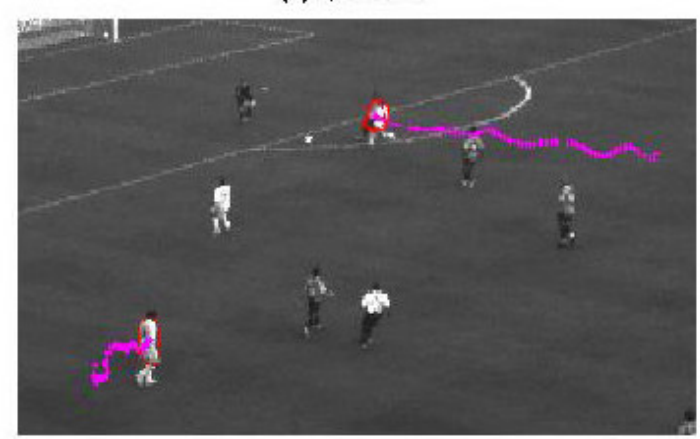

(b) Quadro20

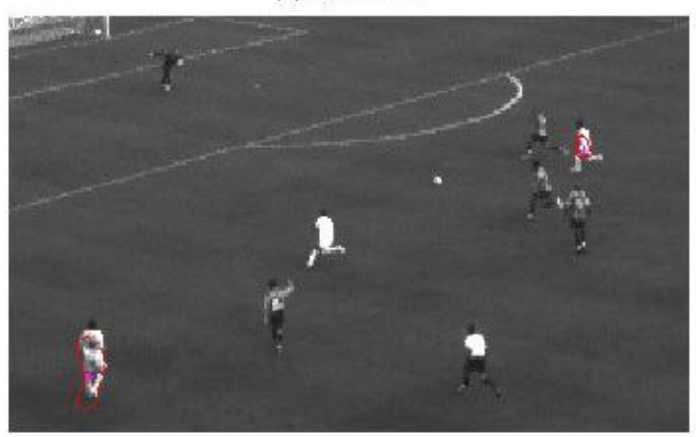

(d) Quadro60

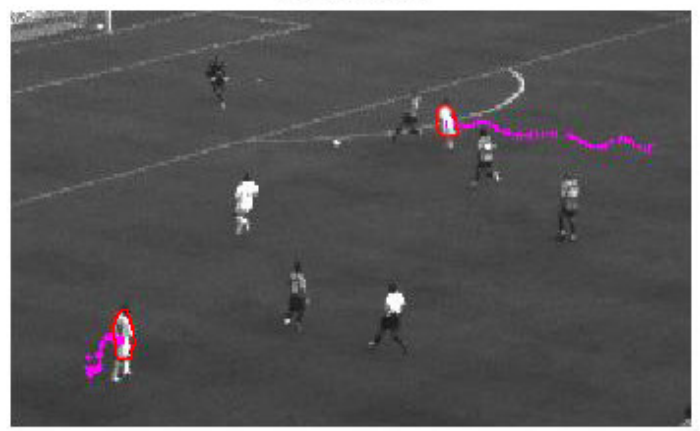

(f) Quadrog9

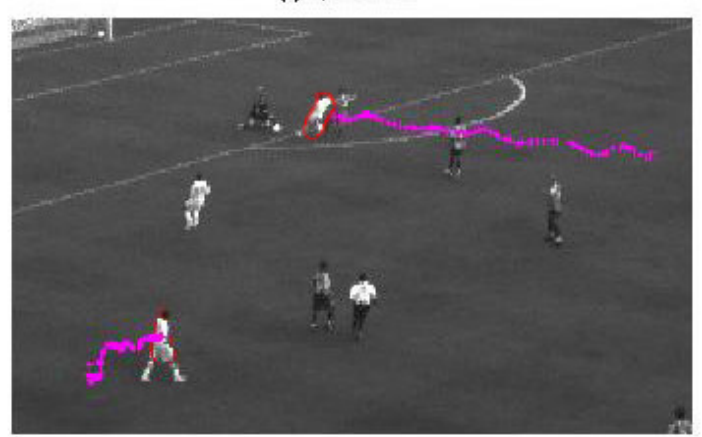

Figura 5.6 - Resultados do teste da cena 3. Sequências de imagens com 89 quadros

Também percebe-se que não ocorre o problema de oclusão entre o quadro 65 e 80 devido à técnica empregada ter uma boa resposta no caso desta oclusão parcial. No Gráfico 5.6 pode ser observado o resultado do teste da cena três, onde a linha vermelha tracejada representa a trajetória estimada, do centro de área do jogador, em posições com coordenadas $\mathrm{X}$ e $\mathrm{Y}$ determinadas em pixels. 


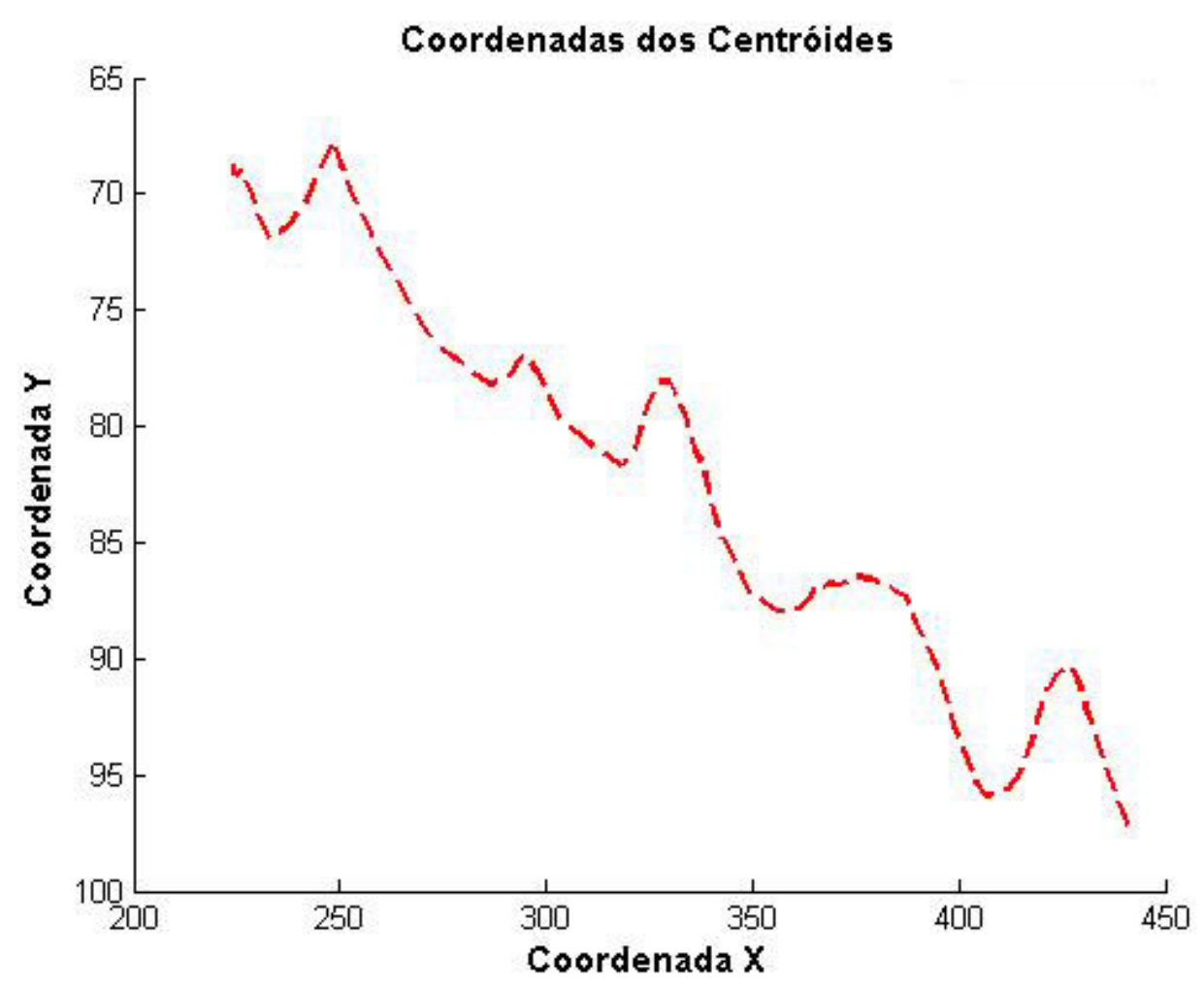

Gráfico 5.6 - Resultado do teste da cena 3. Trajetória estimada do centro de área do alvo em posições com coordenadas $\mathrm{X}$ e $\mathrm{Y}$ determinadas em pixels

\subsection{ANÁLISE COMPARATIVA}

Para a análise comparativa utilizou-se como referência 4 índices diferentes. $O$ Tempo Médio de Processamento de Quadros por Segundo (TMPQS), a Raiz do Erro Quadrado Médio (REQM), o Erro Percentual Relativo às coordenadas $X$ e $Y$ (EPRXY) e, por último, o Erro Percentual Absoluto Médio (EPAM).

O primeiro índice, TMPQS, refere-se à análise da eficiência computacional do algoritmo, e foi calculado com base no tempo médio, em segundos, gasto para o processamento do rastreamento nos quadros da sequência de imagens, considerando os recursos descritos no item 5.1.

Os últimos três índices, descritos anteriormente, referem-se à análise da eficácia do algoritmo em relação à precisão da posição das coordenadas $X$ e $Y$ estimadas pelo algoritmo de rastreamento e à posição visual de referência do 
jogador rastreado em amostras de quadros da sequência de imagens, destacandose o índice REQM como referência geral para a comparação entre as propostas.

O índice REQM é calculado com a seguinte equação:

$$
R E Q M=\sqrt{\frac{\sum_{i=1}^{n}(v e-v r)^{2}}{n}},
$$

em que, $R E Q M$ é a raiz quadrada do somatório de $n$ erros, entre o valor estimado ve e o valor de referência $v r$ (das coordenadas $\mathrm{X}$ e $\mathrm{Y}$ do jogador estimado e do jogador de referência visual), nas amostras dos quadros da sequência de imagens, dividido pelo número total de erros $n$.

O índice EPRXY é calculado através das seguintes equações:

$$
\begin{gathered}
\text { EPRXY }=\frac{\text { ErroXY }}{\text { NúmeroTota lPixels }} \mathrm{e} \\
\text { ErroXY }=\frac{\sum_{i=1}^{n}|X v e-X v r|}{n} \cdot \frac{\sum_{i=1}^{n}|Y v e-Y v r|}{n},
\end{gathered}
$$

em que, o ErroXY é o valor total de pixels calculado pela média de erros na coordenada $\mathrm{X}$, multiplicado pela média de erros na coordenada $\mathrm{Y}$, e NúmeroTotalPixels é a multiplicação da largura pela altura aproximada do jogador.

O índice EPAM é calculado pela equação:

$$
E P A M=\frac{\sum_{i=1}^{n}\left|\frac{v e-v r}{v r}\right|}{n}
$$

EPAM é o somatório de $n$ erros percentuais, entre o valor estimado ve e o valor de referência $v r$, dividido pelo valor de referência $v r$ (das coordenadas $\mathrm{X}$ e $\mathrm{Y}$ 
do jogador estimado e do jogador de referência visual), nas amostras dos quadros da sequência de imagens, dividido pelo número total de erros $n$.

$\mathrm{Na}$ referência visual para as coordenadas de posição da trajetória durante o rastreamento de cada jogador adotou-se uma avaliação visual nos quadros das sequências das imagens selecionadas, e aqui será chamada de Xvr e Yvr.

Esta avaliação visual na proposta baseada em De Bem é feita observando-se os quadros da sequência de imagens de acordo com o centro de área do jogador. No entanto, na proposta inspirada em Xu et al. (2005) os valores de referência são resultantes da avaliação visual dos cantos superiores esquerdos do retângulo envolvente do jogador, na sequência de imagens selecionada.

A seguir mostra-se um resumo com a eficiência e a eficácia do comportamento de cada algoritmo, apresentando os resultados e análises para cada uma das três cenas testadas.

\subsubsection{CENA 1}

Observando o valor do índice TMPQS, nota-se que a proposta de Xu et al. (2005) possui ligeira vantagem com um valor de 1,66 quadros/s, cerca $12 \%$ de eficiência melhor do que a proposta REALIFUT, sendo que esta possui um valor de 1,48 quadros/s. Vale, entretanto, ressaltar que a codificação realizada dos algoritmos não buscou a máxima eficiência possível. Já no critério de qualidade, pela eficácia em relação à posição estimada do alvo, a proposta REALIFUT possui vantagens nos três índices. O valor de erro é 18\% menor no índice REQM (Raiz do Erro Quadrado Médio) de 3,27 pixels ante 3,98 pixels da implementação inspirada em Xu et al. (2005). O índice EPAM chega a ter uma vantagem de $29 \%$ menos erros, comparando com a proposta REALIFUT que possui um valor de $6,92 \%$ de erros contra 9,71\% da proposta inspirada em Xu et al. (2005). Por último, o Erro Percentual Relativo pelas coordenadas X e $Y$ apresenta uma vantagem de $22 \%$ da proposta REALIFUT em relação à proposta inspirada em Xu et al. (2005).

Estes resultados encontram-se nas Tabelas 5.7 e 5.8, e também estão representados nos Gráficos 5.7 e 5.8. 
Tabela 5.7 - Resultados da proposta inspirada em Xu et al. (2005) no teste da cena 1

\begin{tabular}{|c|c|c|c|c|c|}
\hline \multicolumn{6}{|c|}{ Implementação inspirada em Xu et al. (2005) } \\
\hline Cena & Largura & Altura & Quadros & REQM & EPAM (\%) \\
\hline 1 & 153 & 94 & 100 & 3,98 & 9,71 \\
\hline Tamanho & Largura & Altura & Total Pixels & ErroXY pixels & EPRXY (\%) \\
\hline Jogador & 18 & 44 & 792 & 12,92 & 1,63 \\
\hline \multicolumn{4}{|c|}{ Tempo de Processamento Core2Duo } & 79 & $\mathrm{~s}$ \\
\hline \multicolumn{4}{|c|}{ Tempo de Processamento DualCore } & 64 & $\mathrm{~s}$ \\
\hline \multicolumn{4}{|c|}{ Tempo de Processamento Xeon Dual } & 38 & $\mathrm{~s}$ \\
\hline \multicolumn{4}{|c|}{$\begin{array}{c}\text { Tempo médio de processamento } \\
\text { (Quadro/s) }\end{array}$} & 1,66 & quadros/s \\
\hline Quadro & 20 & 40 & 60 & 80 & 100 \\
\hline REQM & 3,0 & 4,1 & 3,8 & 2,5 & 6,4 \\
\hline EPAM & 4,36 & 7,06 & 6,9 & 5,56 & 24,68 \\
\hline ErroX & 3 & 3 & 2 & 2 & 9 \\
\hline ErroY & 3 & 5 & 5 & 3 & 1 \\
\hline Xve & 99 & 84 & 61 & 37 & 10 \\
\hline Yve & 49 & 53 & 53 & 47 & 51 \\
\hline Xvr & 102 & 81 & 59 & 39 & 19 \\
\hline Yvr & 52 & 48 & 48 & 50 & 50 \\
\hline
\end{tabular}

O Gráfico 5.7 mostra uma ligeira vantagem em relação à eficiência computacional do algoritmo inspirado em Xu et al. (2005), durante os testes da cena um em relação a proposta REALIFUT, visto que a proposta inspirada em Xu et al. (2005) utiliza uma abordagem mais simples para a representação da forma dos jogadores através do emprego de retângulos envolventes. No entanto, esta diferença não é muito relevante, considerando que todos os testes foram realizados em ambiente de desenvolvimento utilizando a ferramenta Matlab, e que não se objetivou obter a máxima eficiência possível. Em relação às CPUs utilizadas, fica evidente que a CPU3, em todos os testes, apresentou um desempenho superior. 
Tabela 5.8 - Resultados da proposta REALIFUT no teste da cena 1

\begin{tabular}{|c|c|c|c|c|c|}
\hline \multicolumn{6}{|c|}{ Implementação da proposta REALIFUT com base em De Bem (2007) } \\
\hline Cena & Largura & Altura & Quadros & REQM & EPAM (\%) \\
\hline 1 & 153 & 94 & 100 & 3,27 & 6,92 \\
\hline Tamanho & Largura & Altura & Total Pixels & ErroXY pixels & EPRXY (\%) \\
\hline Jogador & 18 & 44 & 792 & 10,08 & 1,27 \\
\hline \multicolumn{4}{|c|}{ Tempo de Processamento Core2Duo } & 89 & $s$ \\
\hline \multicolumn{4}{|c|}{ Tempo de Processamento DualCore } & 72 & s \\
\hline \multicolumn{4}{|c|}{ Tempo de Processamento Xeon Dual } & 42 & s \\
\hline \multicolumn{4}{|c|}{$\begin{array}{c}\text { Tempo médio de processamento } \\
\text { (Quadro/s) }\end{array}$} & 1,48 & quadros/s \\
\hline Quadro & 20 & 40 & 60 & 80 & 100 \\
\hline REQM & 1,6 & 3,5 & 2,0 & 3,5 & 5,7 \\
\hline EPAM & 1,79 & 5,08 & 3,32 & 6,99 & 17,41 \\
\hline ErroX & 2 & 3 & 2 & 3 & 4 \\
\hline ErroY & 1 & 4 & 2 & 4 & 7 \\
\hline Xve & 106 & 89 & 62 & 44 & 21 \\
\hline Yve & 61 & 64 & 59 & 64 & 69 \\
\hline Xvr & 104 & 86 & 64 & 41 & 17 \\
\hline Yvr & 60 & 60 & 57 & 60 & 62 \\
\hline
\end{tabular}

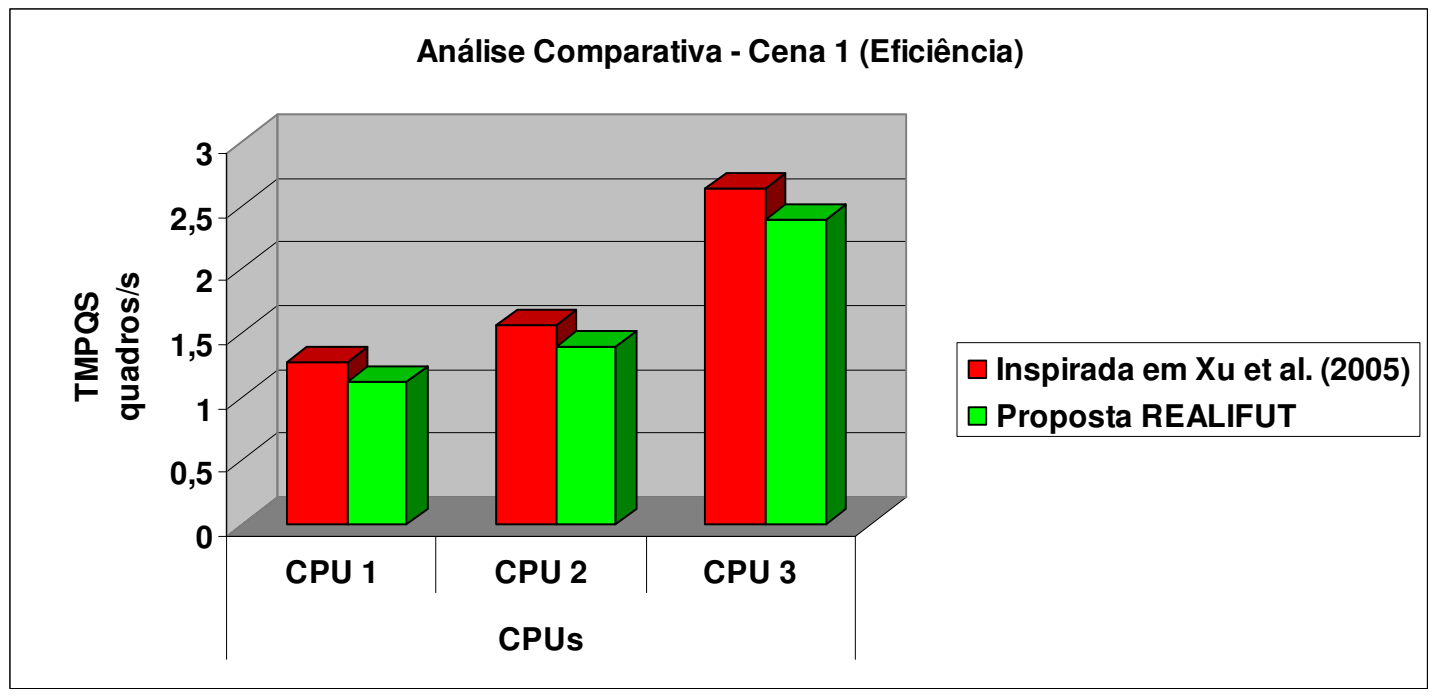

Gráfico 5.7 - Gráfico comparativo em relação à eficiência na cena 1 
Observando o Gráfico 5.8, nota-se que a proposta REALIFUT é a que apresenta a melhor eficácia no algoritmo, avaliando o índice REQM, para a maioria dos quadros analisados, e isso se deve ao fato desta possuir um melhor modelo de observação baseado no contorno da forma dos jogadores.

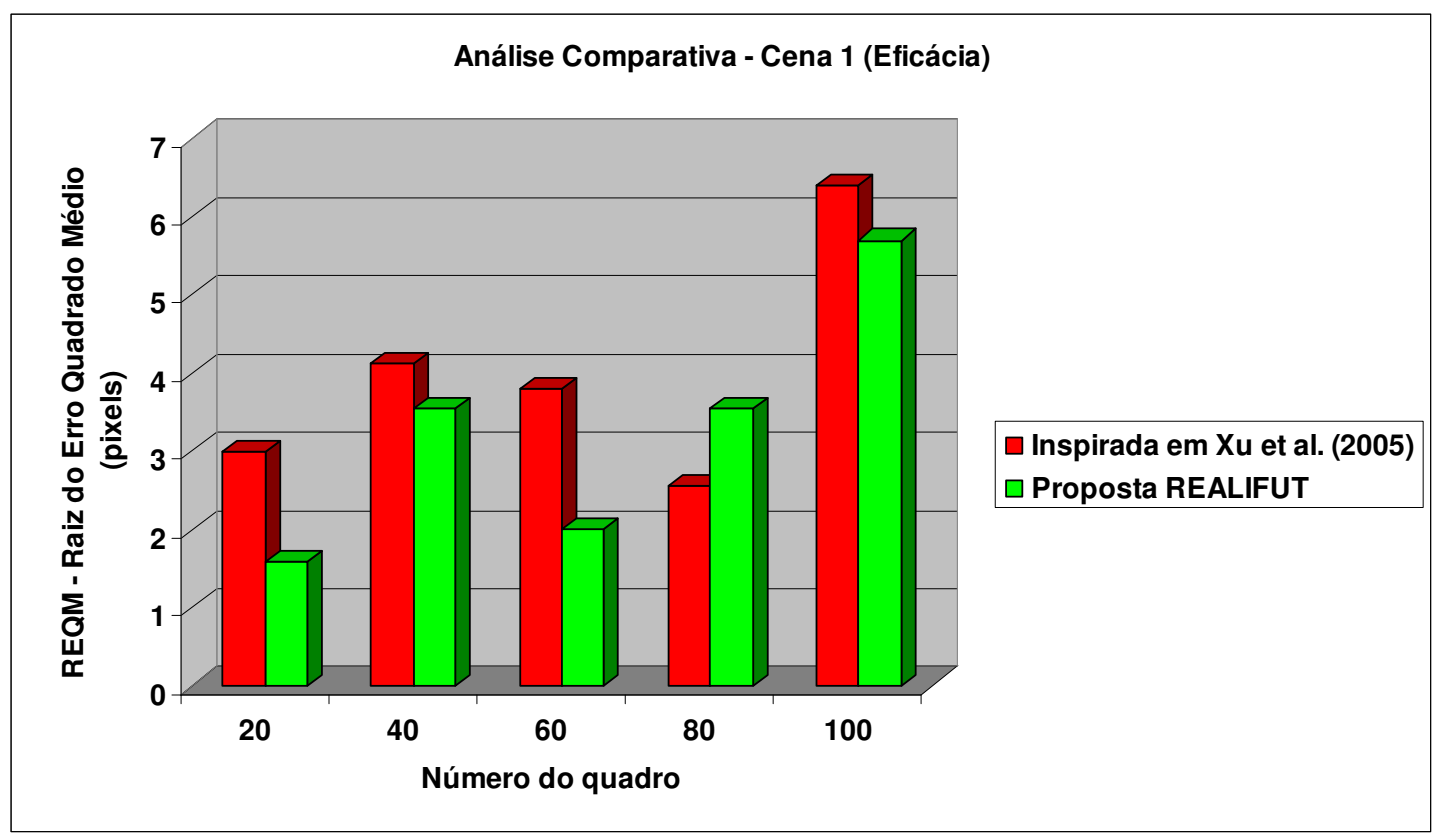

Gráfico 5.8 - Gráfico comparativo em relação à eficácia na cena 1

CENA 2

Nos testes com a cena dois, o índice considerado para avaliar a eficiência dos algoritmos apresentou aproximadamente os mesmos valores do TMPQS para a proposta REALIFUT e a inspirada em Xu et al. (2005), com valores de 1,16 quadros/s e 1,23 quadros/s, respectivamente. Uma diferença de aproximadamente $5 \%$ entre as duas propostas.

Em relação à eficácia dos algoritmos é fato que a proposta REALIFUT apresenta grande vantagem em relação a proposta inspirada em Xu et al. (2005), pois com um valor de REQM de 3,31 pixels, apresenta cerca de 47\% menos erros. Os resultados são apresentados nas Tabela 5.9 e 5.10 e nos Gráficos 5.9 e 5.10 . 
Tabela 5.9 - Resultados da proposta inspirada em Xu et al. (2005) no teste 2

\begin{tabular}{|c|c|c|c|c|c|}
\hline \multicolumn{6}{|c|}{ Implementação inspirada em Xu et al. (2005) } \\
\hline Cena & Largura & Altura & Quadros & REQM & EPAM (\%) \\
\hline 2 & 640 & 480 & 160 & 6,21 & 2,74 \\
\hline Tamanho & Largura & Altura & Total Pixels & ErroXY pixels & EPRXY \\
\hline Jogador & 33 & 80 & 2640 & 29,6 & 1,12 \\
\hline \multicolumn{4}{|c|}{ Tempo de Processamento Core2Duo } & 145 & $\mathrm{~s}$ \\
\hline \multicolumn{4}{|c|}{ Tempo de Processamento DualCore } & 130 & $\mathrm{~s}$ \\
\hline \multicolumn{4}{|c|}{ Tempo de Processamento Xeon Dual } & 115 & $\mathrm{~s}$ \\
\hline \multicolumn{4}{|c|}{$\begin{array}{c}\text { Tempo médio de processamento } \\
\text { (Quadro/s) }\end{array}$} & 1,23 & quadros/s \\
\hline Quadro & 32 & 64 & 96 & 128 & 160 \\
\hline REQM & 2,8 & 3,8 & 6,7 & 9,8 & 7,9 \\
\hline EPAM & 0,63 & 2,09 & 3,1 & 4,2 & 3,67 \\
\hline ErroX & 0 & 5 & 5 & 5 & 5 \\
\hline ErroY & 4 & 2 & 8 & 13 & 10 \\
\hline Xve & 124 & 138 & 155 & 172 & 186 \\
\hline Yve & 314 & 288 & 253 & 220 & 202 \\
\hline Xvr & 124 & 143 & 160 & 177 & 191 \\
\hline Yvr & 318 & 290 & 261 & 233 & 212 \\
\hline
\end{tabular}

Após os testes da cena dois, é notável a vantagem do algoritmo da proposta REALIFUT com relação a proposta inspirada em Xu et al. (2005). O Gráfico 5.10 exibe a grande diferença na análise comparativa dos erros pelo índice da REQM entre as duas propostas. Fica evidente que a proposta REALIFUT possui uma vantagem melhor em relação a sua eficácia para o rastreamento de jogadores de futebol. 
Tabela 5.10 - Resultados da proposta REALIFUT no teste da cena 2

\begin{tabular}{|c|c|c|c|c|c|}
\hline \multicolumn{6}{|c|}{ Implementação da proposta REALIFUT com base em De Bem (2007) } \\
\hline Cena & Largura & Altura & Quadros & REQM & EPAM (\%) \\
\hline 2 & 640 & 480 & 160 & 3,31 & 1,03 \\
\hline Tamanho & Largura & Altura & Total Pixels & ErroXY pixels & EPRXY (\%) \\
\hline Jogador & 33 & 80 & 2640 & 2,76 & 0,1 \\
\hline \multicolumn{4}{|c|}{ Tempo de Processamento Core2Duo } & 155 & $\mathrm{~s}$ \\
\hline \multicolumn{4}{|c|}{ Tempo de Processamento DualCore } & 138 & $\mathrm{~s}$ \\
\hline \multicolumn{4}{|c|}{ Tempo de Processamento Xeon Dual } & 122 & $s$ \\
\hline \multicolumn{4}{|c|}{$\begin{array}{c}\text { Tempo médio de processamento } \\
\text { (Quadro/s) }\end{array}$} & 1,16 & quadros/s \\
\hline Quadro & 32 & 64 & 96 & 128 & 160 \\
\hline REQM & 2,9 & 4,9 & 5,0 & 1,6 & 2,1 \\
\hline EPAM & 1 & 1,16 & 1,6 & 0,69 & 0,68 \\
\hline ErroX & 1 & 0 & 1 & 1 & 0 \\
\hline ErroY & 4 & 7 & 7 & 2 & 3 \\
\hline Xve & 127 & 146 & 163 & 182 & 197 \\
\hline Yve & 334 & 310 & 278 & 245 & 222 \\
\hline $\mathrm{Xvr}$ & 128 & 146 & 164 & 181 & 197 \\
\hline Yvr & 330 & 303 & 271 & 243 & 219 \\
\hline
\end{tabular}

Por outro lado, observando o Gráfico 5.9, nota-se que em relação à eficiência computacional as duas propostas apresentam resultados próximos, com uma variação que chega a 5\%. A diferença na eficiência está nos recursos utilizados como, por exemplo, o processador dos equipamentos, que no caso deste trabalho, os algoritmos executados na CPU3 apresentaram os melhores resultados. 


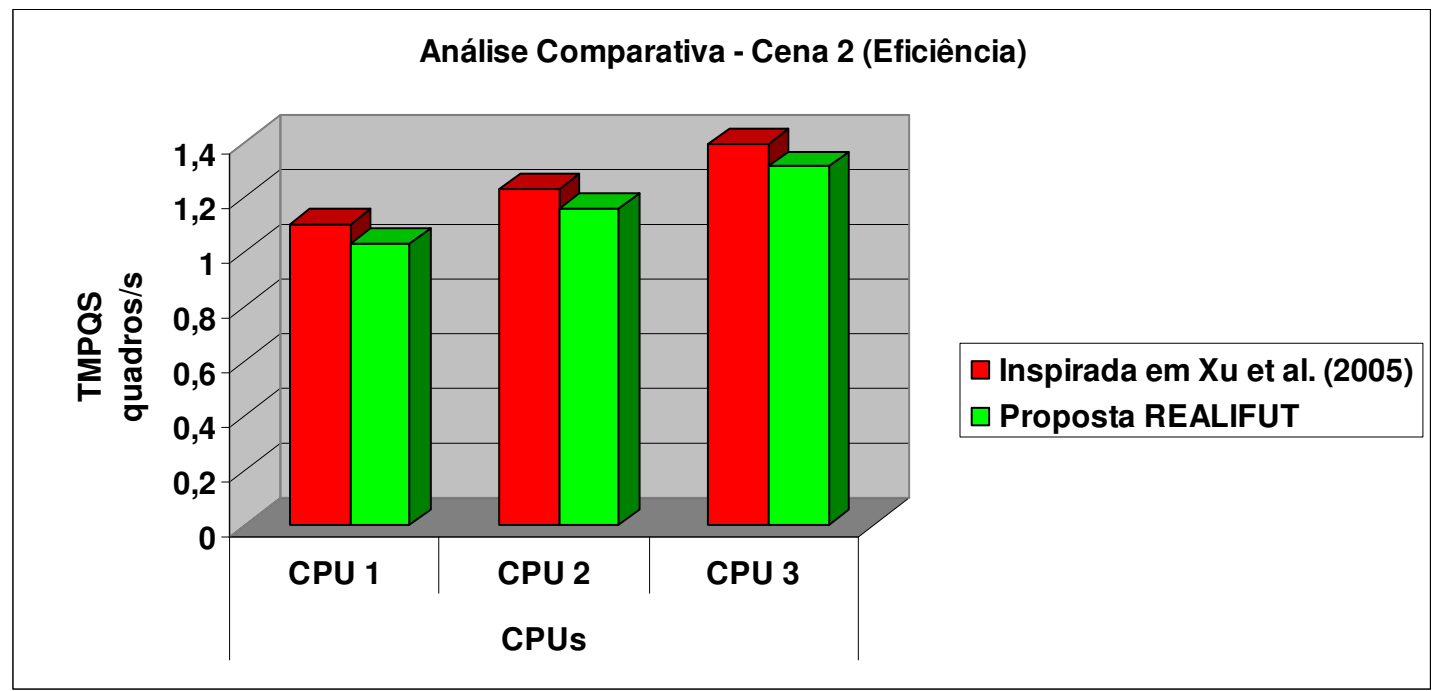

Gráfico 5.9 - Gráfico comparativo em relação à eficiência na cena 2

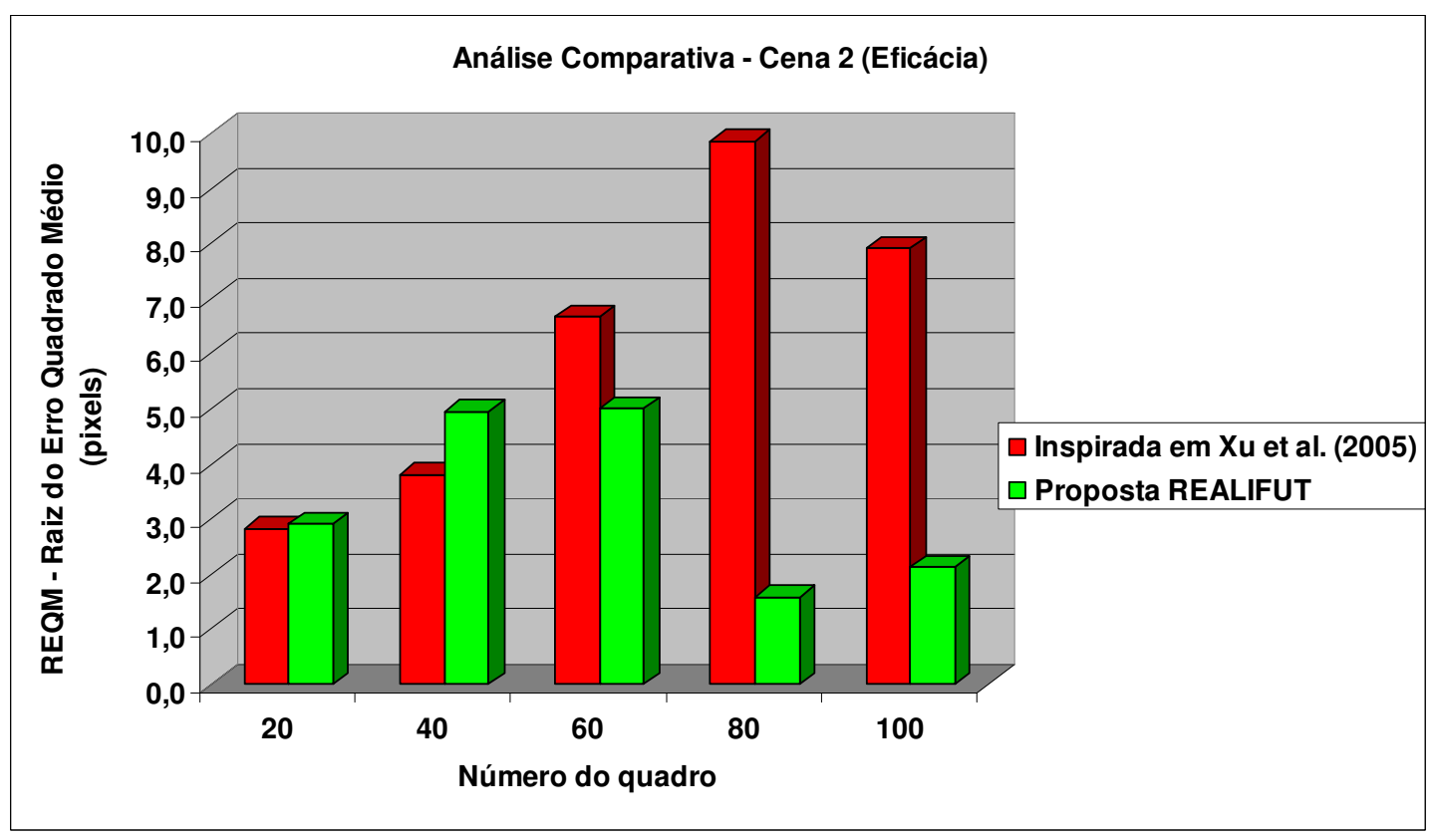

Gráfico 5.10 - Gráfico comparativo em relação à eficácia na cena 2

A terceira cena mostrou um bom resultado para os testes deste estudo. 
$\mathrm{Na}$ avaliação do índice REQM e TMPQS, mesmo considerando erros de oclusão parcial foi possível avaliar os dois algoritmos, e conclui-se que a proposta REALIFUT deste trabalho apresenta também, neste teste, a melhor eficácia e um bom desempenho em relação à eficiência computacional. O índice TMPQS apresentou resultados bem próximos um do outro para as duas propostas, com uma diferença máxima de $12 \%$. Já os índices que avaliam a eficácia revelam diferenças expressivas como, por exemplo, o REQM, onde na proposta REALIFUT apresenta o melhor número com 2,73 pixels de erro ante a 3,35 pixels da proposta inspirada em Xu et al. (2005), registrando 19\% menos erros. Os resultados são apresentados nas Tabelas 5.11 e 5.12 e nos Gráficos 5.11 e 5.12 .

Tabela 5.11 - Resultados da proposta inspirada em Xu et al. (2005) no teste da cena 3 Implementação inspirada em Xu et al. (2005)

\begin{tabular}{|c|c|c|c|c|c|}
\hline Cena & Largura & Altura & Quadros & REQM & EPAM (\%) \\
\hline 3 & 474 & 291 & 99 & 3,35 & 2,3 \\
\hline Tamanho & Largura & Altura & Total Pixels & ErroXY pixels & EPRXY (\%) \\
\hline Jogador & 25 & 40 & 1000 & 8,64 & 0,86 \\
\hline \multicolumn{4}{|c|}{ Tempo de Processamento Core2Duo } & 115 & $\mathrm{~s}$ \\
\hline \multicolumn{4}{|c|}{ Tempo de Processamento DualCore } & 89 & $\mathrm{~s}$ \\
\hline \multicolumn{4}{|c|}{ Tempo de Processamento Xeon Dual } & 65 & $\mathrm{~s}$ \\
\hline \multicolumn{4}{|c|}{$\begin{array}{c}\text { Tempo médio de processamento } \\
\text { (Quadro/s) }\end{array}$} & 1,1 & quadros/s \\
\hline Quadro & 20 & 40 & 60 & 80 & 99 \\
\hline REQM & 3,8 & 1,6 & 5,0 & 4,1 & 2,2 \\
\hline EPAM & 3,34 & 1,41 & 1,85 & 3,34 & 1,56 \\
\hline ErroX & 2 & 1 & 7 & 5 & 3 \\
\hline ErroY & 5 & 2 & 1 & 3 & 1 \\
\hline Xer & 393 & 348 & 296 & 247 & 211 \\
\hline Yer & 86 & 81 & 71 & 67 & 59 \\
\hline Xvr & 395 & 349 & 303 & 252 & 214 \\
\hline Yvr & 81 & 79 & 72 & 64 & 58 \\
\hline
\end{tabular}


Analisando o Gráfico 5.11, percebe-se, novamente, uma proximidade dos valores de eficiência computacional entre as propostas, porém existe certa vantagem na execução dos algoritmos na CPU3 por se tratar, principalmente, de um computador com 4 núcleos de processamento.

Observa-se, no Gráfico 5.12, um considerável aumento no erro desta cena, na maioria dos quadros analisados, principalmente após o quadro 60, onde ocorreu a oclusão parcial entre jogadores. Já a proposta REALIFUT apresentou o menor REQM.

Tabela 5.12 - Resultados da proposta REALIFUT no teste da cena 3

\begin{tabular}{|c|c|c|c|c|c|}
\hline \multicolumn{6}{|c|}{ Implementação da proposta REALIFUT com base em De Bem (2007) } \\
\hline Cena & Largura & Altura & Quadros & REQM & EPAM (\%) \\
\hline 3 & 474 & 291 & 99 & 2,73 & 2,16 \\
\hline Tamanho & Largura & Altura & Total Pixels & ErroXY pixels & EPRXY (\%) \\
\hline Jogador & 25 & 40 & 1000 & 6,72 & 0,67 \\
\hline \multicolumn{4}{|c|}{ Tempo de Processamento Core2Duo } & 119 & $\mathrm{~s}$ \\
\hline \multicolumn{4}{|c|}{ Tempo de Processamento DualCore } & 93 & $\mathrm{~s}$ \\
\hline \multicolumn{4}{|c|}{ Tempo de Processamento Xeon Dual } & 71 & $\mathrm{~s}$ \\
\hline \multicolumn{4}{|c|}{$\begin{array}{c}\text { Tempo médio de processamento } \\
\text { (Quadro/s) }\end{array}$} & 1,05 & quadros/s \\
\hline Quadro & 20 & 40 & 60 & 80 & 99 \\
\hline REQM & 3,0 & 3,5 & 2,5 & 3,2 & 1,4 \\
\hline EPAM & 2,05 & 2,85 & 2,31 & 3,18 & 0,43 \\
\hline ErroX & 3 & 3 & 2 & 2 & 2 \\
\hline ErroY & 3 & 4 & 3 & 4 & 0 \\
\hline Xve & 404 & 365 & 322 & 270 & 237 \\
\hline Yve & 92 & 86 & 78 & 75 & 68 \\
\hline Xvr & 407 & 362 & 320 & 272 & 235 \\
\hline Yvr & 89 & 82 & 75 & 71 & 68 \\
\hline
\end{tabular}




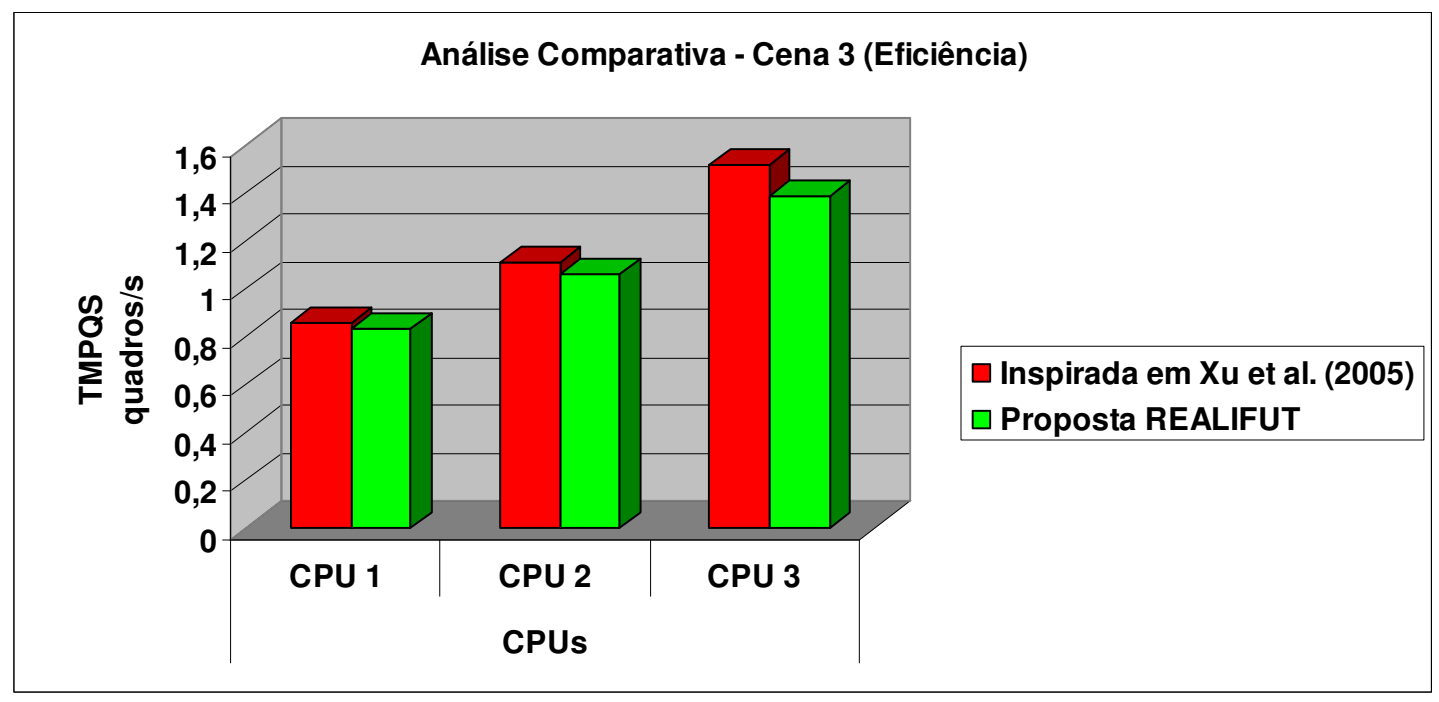

Gráfico 5.11 - Gráfico comparativo em relação à eficiência na cena 3

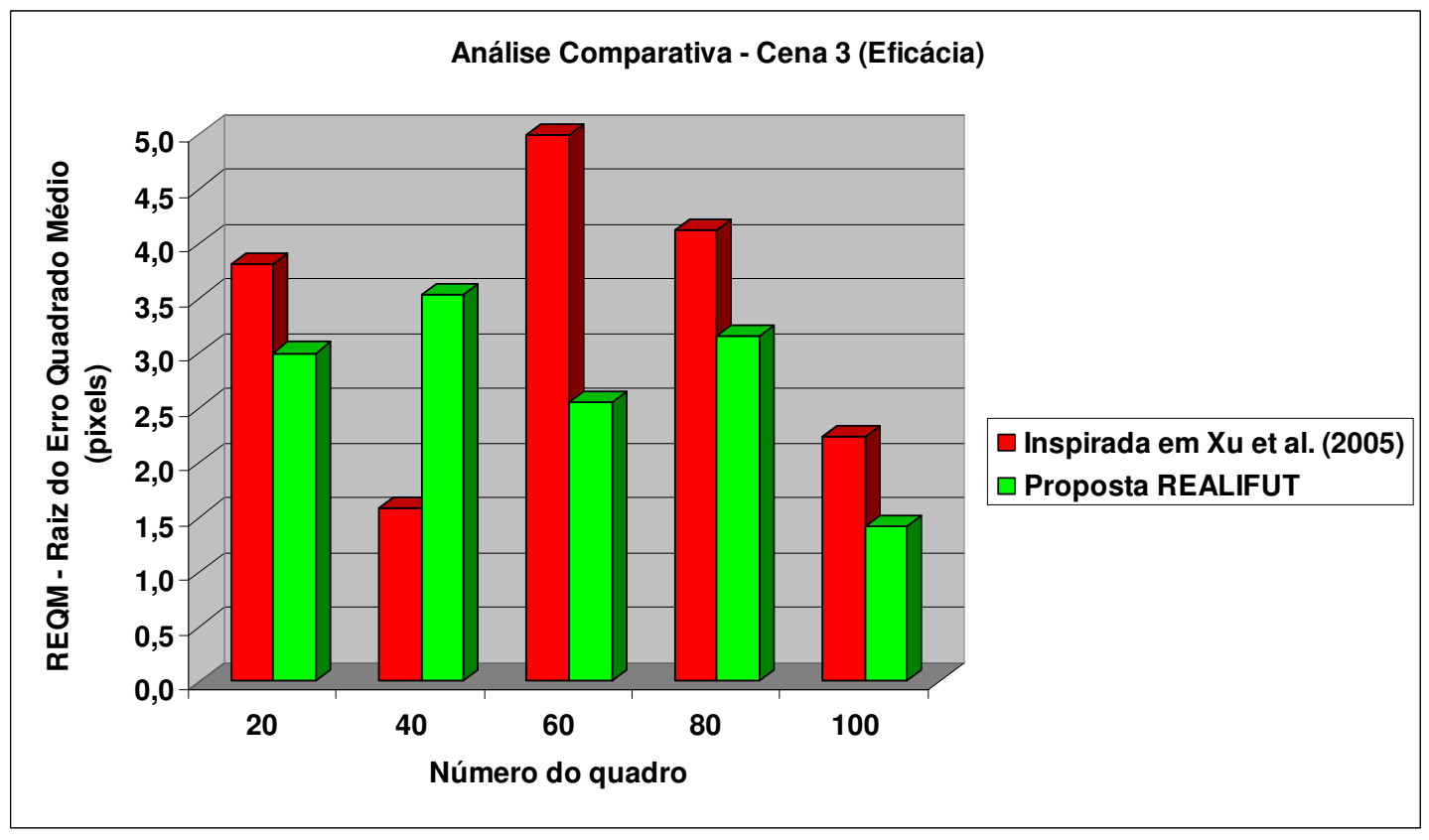

Gráfico 5.12 - Gráfico comparativo em relação à eficácia na cena 3

5.4 .4 CONSIDERAÇÕES FINAIS DO CAPÍTULO

Do ponto de vista de eficiência computacional, quanto mais rápido ocorrer o processamento mais eficiente é a proposta, consideramos que as duas propostas 
apresentaram bons resultados, dado que em todos os testes foram executados em ambiente de desenvolvimento, utilizando o Matlab como principal ferramenta.

Analisando a eficácia dos algoritmos, no fato de a proposta executar o rastreamento do jogador em relação à posição do alvo, durante toda a cena, mantendo o contorno da forma do jogador o máximo parecido com sua forma visual real, conclui-se que a proposta REALIFUT apresentou resultados satisfatórios em todos os testes, garantindo sempre uma Raiz do Erro Quadrado Médio (REQM) com boa vantagem em relação à proposta inspirada em Xu et al. (2005) aqui implementada.

Para o bom entendimento destes critérios e dos índices foram analisados os resultados e seus valores com relação à eficiência e eficácia das propostas, e estão resumidos no quadro da Tabela 5.13 para cada cena.

Tabela 5.13 - Tabela comparativa com os resultados e análise final

\begin{tabular}{|c|c|c|c|c|}
\hline $\begin{array}{l}\text { ANÁLISE COMPARATIVA } \\
\text { FINAL }\end{array}$ & \multicolumn{3}{|c|}{ IMAGENS SELECIONADAS } & $\begin{array}{l}\text { MÉDIA } \\
\text { FINAL }\end{array}$ \\
\hline EFICIÊNCIA (TMPQS) & Cena 1 & Cena 2 & Cena 3 & (quadros/s) \\
\hline $\begin{array}{l}\text { Proposta inspirada em Xu et al. } \\
(2005)\end{array}$ & 1,66 & 1,23 & 1,1 & 1,33 \\
\hline Proposta REALIFUT & 1,48 & 1,16 & 1,05 & 1,23 \\
\hline EFICÁCIA (REQM) & Cena 1 & Cena 2 & Cena 3 & (pixels) \\
\hline $\begin{array}{l}\text { Proposta inspirada em Xu et al. } \\
(2005)\end{array}$ & 3,98 & 6,21 & 3,35 & 4,5 \\
\hline Proposta REALIFUT & 3,27 & 3,31 & 2,73 & 3,1 \\
\hline EFICÁCIA (EPRXY) & Cena 1 & Cena 2 & Cena 3 & (\%) \\
\hline $\begin{array}{l}\text { Proposta inspirada em Xu et al. } \\
(2005)\end{array}$ & 1,63 & 1,12 & 0,86 & 1,2 \\
\hline Proposta REALIFUT & 1,27 & 0,1 & 0,67 & 0,7 \\
\hline EFICÁCIA (EPAM) & Cena 1 & Cena 2 & Cena 3 & $(\%)$ \\
\hline $\begin{array}{l}\text { Proposta inspirada em Xu et al. } \\
(2005)\end{array}$ & 9,71 & 2,74 & 2,3 & 4,9 \\
\hline Proposta REALIFUT & 6,92 & 1,03 & 2,16 & 3,4 \\
\hline
\end{tabular}


Em relação à eficiência computacional, a proposta inspirada em Xu et al. (2005) apresentou resultados ligeiramente melhores do que a proposta REALIFUT, como pode ser observado no Gráfico 5.13, mas considerando que todos os testes foram realizados em ambiente de desenvolvimento com a ferramenta Matlab, estes valores podem ser melhorados com ferramentas e linguagens de programação mais eficientes. A proposta inspirada em Xu et al. (2005) possui uma eficiência de 1,3 quadros por segundo, um pouco melhor do que a proposta REALIFUT de 1,23 quadros por segundo. Esta diferença ocorre principalmente devido à simplicidade do algoritmo de rastreamento com o emprego de retângulos envolventes.

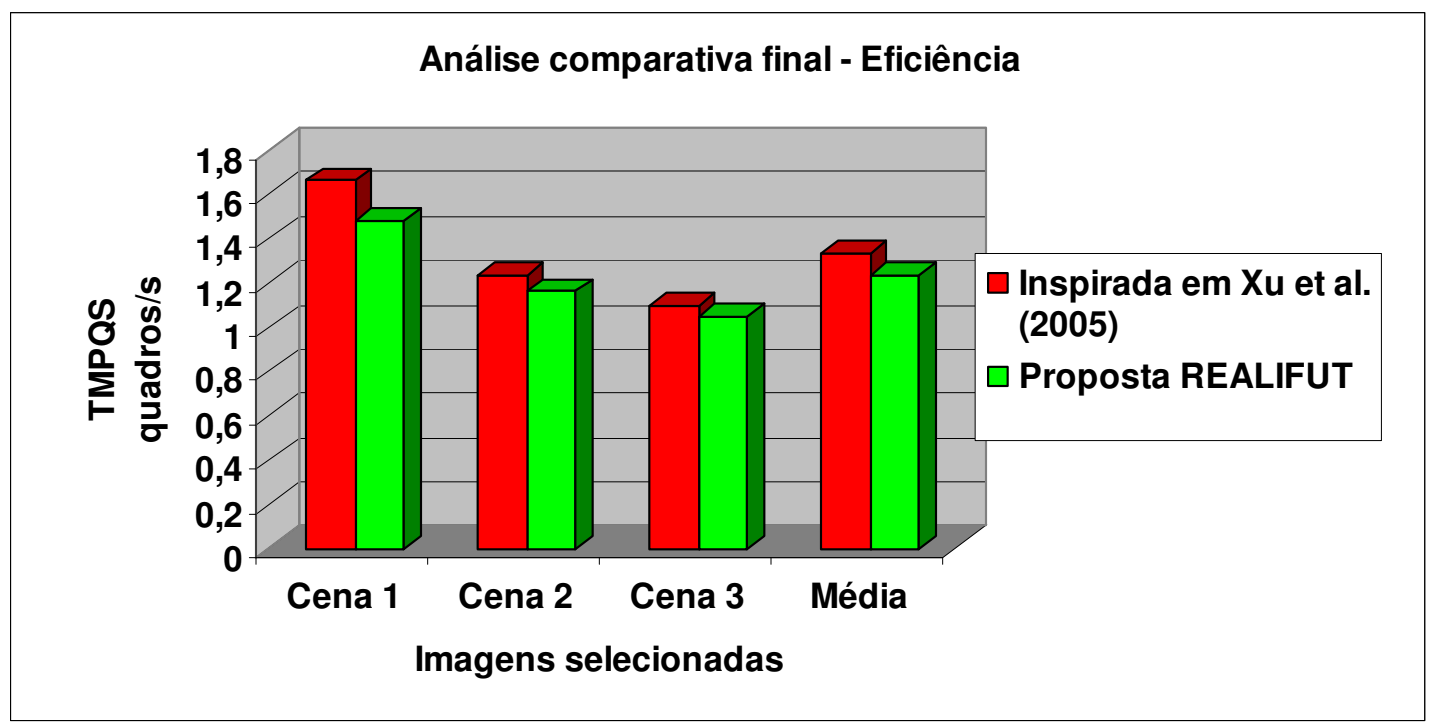

Gráfico 5.13 - Gráfico comparativo em relação à eficiência de todas as cenas

Em todos os gráficos relativos à eficácia, a proposta REALIFUT deste trabalho é a que apresenta melhores resultados, com menos erros em relação à posição do jogador na cena devido à boa representação do contorno de sua forma.

O Gráfico 5.14 mostra a análise comparativa final com o índice REQM (Raiz do Erro Quadrado Médio) da proposta REALIFUT de aproximadamente 3,1 pixels, contra 4,5 da proposta inspirada em Xu et al. (2005).

Os resultados relativos ao índice EPRXY (Erro Percentual Relativo nas coordenadas X e Y) são apresentados no Gráfico 5.15. Este erro é atualizado com base no valor médio de erro apresentado em relação à coordenada $X$ e $Y$, dividido pelo total de pixels do jogador, que é calculado de acordo com sua largura e altura. 
Por isso, nota-se no gráfico que a proposta REALIFUT é a que apresenta o menor valor deste índice, ficando abaixo de 1\% na média.

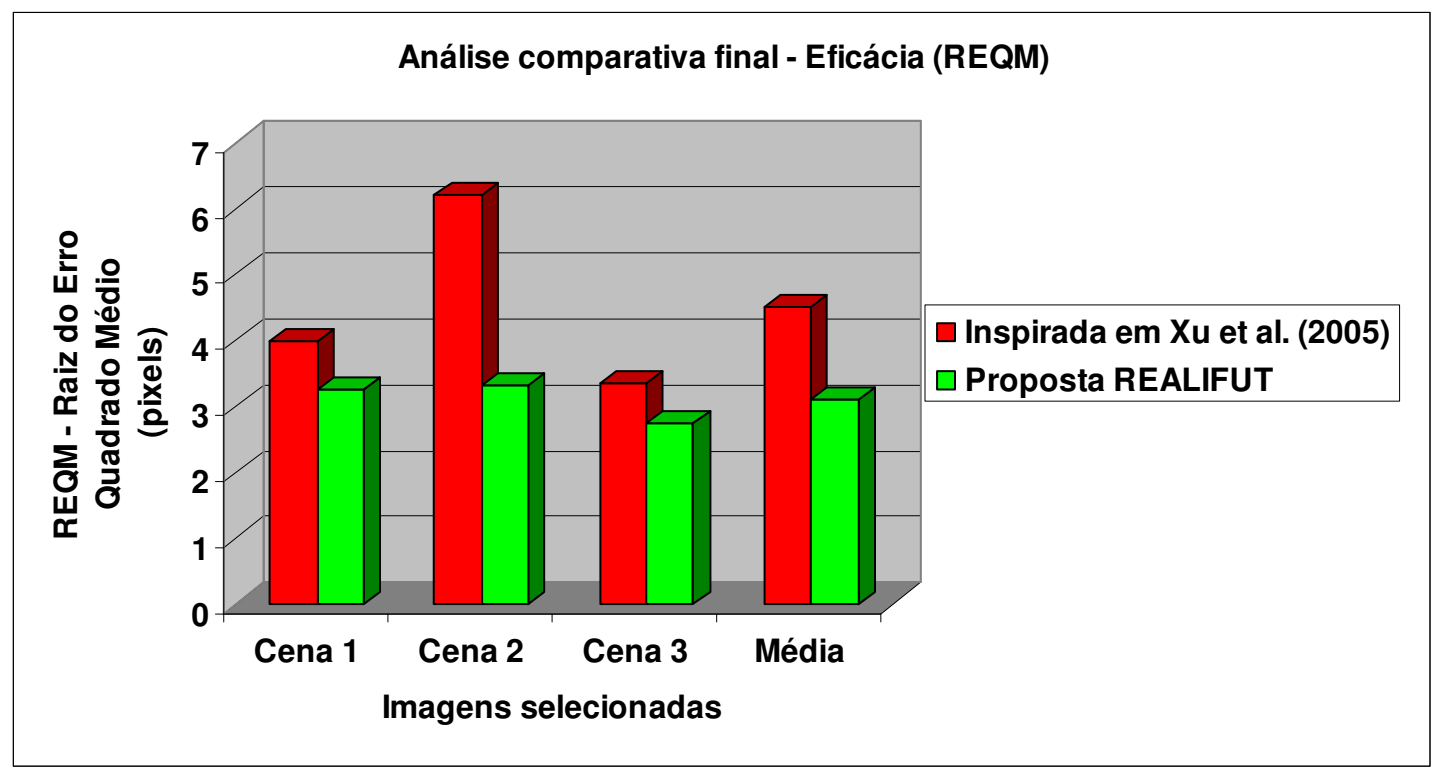

Gráfico 5.14 - Gráfico comparativo em relação à eficácia (REQM) de todas as cenas

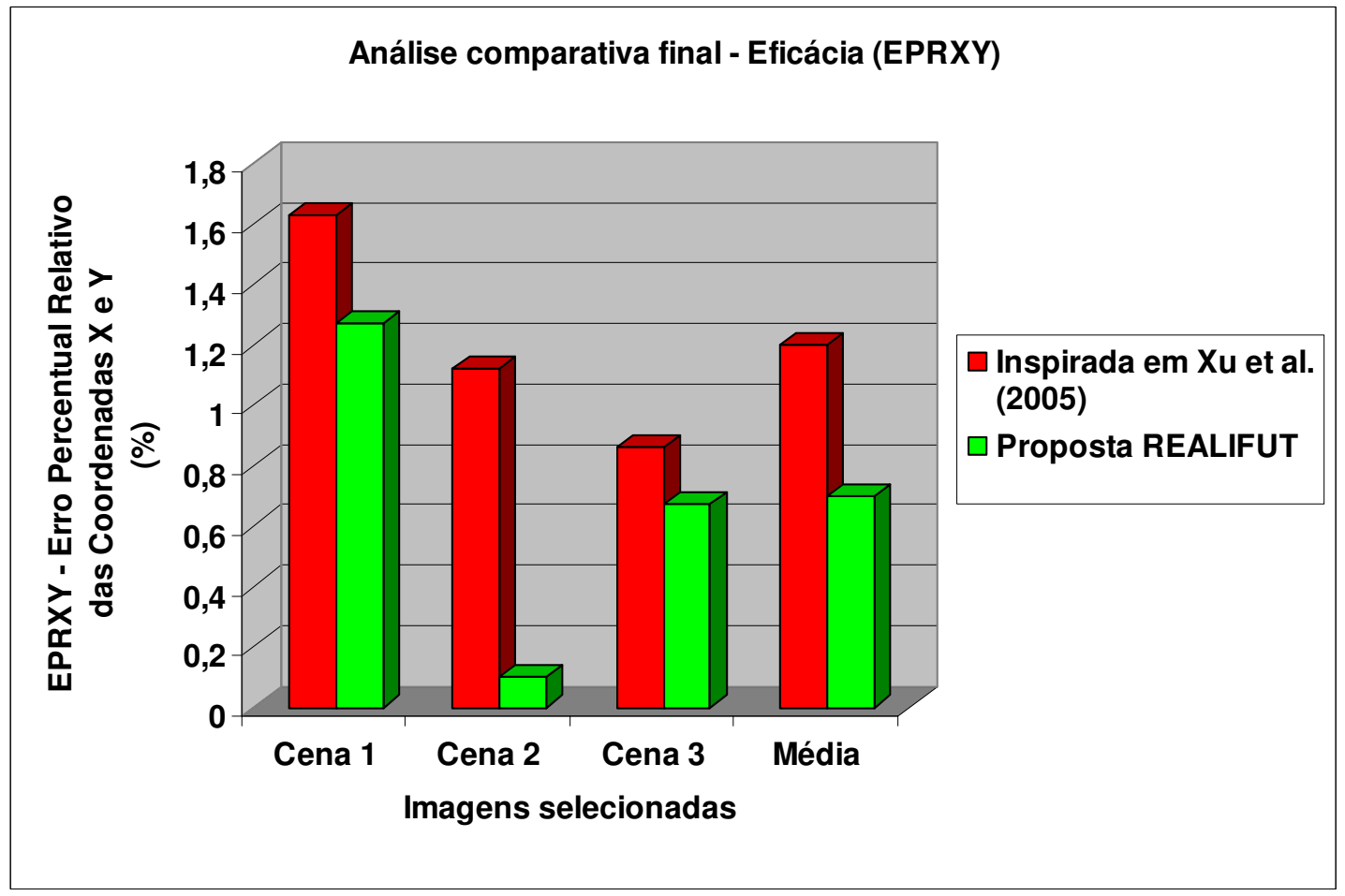

Gráfico 5.15 - Gráfico comparativo em relação à eficácia (EPRXY) de todas as cenas 
O índice EPAM (Erro Percentual Absoluto Médio) apresenta o erro entre o valor estimado e o valor de referência visual dos jogadores conforme o Gráfico 5.16, e observa-se que a proposta REALIFUT possui o menor valor deste índice, aproximadamente $3,4 \%$ na média.

$\mathrm{O}$ destaque mais significante desta análise comparativa é o fato de que a eficácia define a precisão e a qualidade dos resultados da melhor proposta aqui implementada. Sendo assim, conclui-se que a proposta REALIFUT possui a melhor eficácia, na maioria dos quadros analisados, considerando todos os três índices: REQM, EPRXY e EPAM.

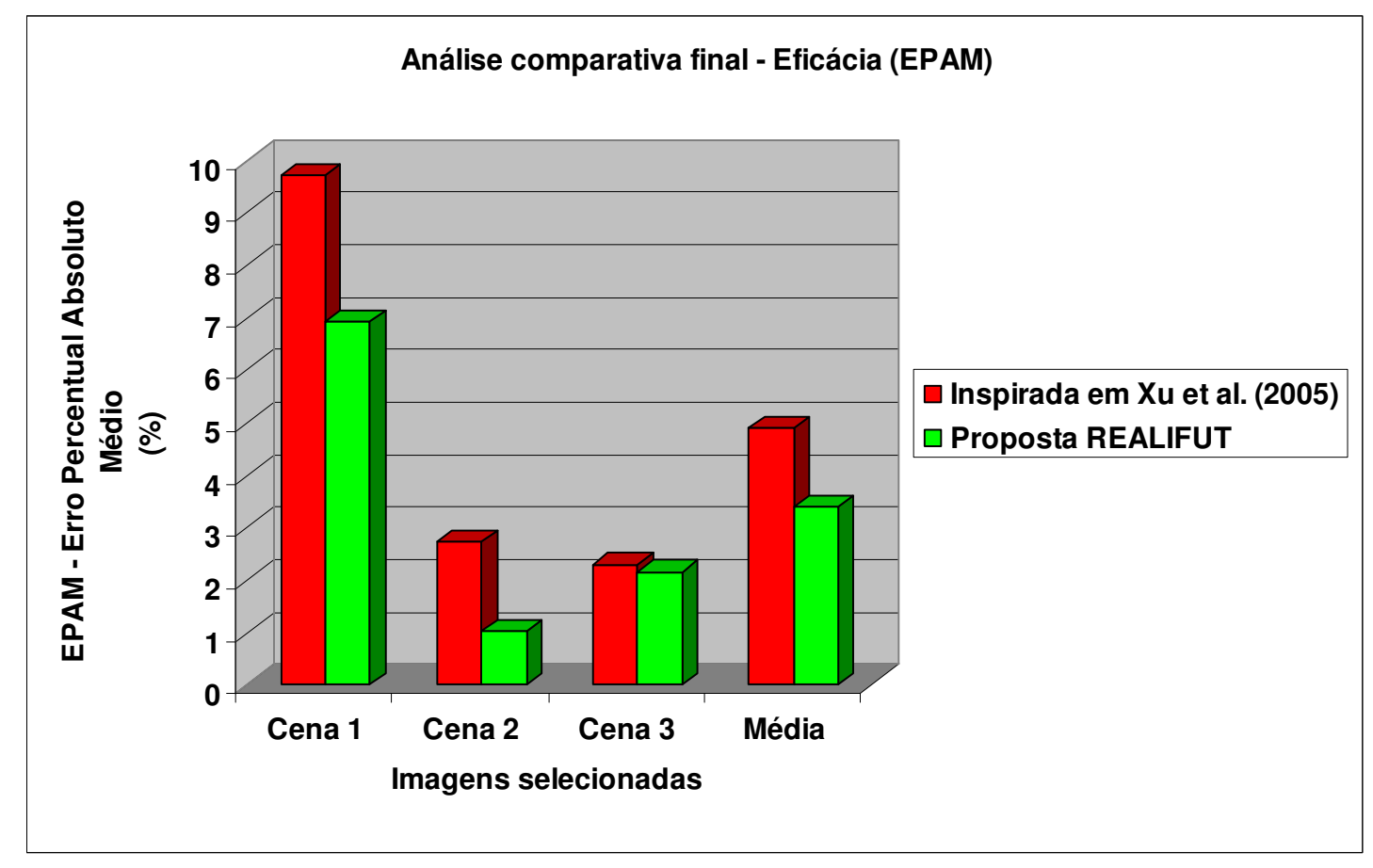

Gráfico 5.16 - Gráfico comparativo em relação à eficácia (EPAM) de todas as cenas 


\section{CONCLUSÃO}

Neste capítulo é apresentado um resumo da pesquisa realizada, suas principais contribuições e também limitações. Além disso, são indicadas algumas pesquisas futuras a serem conduzidas.

Esta pesquisa utilizou como estimador o Filtro de Kalman. Alguns trabalhos bem sucedidos no rastreamento automático de alvos com a utilização do Filtro de Kalman foram avaliados em detalhes e inspiraram a proposta deste trabalho. Uma das vantagens em se adotar este filtro como um estimador ótimo para tratar o problema do rastreamento de jogadores de futebol é o fato de ser mais eficiente computacionalmente e eficaz no resultado do que, por exemplo, a implementação da técnica MHT (Multiple Hypothesis Tracker) proposta por Reid (1979), ou o Condensation (Conditional Density Propagation), proposto por Isard e Blake (1998). Esta vantagem decorre pelo fato do algoritmo do Filtro de Kalman trabalhar com operações simples de matrizes, tais como soma, subtração, produto, transposição e inversão de matrizes, configurando, assim, uma implementação mais eficaz, com algoritmos menos complexos. Vale ressaltar, também, que as previsões deste filtro tornam-se mais acuradas com o passar do tempo devido à metodologia de estimação empregada. Esta vantagem permite, por exemplo, o emprego do Filtro de Kalman em situações que exijam que o algoritmo trabalhe em tempo real. Entretanto, para que estas vantagens possam beneficiar o trabalho, a modelagem deve ser de sistemas lineares.

Escolheu-se sustentar o presente trabalho sobre dois outros: o trabalho de $\mathrm{Xu}$ et al. (2005) e o de De Bem (2007). A proposta de De Bem (2007) foi utilizada como base para a implementação da proposta REALIFUT, sendo aquela adaptada para poder ser aplicada com sucesso no rastreamento de jogadores em imagens reais de partidas de futebol. Para isso, foi de suma importância o uso do modelo de observação baseado em linhas de medidas que realizam a observação do contorno da forma de cada jogador, de acordo com a intensidade da cor de fundo de cena, tornando-se um algoritmo robusto e eficaz. O uso deste modelo foi inspirado pelo trabalho de Xu et al. (2005). 
Os resultados das variáveis de estado, definidas pelas posições e velocidades dos pontos de controle dos contornos de cada jogador rastreado, analisadas nas duas implementações durante os experimentos, apresentaram-se satisfatórias, mas a proposta aqui apresentada obteve uma boa vantagem em relação à proposta inspirada em Xu et al. (2005).

Uma das desvantagens na utilização do Filtro de Kalman em projetos de rastreamento de alvos está na falha do algoritmo quando algum objeto desaparece por inteiro e de forma repentina, reaparecendo posteriormente, como um efeito de completa oclusão, dificultando, desta forma, a continuidade da estimação da trajetória correta do alvo.

Outra inconveniência na adoção de estimadores com abordagem probabilística, como o Filtro de Kalman, está na definição dos parâmetros de inicialização do filtro, por se tratar de uma tarefa muito complexa e exaustiva. Como já dito, o uso do Filtro de Kalman limita-se a sistemas lineares. Para sistemas nãolineares é necessário realizar o desacoplamento dos sistemas, como na proposta aqui adotada, ou utilizar Filtros de Kalman que tratem de sistemas não-lineares, como o FKE - Filtro de Kalman Estendido (WELCH; BISHOP, 1995) ou filtros de partículas, como o Condensation (ISARD; BLAKE, 1998). Entretanto, é inegável a eficiência alcançada pelo Filtro de Kalman na estimação para o rastreamento de alvos em sequencias de imagens, daí a justificativa para sua escolha no presente trabalho, o que propiciou eficácia e eficiência do REALIFUT.

Para trabalhos futuros sugere-se o desenvolvimento e aprimoramento desta técnica para aplicações que exijam resultados em tempo real. Recomenda-se a implementação desta técnica em linguagens de desenvolvimento que possuam um desempenho superior à ferramenta Matlab, aqui usada. Ainda, seria interessante efetuar uma análise comparativa do desempenho do rastreador quando utilizam-se abordagens para sistemas não-lineares ao invés de desacoplamento dos filtros, como feito nesta pesquisa.

Outro importante ponto, e que deve ser considerado para a evolução desta técnica na aplicação em jogadores de futebol, é o desenvolvimento de algoritmos que consideram, além da informação de contorno e cor do jogador, a informação de iluminação variável do estádio de futebol, garantindo e melhorando a robustez do sistema nas variações bruscas de iluminação da cena de fundo durante uma partida. 
Finalmente, após desenvolver uma técnica eficaz que garanta o rastreamento automático com sucesso de jogadores, livre de intervenções humanas, recomendase a expansão da técnica para englobar todos os alvos móveis presentes dentro do campo de futebol, tais como jogadores, árbitros e a bola. Para implementar o rastreamento simultâneo de todos os alvos dentro de todo o campo de futebol, recomendam-se observar alguns pontos importantes: empregar o uso de câmeras de altíssima resolução de imagens, como por exemplo $2000 \times 2000$ pixels, e com rápidas taxas de captura, como por exemplo 50, 60 ou até 80 quadros por segundo, integradas com lentes varifocal, permitindo a máxima representação visual de cada alvo; para a abrangência visual total do campo de futebol, sugere-se também a divisão do campo de futebol em pelo menos 4 quadrantes e o emprego, neste caso, de 8 câmeras para capturar as sequências de imagens, permitindo a incorporação dos benefícios das técnicas de estereoscopia, resultando em duas visões diferentes de cada quadrante. Dessa forma é possível resolver problemas críticos como o tratamento de todos os tipos de oclusões e garantir um bom rastreamento automatizado, também livre de intervenções humanas. Sistemas limitados, que utilizam 4 câmeras ou menos para capturar as imagens de todo o campo de futebol, possuem como consequência a necessidade de executar muitas intervenções humanas durante todo o processo de rastreamento nas partidas de futebol, diminuindo a precisão e qualidade final dos resultados gerados pelo sistema. 


\section{REFERÊNCIAS}

ANDERSIN, A. et al. INMOVE - D1.2.22 Public Final Report. INMOVE Consortium. [S.I.]: 2005. (Project Number: IST 2001-37422).

BAUMBERG, A. M. Learning Deformable Models for Tracking Human Motion. Dissertação (PhD) - School of Computer Studies, University of Leeds, Leeds, Inglaterra, 1995.

BAR-SHALOM, Y.; LI, X. R.; KIRUBARAJAN, T. Estimation with Applications to Tracking and Navigation. New York, USA: John Wiley \& Sons Inc., 2001.

BEETZ, M.; GEDIKLI, S.; BANDOUCH, J.; KIRCHLECHNER, B.; OYNINGENHUENE, N. V.; PERZYLO, A. Visually Tracking Football Games Based on TV Broadcasts. In: Anais XX International Joint Conference on Artificial Intelligence IJCAI 2007, v.1, p. 2066-2071, India, 2007.

BORG, J. Detecting and Tracking Players in Football Using Stereo Vision.

Dissertação (Mestrado) - Department of Electrical Engineering, Linköping University, Suécia, 2007.

COX, I. J.; HINGORANI, S. L. An efficient implementation of Reid's multiple hypothesis tracking algorithm and its evaluation for the purpose of visual tracking. In: Proc. IEEE Transactions on Pattern Analysis and Machine Intelligence, p. 138-150, 1996.

DE BEM, R. A. Uma abordagem livre de modelo para rastreamento de objetos em sequências de imagens. 2007. 84 p. Dissertação (Mestrado em Engenharia Elétrica), Universidade de São Paulo, São Paulo, 2007.

GOLDENSTEIN, S. K. A gentle introduction to predictive filters. Revista de Informática Teórica e Aplicada (RITA), v. 11, n. 1, p. 61-89, Outubro 2004.

GONZALEZ, R. C.; WOODS, R. E. Digital Image Processing. EUA: Ed. Addison Wesley, 1993. 716 p. 
GREWAL, M. S.; ANDREWS, A. P. Kalman Filtering: Theory and Practice Using MATLAB®. EUA: Ed. John Wiley, 3. ed., 2008. 575 p.

ISARD, M.; BLAKE, A. CONDENSATION - conditional density propagation for visual tracking. International Journal of Computer Vision, v. 29, n. 1, p. 5-28, 1998.

KALMAN, R. E. A New Approach to Linear Filtering and Prediction Problems. In: Transaction of the ASME - Journal of Basic Engineering, 82 (S. D.), p. 35-45, 1960.

KOLLER-MEIER, E. B.; ADE, F. Tracking Multiple Objects Using the Condensation Algorithm. Journal of Robotics and Autonomous Systems, v. 34 (2-3), p. 93-105, 2001.

LIANG D.; HUANG, Q.; LIU, Y.; ZHU, G.; GAO, W. Video2Cartoon: A System for Converting Broadcast Soccer Video into 3D Cartoon Animation. IEEE Transactions on Consumer Electronics, v. 53, n. 3, p. 1138-1146, 2007.

MAYBECK, P. S. Stochastic models, estimation, and control. Ed. Academic Press, v. 1, p. 1-16, 1979.

OWENS, N.; HARRIS, C.; STENNETT, C. Hawk-eye tennis system. In: Proceedings of International Conference on Visual Information Engineering. VIE 2003, p. 182-185, 2003.

REID, D. B. An algorithm for tracking multiple targets. In: IEEE Transactions on Automatic Control, v. 24, n. 6, p. 843-854. 1979

RUSSELL, S.; NORVIG, P. Inteligência Artificial. Rio de Janeiro: Ed. Campus, 2. ed. traduzida, p. 521-542, 2004.

SÄRKKÄ, S.; TAMMINEN, T.; VEHTARI, A.; LAMPINEN, J. Probabilistic Methods in Multiple Target Tracking. Helsinki, Finlândia, 2004.

SIEBEL, N. T. Design and Implementation of People Tracking Algorithms for Visual Surveillance Applications. Tese (Doutorado) - Department of Computer Science, The University of Reading, Reading, UK. 2003.

SMITH, S. W. The Scientist and Engineer's Guide to Digital Signal Processing. California Technical Publishing, p. 261-349, 1997. 
TRACAB - Copyright (C Svenska TRACAB Aktiebolag. Suécia. Oferece soluções para identificação das posições de jogadores de futebol em tempo real. Disponível em: <http://www.tracab.com>. Acesso em: 01 out. 2009.

XU, M.; ELLIS, T. Partial observation vs. blind tracking through occlusion. In: Proceedings of BMVC, p. 777-786, 2002.

XU, M.; ORWELL, J.; JONES, G. Tracking Football Players With Multiple Camera. United Kingdom. In: Image Processing, ICIP '04. International Conference on, v. 5, p. 2909-2912, 2004.

XU, M.; ORWELL, J.; LOWEY, L.; THIRDE, D. Architecture and algorithms for tracking football players with multiple cameras. United Kingdom. In: Proceedings of IEEE Proceedings - Vision, Image and Signal Process., v. 152, n. 2, p. 232-141. 2005.

WELCH, G.; BISHOP, G. An Introduction to the Kalman Filter. Relatório Técnico: TR95-041, University of North Carolina at Chapel Hill, NC, EUA, 1995. 